\title{
Transport properties of glassy and molten lavas as a function of
}

\section{temperature and composition}

Anne M. Hofmeister ${ }^{1, *}$, Alexander Sehlke $e^{2,5}$, Geoffroy Avard ${ }^{2,3}$, Anthony J. Bollasina ${ }^{2}$,

Geneviève Robert ${ }^{2,4}$ and Alan G. Whittington ${ }^{2}$ 
Abstract

25 We provide measurements of thermal diffusivity $(D)$, heat capacity $\left(C_{P}\right)$, and viscosity $(\eta)$ for 12

26 remelted natural lavas and 4 synthetic glasses and melts, ranging in composition from

27 leucogranite to low-silica basalt, and calculate their thermal conductivity $(k)$. Both viscosity and

28 the glass transition temperature decrease with decreasing melt polymerization. For basaltic

29 glasses, $D$ is low, $\sim 0.5 \mathrm{~mm}^{2} \mathrm{~s}^{-1}$ at room temperature, decreases slightly with increasing

30 temperature, and then drops upon melting to $\sim 0.25$ to $0.35 \mathrm{~mm}^{2} \mathrm{~s}^{-1}$. Other samples behave

31 similarly. Despite scatter, clear correlations exist between $D$ of glass or melt with Si content,

32 density, NBO/T, and, most strongly, with fragility $(m)$. Glass thermal diffusivity is represented

33 by $D=\mathrm{FT}^{-\mathrm{G}}+\mathrm{H} T$, where $\mathrm{F}, \mathrm{G}$ and $\mathrm{H}$ are fitting parameters. For melts, $\partial D / \partial T$ was resolved only

34 for dacite-andesite and MORB: a positive slope is consistent with other iron-bearing samples.

35 Glass and liquid $C_{P}$ depend on density and other physical properties, but not exactly in the same

36 manner as $D$.. We calculate thermal conductivity $(k)$ from these data and demonstrate that $k$ for

37 glasses is described by a Maier-Kelly formula. Large scatter exists for $k$ at $298 \mathrm{~K}$, but silicic to

38 intermediate melts have $k$ between 1.8 and $1.3 \mathrm{Wm}^{-1} \mathrm{~K}^{-1}$, whereas basaltic melts are constrained

39 to $\sim 1.4 \pm 0.1 \mathrm{Wm}^{-1} \mathrm{k}^{-1}$. Low values for thermal diffusivity and viscosity for basaltic melts

40 suggests that basalts transfer heat much more efficiently by advection than by conduction alone,

41 and that partially molten zones in the mantle quickly become more thermally insulating than

42 non-molten zones, potentially contributing to melt localization during decompression melting.

45 Keywords: high-temperature, thermal diffusivity, viscosity, heat capacity, thermal conductivity, 46 lavas, glass, melt 


\section{INTRODUCTION}

Heat transport plays a crucial role in the thermal evolution of high-temperature,

49 magmatic regimes (e.g., Nabelek et al. 2012). Conduction of heat is quantified by Fourier's law

50 based on thermal conductivity $(k)$. However, large uncertainties exist in $k$ because conventional

51 experimental techniques involving physical contacts are inaccurate for materials that bond poorly

52 with metal contacts or are partially transparent, such as glasses and melts, especially at high

53 temperatures (T) relevant to magmatic processes (e.g., Hofmeister et al. 2007). In contrast,

54 thermal diffusivity $(D)$ can be measured with a high degree of accuracy $(\sim \pm 2 \%)$ using laser-flash

55 analysis (LFA: Parker et al. 1961). This method is contact-free and lacks systematic errors

56 associated with conventional methods, such as thermal losses at interfaces of $\sim 10 \%$ per contact

57 (Hofmeister 2007). Most importantly, removal of boundary-to-boundary radiative transfer gains

58 (Degiovanni et al. 1994; Mehling et al. 1998), which can overwhelm intrinsic behavior at

59 temperatures as low as $1000 \mathrm{~K}$, makes the LFA technique optimal for measuring glasses and

60 melts which are partially transparent in the near-IR. Measurements up to several hundred K

61 above the glass transition (i.e., prior to flow or crystallization) are also possible using LFA,

62 thereby providing information on the liquid state. Combining measurements of heat capacity at

63 constant pressure $\left(C_{P}\right)$, density $(\rho)$, and $D$ allows determination of $k$ associated with vibrational

64 modes from its definition:

65

$$
k_{\text {lat }}=\rho C_{P} D .
$$

66 For melts, heat can also be transported by advection. Mass transport depends on melt

67 viscosity, which can be measured by various means (e.g. Dingwell 1995), and provides

68 information on the liquid state to high temperatures. 
Our previous efforts using LFA focused on the dependence of thermal and mass transport

70 properties on melt chemistry by studying magma analogs. We began with simple glass

71 compositions corresponding to crustal minerals: quartz $\left(\mathrm{SiO}_{2}\right)$, alkali feldspar $\left(\mathrm{XAlSi}_{3} \mathrm{O}_{8}\right.$ where

$72 \mathrm{X}=\mathrm{Li}, \mathrm{K}, \mathrm{Na})$, anorthite $\left(\mathrm{CaAl}_{2} \mathrm{Si}_{2} \mathrm{O}_{8}\right)$, and clinopyroxene $\left(\mathrm{XYSi}_{2} \mathrm{O}_{6}\right.$ where $\mathrm{XY}=\mathrm{CaMg}$ or

73 LiAl) (Pertermann et al. 2008; Hofmeister et al. 2009; Hofmeister and Whittington 2012), and

74 found that mass and heat transport properties are linked: felsic liquids have both high viscosity

75 and high thermal diffusivity compared to mafic liquids. This correlation also holds for more

76 complex melt compositions with high silica contents (71-80 wt. \% $\mathrm{SiO}_{2}$ ), despite variable

77 quantities of $\mathrm{Al}_{2} \mathrm{O}_{3}, \mathrm{FeO}, \mathrm{MgO}, \mathrm{CaO}, \mathrm{Na}_{2} \mathrm{O}$, and $\mathrm{K}_{2} \mathrm{O}$ (Hofmeister et al. 2014a). The latter

78 measurements further indicate that $\mathrm{Ca}$ and Fe strongly affect transport properties. The effect of

79 Fe on $D$, in the absence of $\mathrm{Al}$, was probed by examining the enstatite-ferrosilite binary, which

80 showed strong and positive $\partial D / \partial T$ at high temperature (Hofmeister et al. 2014b).

81 The present paper reports coordinated LFA, heat capacity, and viscosity measurements

82 on synthetic and remelted natural lavas. Effects of oxidation state and minor crystallites are also

83 probed. Our focus is on basaltic compositions, which are important due to their ubiquitous

84 occurrence on Earth and other planetary bodies. We find that $D$ depends roughly on density,

$85 \mathrm{NBO} / \mathrm{T}$, and fragility, which in turn largely depend on Si content, although a predictive model

86 for $k$ remains elusive. Viscosity and $D$ for basaltic melts are particularly low, implying that heat

87 transfer by advection is relatively more efficient than conduction. Our new measurements pave

88 the way for an improved understanding of magmatic processes. 


\section{Synthesis procedures}

94 Synthetic rhyodacite glass was prepared by weighing and mixing reagent grade oxides in

95 the desired proportions with acetone in an iron-free platinum crucible. The mixture was

96 decarbonated slowly during heating over many hours from 900 to $1100{ }^{\circ} \mathrm{C}$ prior to fusion in the

97 same platinum crucible in a muffle furnace in air at $1600{ }^{\circ} \mathrm{C}$ for 60 minutes. The crucible was

98 removed from the furnace and allowed to cool to room temperature, producing a clear crystal-

99 free glass. If not, samples were reground and remelted until a homogeneous glass was obtained.

100 Chemical homogeneity and absence of crystallites were ascertained by visual inspection with an

101 optical microscope, and by electron microprobe analysis and scanning electron microscopy, see

102 below. Synthetic andesite, basaltic andesite, and basalt were made in a similar way.

103 Likewise, twelve glasses were made by remelting the lavas described in Table 1. Crushed

104 rock was placed in iron-saturated platinum or platinum-rhodium crucibles and remelted in a

105 muffle furnace in air at $1600^{\circ} \mathrm{C}$ for between 1 and 2 hours, stirred, then quenched to form glasses

106 either by dipping the bottom of the crucible in water, or by pouring on to a copper plate.

107 The as received sample of MORB had glassy rims sufficient in size to make

108 measurements of thermal diffusivity. The small size of the rims, and rapid crystallization at high

$109 T$, prohibited remelting and viscosity measurements.

\section{Sample preparation}

112 For parallel plate viscometry, cylindrical samples were cored from glass lumps using a

113 diamond core drill, avoiding visible bubbles. The cylinders were cut to lengths of 5 to $10 \mathrm{~mm}$

114 using a diamond wafer saw, polished on successively finer grit papers, and parallel faces were 
115 verified using a micrometer. For LFA, sections were sawed and ground into disks of $\sim 12 \mathrm{~mm}$

116 diameter with 0.2 to $1.1 \mathrm{~mm}$ thicknesses and nearly parallel surfaces, and sand-blasted with 50-

$117150 \mu \mathrm{m}$ alumina grit. For calorimetry, samples were cut into flat disks (4-5 $\mathrm{mm}$ in diameter)

118 with uniform thickness, of $\sim 600-1100 \mu \mathrm{m}$, and weights between 40 to $60 \mathrm{mg}$. For spectroscopic

119 measurements, double-polished sections were prepared. Polished chips were used in electron

120 microprobe analysis.

121

122 Chemical analyses

123 Samples were characterized by wavelength dispersive analysis (WDS) using standard

124 procedures on the JXA-8200 electron microprobe at Washington University. We used "Probe for

125 Windows" for data reduction (see http://www.probesoftware.com/). The measured data were 126 corrected using CITZAF after Armstrong (1995). Oxide and silicate standards were used for 127 calibration (e.g., Amelia albite for $\mathrm{Na}, \mathrm{Si}$; microcline for K; Gates wollastonite for Ca; Alaska 128 Anorthite for $\mathrm{Al}$; synthetic fayalite for $\mathrm{Fe}$; synthetic forsterite for $\mathrm{Mg}$; synthetic $\mathrm{TiO}_{2}$ for $\mathrm{Ti}$;

129 synthetic $\mathrm{Mn}$-olivine for $\mathrm{Mn}$; synthetic $\mathrm{Cr}_{2} \mathrm{O}_{3}$ for $\mathrm{Cr}$ ). Large beam size and measurement of $\mathrm{Na}$ at 130 first during each analysis was used to avoid volatilization, which was confirmed by high totals 131 obtained (see Table 2). Millimeter-scale homogeneity was verified by analyzing different areas 132 of glass chips.

133 Wet chemistry was performed to determine the $\mathrm{Fe}^{3+} / \mathrm{Fe}^{2+}$ in the remelted dolerite and

134 continental basalt. Procedures are described by Sehlke et al. (2014), who measured the $\mathrm{Fe}^{3+} / \mathrm{Fe}^{2+}$ 135 ratio for OIB2.

137 Spectroscopic characterization of impurity ions 
139 were collected using a double-beam Shimaduzu UV-1800 with $1 \mathrm{~nm}$ resolution. For lower

140 frequencies ( 2000-14000 $\left.\mathrm{cm}^{-1}\right)$, a Bomen Fourier transform infrared (FTIR) spectrometer was

141 used with an InSb detector and each of a $\mathrm{CaF}_{2}$ and quartz beamsplitter. Absorption coefficients

142 (A) were calculated using thickness $(L)$ measured with a digital micrometer and from $A L=-$

$143 \log \left(I_{\text {trans }} / I_{0}\right)$.

\section{Evaluation of crystallinity}

146 All transparent samples, whether colorless, green, or brown, were visibly free of crystals,

147 which was confirmed using high magnification electron microscopy during chemical analysis. It

148 is possible that the dacite has very tiny crystallites in small amounts, given its color, as in natural 149 rhyolites. Pieces of the various basalts used for thermal diffusivity analysis are opaque at the 150 thickness used, so it is possible that the interiors of these outwardly glassy black samples had 151 some crystals, even when electron microscopy did not reveal any crystallites. To recognize when

152 data are affected by crystallites, we include sample OIB1 in our study for which a small amount 153 of crystallites was consistently detected by electron microscopy, although they were not visible 154 on its surface. Sample P-MORB may have crystallites, because these were detected in one of the 155 three chips examined. Unlike the other black basalts and transparent glasses, $D$ of OIB1 depends 156 nearly linearly on $T$. This behavior was also seen in reheated samples which have some 157 crystallites (data not reported). Moreover, the viscosity measurements on OIB1 are discordant 158 with the other basalts and shifted to higher viscosity for a given temperature, suggesting the 159 presence of several volume percent crystallites. From these comparisons, the data we report on 160 all other black samples represent glass with very low amounts of crystallites, if any. 


\section{Density determinations}

Glass density was obtained using the Archimedean method, with ethanol as the

163 immersion liquid. Repeat measurements indicate precision is $\pm 2 \mathrm{~kg} \mathrm{~m}^{-3}$ except for MORB,

164 which showed variation of $\pm 17 \mathrm{~kg} \mathrm{~m}^{-3}$ among three pieces. This (not remelted) sample contained 165 minor quantities of microscopic bubbles, which may explain the larger variability.

167 Viscosity measurements

Cylindrical glass cores of $\sim 6 \mathrm{~mm}$ diameter were drilled and then sliced to $\sim 6$ to $20 \mathrm{~mm}$

169 length. The ends were polished until parallel. Viscosity above the glass transition but below

170 liquidus temperatures was measured using a Theta Instruments Rheotronic III parallel plate

171 viscometer, with a constant uniaxial load of $1500 \mathrm{~g}$, and a maximum temperature of $1000^{\circ} \mathrm{C}$.

172 Viscosity is calculated from the measured longitudinal strain rate, known load and calculated

173 instantaneous surface area, assuming perfect slip between sample and plates. Relatively low

174 finite strains were used $(\leq 20 \%)$ and samples remained cylindrical after measurement, justifying

175 this assumption. Measurements made in this study ranged in temperature from 630 to $889^{\circ} \mathrm{C}$, and

176 in viscosity from $8.7 \times 10^{8}$ to $1.3 \times 10^{13}$ Pa.s. The accuracy and precision of the measurements are

$177 \pm 0.06 \log$ units, confirmed by repeat measurements on multiple glass cores where sufficient

178 sample was available. Whittington et al. (2009b) give details regarding experimental protocol

179 and instrument calibration. In one case, crystallization caused two measurements to deviate to

180 higher viscosity than predicted from the trend of previous measurements on the same sample

181 (MORB, Table 3). These data were not used in fitting the VFT equations and should not be used

182 in viscosity modeling because they no longer represent a pure liquid phase. 
184 Rheotronic II 1600C Rotating Viscometer, equipped with a Brookfield HBDV-III Ultra

185 measuring head, which can measure over the range 1 to $10^{5} \mathrm{~Pa}$ s with accuracy and precision of

$186 \pm 0.03 \log$ units, based on repeat measurements of NIST standard glasses. Calibration and

187 experimental protocols are described fully by Getson and Whittington (2007). Data collection

188 began at $1600^{\circ} \mathrm{C}$ and measurements were typically made at 20 to $30^{\circ} \mathrm{C}$ intervals. At some point

189 the liquidus was crossed, and crystallization would cause measurements to deviate to higher

190 viscosity than predicted from the trend of previous measurements (e.g. P-MORB, Table 3).

191 These data were not used in fitting the VFT equations and should not be used in viscosity

192 modeling because they no longer represent a pure liquid phase. In each case we reheated the

193 sample above its liquidus, and reproduced the earlier measurements within experimental

194 uncertainty. The low rmsd of each fit reported in Table 4 shows that the results of both

195 viscometric techniques are in excellent agreement.

\section{Thermal diffusivity measurements}

198 Our LFA 427 apparatus is manufactured by Netzsch Gerätebau, Germany. Glasses were

199 sawed and ground into disks of $\sim 8-12 \mathrm{~mm}$ diameter with 0.2-1.1 mm thicknesses and nearly

200 parallel surfaces, and sand-blasted with $50-150 \mu \mathrm{m}$ alumina grit. Specimens are held in a furnace

201 in an Ar gas atmosphere using graphite holders. The temperature dependence of $D$ is obtained by

202 varying furnace temperature, which is measured to within $\sim 1^{\circ} \mathrm{C}$ using calibrated $\mathrm{W}-\mathrm{Re}$

203 thermocouples. A pulse with $~ 0.5 \mathrm{~ms}$ width from a $400 \mathrm{~W}$ Nd-GGG laser heats the sample from

204 below, providing a difference of $\sim<4^{\circ} \mathrm{C}$ across the sample. As heat diffuses from the bottom to

205 the top of the sample, emissions upward are recorded as a function of time with an InSb detector. 
206 Graphite coatings on the sample serve to block laser light, enhance absorption of the laser pulse 207 and sample emissions, and buffer oxygen fugacity at high temperatures to C-CO. Data were 208 obtained at $50-100{ }^{\circ} \mathrm{C}$ intervals with $\sim$ three acquisitions at each temperature which take a few 209 seconds, and 1 minute between acquisitions. Heating rates varied from 8 to $18 \mathrm{~K}$ per minute, and 210 stability was reached before each acquisition, as confirmed by repeatability among the 3 data

211 points. Runs typically take a total of 6 to 8 hours. These rates are not important due to the 212 rapidity of the data collection (see discussion of $T_{12}$ vs $T_{\mathrm{g}, \mathrm{LFA}}$ below).

213 Data were processed using the algorithm of Mehling et al. (1998) to extract thermal 214 diffusivity from the time-dependent emissions. This model accounts for radiative surface losses

215 to the surroundings and spurious radiative transfer through the sample between the top and

216 bottom graphite coats, and allows for absorbance being frequency dependent, although the 217 detailed values of optical properties are not needed. The measured shape of the laser pulse is 218 accounted for (Blumm and Opfermann 2002).

219 Thermal diffusivity is accurate to $2 \%$, verified against opaque reference materials (see

220 Pertermann et al. 2008). We emphasize that this uncertainty arises from uncertainties in

221 thickness and in slight departures from parallel faces. The precision within any given run is much

222 higher, so the temperature dependence of $D$ is better constrained than the absolute values of $D$.

\section{Heat Capacity}

225 Isobaric heat capacities $\left(C_{P}\right)$ were measured between room temperature and $1770 \mathrm{~K}$ using

226 a Netzsch DSC 404 Pegasus F1 Differential Scanning Calorimeter (DSC) with a Pt-furnace. A

$22720 \mathrm{ml} \mathrm{min}^{-1}$ nitrogen gas flow was used to stabilize atmospheric conditions within the

228 measurement cell. Pt-Rh alloy was used as sample and reference pan materials. 
230 empty sample and reference pans, (2) a standard run with empty reference pan but using a pure 1

231 mm thick sapphire $\left(\alpha-\mathrm{Al}_{2} \mathrm{O}_{3}\right)$ disk with a weight of $\sim 115 \mathrm{mg}$, and (3) a sample run with an empty

232 reference pan. Each run segment consisted of a 15 minute isothermal equilibration segment at

$233325 \mathrm{~K}$, data collection while the cell was continuously heated at a constant rate of $20 \mathrm{~K} \mathrm{~min}^{-1}$ up

234 to some maximum temperature, a 5 minute isothermal equilibration segment, after which the

235 furnace was turned off and the measurement cell cooled ballistically.

236 The $\alpha-\mathrm{Al}_{2} \mathrm{O}_{3}$ disk yielded values within $1 \%$ of reference values (Ditmars et al., 1982) for

237 measurements up to $\sim 1200 \mathrm{~K}$, but differed by $\sim 2 \%$ toward higher temperatures up to $1770 \mathrm{~K}$.

238 These differences indicate experimental uncertainties.

RESUltS

\section{Chemical compositions, NBO/T, and density}

Chemical analyses are given in Table 2. The remelted glasses have compositions

243 consistent with the stated rock types. Our remelted Chengwatana, WI rift basalt is enriched in

244 silica compared to analyses of other batches (Wirth et al. 1997). Water contents are uniformly

245 low, $<200$ ppm, from the spectroscopic measurements of transparent samples in Fig. 1. Because

246 this behavior pertains to all samples prepared by us, and such low water contents do not affect $D$

247 values, we do not pursue this aspect further.

248 Values of NBO/T, calculated from the chemical compositions span a wide range, from 0

249 to 1 (Table 2). Andesite has a low NBO/T for its silica content, due to its relatively high Al

250 content, whereas OIB2 has a high NBO/T for its silica content, due to its relatively low A1

251 content. 
253 Calculated $\rho$ for the liquids (Table 2, after Lange, 1997) show a similar trend. Liquid densities

254 are lower than glass densities across the compositional spectrum, especially for the basalts, 255 whose liquidus temperatures are much higher than those of silicic to intermediate melts.

\section{Oxidation state}

Visible spectra (Fig. 1a) show that all samples strongly absorb above $300 \mathrm{~nm}$, attributable

259 to metal-oxygen charge transfer. All Fe-bearing samples have bands near $1000 \mathrm{~nm}$ due to $\mathrm{Fe}^{2+}$

260 transitions (Fig. 1b). Brown Fe-bearing samples (including leucogranite and rhyolite:

261 Hofmeister et al. 2014a) absorb strongly near $400 \mathrm{~nm}$, attributable to $\mathrm{Fe}^{3+}$ transitions and to $\mathrm{Fe}^{2+}$ -

$262 \mathrm{Fe}^{3+}$ charge transfer. Green dacite-andesite appears to lack $\mathrm{Fe}^{3+}$, despite its substantial total $\mathrm{Fe}$

263 content of $3.26 \mathrm{wt} \%$ (as $\left.\mathrm{FeO}_{\text {total }}\right)$. Comparing peak heights suggests $\mathrm{FeO}$ near $0.03 \mathrm{wt} \%$ for

264 synthetic andesite-basalt and $0.01 \mathrm{wt} \%$ for basalt. Low amounts are resolved via use of thick

265 sections. The synthetic andesites have negligible amounts of iron cations.

266 We did not attempt to quantify Fe concentrations from spectra with mixed valances

267 because d-d peak heights can be affected by the presence of charge transfer and can depend on

268 the concentration (see Rossmann, 1988). However, qualitatively, $\mathrm{Fe}^{3+} / \mathrm{Fe}^{2+}$ is similar for dacite,

269 basalt-andesite, and also for the arc basalt, which was measured by wet chemistry as $\sim 1$ (Robert

270 et al. 2014). The dolerite has lower ferric content, given its strong $\mathrm{Fe}^{2+}$ peak, which is consistent

271 with $\mathrm{Fe}^{3+} / \mathrm{Fe}^{2+}=0.45$ from our wet chemical analyses. Spectra were not obtained for the iron

272 rich samples. Wet chemistry gave $\mathrm{Fe}^{3+} / \mathrm{Fe}^{2+}=2.1$ for OIB2 (Sehlke et al. 2014) and 1.7 for

273 continental, so it is likely that MORB and P-MORB with high total Fe also have $\mathrm{Fe}^{3+} / \mathrm{Fe}^{2+} \sim 1.7$

274 or larger. 


\section{Viscosity}

Near the glass transition, viscosity is close to a linear function of inverse temperature for

277 all samples. The most silica-rich samples have the highest viscosity and show shallower slopes

278 than basaltic melts (Fig. 2; Table 3). Both viscosity and the viscometric glass transition

279 temperature, taken to be the temperature of the $10^{12} \mathrm{~Pa}$ s isokom $\left(T_{12}\right)$, decrease with decreasing

280 melt polymerization (Table 4). At high temperatures, above their liquidii, basaltic melts remain

281 more fluid than silicic melts but they now have the shallower slope on an Arrhenian diagram.

282 The datasets for individual compositions were fitted with the non-Arrhenian Vogel-

283 Fulcher-Tamman (VFT) equation:

$284 \quad \log \eta=\mathrm{A}+\mathrm{B} /(T-\mathrm{C})$

285 where A, B and C are adjustable parameters. Best-fit values are given in Table 4, excluding

286 OIB1 due to the presence of crystallites. It is generally accepted that all silicate melts tend

287 towards a common value of A of about -4.5 at very high temperatures (Russell et al. 2003), and

288 most of our A values were in the range $-4.5 \pm 0.5$. Leucogranite and rhyolite are more negative (-6

289 to -7) whereas MORB and P-MORB are more positive ( - 2.6). The viscosity dataset and fitted

290 VFT equations allow interpolation of viscosity with a high degree of confidence from the glass

291 transition up to the highest temperatures at which samples were analyzed by LFA, which is

292 useful in interpreting changes in $D$ observed at high temperatures.

293 One way to quantify the degree of non-Arrhenian behavior, or "fragility", is to calculate

294 the gradient of the viscosity curve at the glass transition temperature on a reduced temperature

295 scale (Plazek and Ngai 1991); see Table 4. Melt fragility can be calculated from the VTF

296 coefficients:

297

$$
\mathrm{m}=\mathrm{B} /\left[T_{12}\left(1-\mathrm{C} / T_{12}\right)^{2}\right]
$$


298 Calculated values of fragility range from 22 for leucogranite to 48 for P-MORB, with all the 299 basaltic samples $(\mathrm{NBO} / \mathrm{T} \geq 0.5)$ having a fragility near $45 \pm 3$.

300 Fragility is directly related to configurational heat capacity, $C_{P}{ }^{\text {conf }}$, which is the difference 301 between $C_{P}$ of the glass at $T_{\mathrm{g}}$ and $C_{P}$ of the melt (Richet et al. 1986). From the temperature 302 dependence of relaxation times in viscous liquids (Adam and Gibbs 1965), the viscosity of a 303 liquid can be related to its configurational entropy $\left(S^{c o n f}\right)$ through:

$$
\log \eta=A_{e}+\frac{B_{e}}{T S^{\text {conf }}}
$$

305 where $A_{e}$ and $B_{e}$ are constants differing from A, B and C above. These reflect the Gibbs free306 energy barriers hindering co-operative rearrangements in the liquid (Richet 1984). Melts with

307 small values of $C_{P}{ }^{\text {conf }}$ have small changes in $S^{\text {conf }}$ with temperature, and hence exhibit near308 Arrhenian or "strong" behavior. Melts with large values of $C_{P}{ }^{\text {conf }}$ have correspondingly large 309 changes in $S^{\text {conf }}$ with temperature, and hence exhibit distinctly fragile, non-Arrhenian, behavior.

\section{Thermal Diffusivity}

312 Thermal diffusivity of the glasses is highest at room temperature and decreases as 313 temperature increases from 298 to about $1000 \mathrm{~K}$ (Fig. 3; Table 5). By about $800 \mathrm{~K}, D$ becomes 314 nearly constant, as observed for other silicate glasses (e.g., Hofmeister et al. 2009). In some 315 cases (leucogranite, dacite, arc basalt, OIB2) $D$ reaches a minimum near 600 to $800 \mathrm{~K}$ and then 316 clearly increases at higher $T$. The positive, high-temperature slopes are discussed below after 317 presenting fits to the $D(T)$ data.

318 As discussed earlier, OIB1 with minor amounts of crystallites has a straight trend that is 319 not seen in the homogeneous glasses. P-MORB had some tiny crystallites in some chips. The 320 trend in $D$ is slightly less bowed, which may be due to small amounts of crystallites, but 
321 similarities to other trends, suggest that this variation could equally well be due its particular 322 chemical composition and structure. We do not see evidence for crystallites in the response of 323 the dacite glass to temperature. Tiny amounts of crystallites having a small effect is consistent 324 with behavior of the natural rhyolites (Romine et al. 2012).

As in our previous studies, $D$ decreases substantially upon crossing the glass transition

326 (Fig. 3). Behavior above the glass transition is complicated (discussed below).

Our measurements probe relaxed melt, starting at $T$ corresponding to a viscosity of

$328 \sim 2 \times 10^{8}$ Pa s. As detailed in Pertermann et al. (2008) and Hofmeister et al. (2009), the

329 temperature of the transition in LFA $\left(T_{\mathrm{g}, \mathrm{LFA}}\right)$ is higher than that in viscometric experiments $\left(T_{12}\right)$

330 due to the time-scales of the experiments. At low $T$, a viscous melt appears frozen (glassy) on the

331 short timescale of the laser pulse, although it can still flow over the longer (minutes to hours)

332 timescale of a viscosity measurement. Although the state immediately above the glass transition

333 is supercooled (metastable) liquid, thermal diffusivity above $T_{\mathrm{g}, \mathrm{LFA}}$ represents that of melt up to

334 and including superliquidus conditions, and is thus denoted $D_{\text {melt }}$. For brevity, we refer to this

335 state as liquid or melt.

336 Roughly, siliceous lavas have $D_{\text {melt }}=0.52 \mathrm{~mm}^{2} \mathrm{~s}^{-1}$, intermediate lavas have $D_{\text {melt }}$ near

$3370.40 \mathrm{~mm}^{2} \mathrm{~s}^{-1}$, and basalts have $D_{\text {melt }}$ of $>0.20$ to $0.37 \mathrm{~mm}^{2} \mathrm{~s}^{-1}$ (Table 6). In detail, for the synthetics

338 with very little Fe, $D_{\text {melt }}$ was observed over a few hundred K, and was found to be constant (Fig.

339 3). Recovered synthetic samples retained their original thickness and appearance. In contrast, for

340 most Fe-bearing samples, observing the temperature dependence of $D_{\text {melt }}$ was precluded by these

341 low viscosity samples flowing, outgassing, and sometimes partially crystallizing after melting

342 (Fig. 3), so Table 6 only reports $D$ at the completion of melting, but prior to the above behaviors.

343 Recovered samples of OIB1 and P-MORB had flowed and warped. In these two cases, because 
344 the true thickness during the highest $T$ acquisitions is larger than the initial thickness used in 345 calculations by the instrument software, and because $D$ goes as $1 / L^{2}$ (Parker et al. 1961), the 346 reported low values of $D\left(0.17\right.$ to $\left.0.25 \mathrm{~mm}^{2} \mathrm{~s}^{-1}\right)$ likely underestimate $D_{\text {melt }}$, as indicated in Table

347 6. Due to similar limitations, a few samples provide upper limits on $D_{\text {melt }}$ (Table 6). For the $2^{\text {nd }}$ 348 run on arc basalt, the sample melted and fell in the heating interval between temperature set 349 points so data could not be collected on $D_{\text {melt }}$.

$350 \quad$ The Si-rich natural samples (Fig. 3a) did not crystallize, but with time flowed and 351 degassed slightly, as indicated by the slightly increased thickness and bumpy texture of the 352 recovered samples. The increase in thickness due to flow precludes accurately determining $353 \partial D_{\text {melt }} / \partial T$. For these Si-rich compositions (Fig. 3a), $D$ for the melt can only be obtained reliably 354 from the lowest $T$ data on the melt.

355 The data for the dacite-andesite melt indicate positive $\partial D / \partial T$ (Fig. 3b). This positive 356 slope is not due to crystallization or degassing because the recovered sample remained 357 transparent, with few bubbles. Although the thickness on one edge had increased slightly, the 358 center was unchanged, so positive $\partial D / \partial T$ for dacite-andesite is intrinsic. If the edge thickening 359 were the source of the $T$ dependence of $D$, then the slope would have been negative, not positive 360 as observed.

361 For MORB, the two sections examined have different melting temperatures (Table 6) due 362 to variations in initial water content. Because water contents are not near the $>0.1 \mathrm{wt} . \%$ level 363 needed to alter $D$-values (Hofmeister et al. 2006), the data instead constrain the $T$ dependence of $364 D_{\text {melt }}$ for MORB (Fig. 3d). The slope for MORB is similar to that found for dacite-andesite melt 365 (Table 6, footnotes). The strong dependence of melting temperature on water content will be 366 quantified elsewhere. 
We considered several different formulae in fitting $D$ of glass to a function of $T$. The $T^{1}$

368 form that is frequently used to describe phonon scattering of crystalline material (e.g., Julian

369 1965) is obviously too steep for the flat lying trends of Fig. 3. Nor did a simple power law

370 accurately reproduce most trends. This finding, coupled with observed upturns at high $T$ for $\mathrm{SiO}_{2}$

371 glass (Hofmeister and Whittington 2012), Fe-bearing high-silica glasses (Hofmeister et al.

372 2014a), and Fe-rich pyroxene glasses (Hofmeister et al. 2014b), suggests that the following form

373 best describes the temperature dependence of $D$ :

$374 \quad D=\mathrm{FT}^{-\mathrm{G}}+\mathrm{H} T$

375 Note that parameters $\mathrm{F}$ and $\mathrm{G}$ are not independent due to trade-offs in the fitting. Also, because

376 precision during the run is much better than the $2 \%$ uncertainty in the absolute values of $D$

377 arising from $L$, the $T$ dependence is well-constrained.

Equation 4 is not limited to glasses but was originally developed to describe data on

379 crystals (Hofmeister et al. 2014c), where G depends on the crystal structure and cation disorder.

380 The crystalline material (of those studied) most similar to glasses are feldspars, which are highly

381 disordered, and have low $\mathrm{G}$ (0.30 to 0.85 ). For our remelted lavas, fitted values of $\mathrm{G}$ are even

382 lower, ranging from 0.07 to 0.52 (Table 6), which is consistent with glasses being more

383 disordered than feldspars.

384 Regarding the physical basis of Eq. (4), the $\mathrm{F} T^{-\mathrm{G}}$ term describes phonon-phonon

385 scattering whereas the $\mathrm{H} T$ term is attributed to radiative transfer at infrared frequency

386 (Hofmeister et al. 2014c). More exactly, the proposed radiative mechanism involves polaritons,

387 which, in essence, are a blend of infrared and acoustic modes. 


\section{Heat Capacity}

Table 7 lists heat capacity data. For all glasses, $C_{\mathrm{P}}$ first gradually increases as $T$ increases,

392 following the Maier-Kelly (1932) formulation (Fig. 5; Table 8). The glass transition is

393 represented by a lambda-shaped curve and an abrupt increase in $C_{\mathrm{P}}$ that represents the

394 configurational heat capacity. The very narrow range of $C_{\mathrm{P}}$ at the glass transition reflects the

395 Dulong-Petit harmonic limit of $3 R \mathrm{~J} \mathrm{~mol}^{-1} \mathrm{~K}^{-1}$, where $R$ is the universal gas constant (Neuville 396 and Richet 1991, Richet 1984).

397 Regarding the liquid phase, for low silica, low Fe samples (Fig. 4a) and the dacite-

398 andesite, $C_{P}$ of liquid can be confidently fitted as linear with temperature. For most low-Fe

399 liquids, $C_{P}$ of liquid is nearly constant, but for rhyodacite and dacite-andesite liquids, that lack

$400 \mathrm{Fe}^{3+}, C_{P}$ increases as $T$ increases. For the high Fe liquids, good data could be collected over a

401 limited $T$-range. Samples with significant Fe cations first crystallize upon reaching the glass

402 transition (e.g., P-MORB and Contl.), and then remelt as $T$ rises, with the associated latent heat

403 resulting in large variations in apparent $C_{P}$ vs $T$. Upon reaching the relevant liquidus $T$, the

404 whole sample becomes stable, crystal-free melt. These high- $T$ data (Fig. 4bc) are accurate and

405 are included in the fits, as shown. However, because we excluded regions of crystallization and

406 remelting from the fits, $\partial C_{P} / \partial T$ for liquids of basalt-andesite FU-18 and the other Fe-rich (and Si-

407 poor) samples is somewhat uncertain.

\section{DISCUSSION}

\section{Relationships among physical properties and dependence on composition}

Values of fragility show a positive but non-linear correlation with NBO/T (Fig. 5a),

412 whereby highly polymerized melts have low fragility, low $C_{\mathrm{P}}{ }^{\text {conf }}$, and show near-Arrhenian 
413 viscosity behavior, in contrast to depolymerized melts which are fragile, have high $C_{\mathrm{P}}{ }^{\text {conf }}$, and

414 show highly non-Arrhenian behavior. Our viscosity data and calculated fragility values are

415 consistent with previous data for similar compositions (e.g. Giordano et al. 2008). We find a

416 roughly linear correlation between fragility and density (Fig. 5b), and between fragility and silica

417 content (Fig. 5c). Scatter in these plots reflects variations in $\mathrm{FeO}$ and $\mathrm{MgO}$ content for example,

418 which nominally play the same role in calculating NBO/T but have very different partial molar

419 densities.

420 A direct dependence of $D$ on more readily measured physical properties is sought in this

421 section, in order to provide a means of interpolating or extrapolating our measurements to lavas

422 of other chemical compositions. Because correlations exist among the various physical properties

423 for our series of glasses (Fig. 5bc), demonstrating a direct dependence of $D$ on any one of the

424 various physical properties is likely equivocal.

425 The linear dependence of $D$ on Si content (Fig. 6a) is probably most useful, although Si

426 content cannot possibly represent all the changes in chemical composition from leucogranites to

427 ultramafic lavas. The trend at $298 \mathrm{~K}$ is associated with phonon-phonon scattering because the

428 high- $T$ radiative mechanisms contribute negligibly to $D$ at $298 \mathrm{~K}$ per Eq. (5) and Planck's

429 blackbody curve. Similarly, linear trends of $D$ exist with fragility (Fig. 6b) and also density and

$430 \mathrm{NBO} / \mathrm{T}$ (not shown), in part due to the physical properties and chemical compositions being

431 correlated (Fig. 5). The scatter for the glass trends (exemplified by Fig. 5a) can be attributed in

432 part to uncertainties in $D$ and in part due to low amounts of both crystallinity for the naturally

433 occurring samples (at the percent level), and strain, which also affects thermal diffusivity values

434 of glasses (Hofmeister and Whittington, 2012; Romine et al. 2012). However, the single largest

435 contributor to scatter is probably the variations in glass and melt structure and density at a given 
436 value of $\mathrm{NBO} / \mathrm{T}$.For example, melt and glass structure depend on variables such as the ratio of

437 alkali to alkaline-earth cations, the $\mathrm{Al} / \mathrm{Si}$ ratio, and $\mathrm{Fe}$ content and redox state, none of which are 438 addressed in the formulation for NBO/T.

439 Melts are less dense than the corresponding glasses, so from Fig. 5b, one might expect $D$ 440 to increase during the transition: instead, $D$ decreases across the glass transition. This behavior is 441 due to an increase in disorder: melts have a configurational heat capacity which glasses do not, 442 and consequently the entropy of the melts rises rapidly above $T_{\mathrm{g}}$ (Richet 1984). Dimensionally, 443 thermal diffusivity of phonons is the product of the compressional velocity $\left(u_{\mathrm{p}}\right)$ with the mean 444 free path ( $\lambda$ ), e.g. (Hofmeister 2010). The smallest $\lambda$ can be is the cube root of atomic volume.

445 We use molar volume (Table 2) and compute up from a linear fit with volume to the P-wave 446 velocity data in Whittington et al. (2012). As generally occurs (Shankland 1972), speed increases

447 with density. The resulting trend (Fig. 6c) is opposite that expected from $D=u_{\mathrm{p}} \lambda$, suggesting that 448 another, compositionally dependent, factor must pertain to $\lambda$.

449 In previous studies we have noted that more polymerized melts tend to have higher $D$ 450 than less polymerized melts (Hofmeister et al. 2009; 2014a; Romine et al. 2012). In the present 451 study, our samples span a wide range of polymerization, with NBO/T varying from 0 to 1. 452 Thermal diffusivity of glass and melt decrease as fragility (Fig. 7b) and NBO/T increase (not 453 shown). One possible explanation is that as the melt becomes less polymerized, fewer high 454 frequency vibrations exist (e.g., the O-Si-O bending modes), so the average frequency decreases. 455 This interpretation, where $D$ depends on vibrational frequency, is consistent with anisotropy in 456 chain silicates whereby $D$ along the chains of Si tetrahedra (which involve high frequency 457 tetrahedral modes) is $\sim 1.5$ times $D$ across the chains (which involve low frequency modes of the 
divalent cations: see e.g., Hofmeister 2012). Essentially, spatially extensive Si-O-Si linkages

459 provide a "faster track" for heat transfer in polymerized glasses.

461 representation of $D_{\text {melt }}$ is the least squares fit:

$$
D_{\text {melt }}\left(\mathrm{mm}^{2} \mathrm{~s}^{-1}\right)=0.694-0.0082 \mathrm{~m} \text {, }
$$

463 This can be used to estimate $D_{\text {melt }}$ to within $\sim 0.04 \mathrm{~mm}^{2} \mathrm{~s}^{-1}$, where the uncertainty approximates 464 the fit, and does not address the outliers. If only chemical data are available, then the following 465 correlation with NBO/T can be used:

$$
D_{\text {melt }}\left(\mathrm{mm}^{2} \mathrm{~s}^{-1}\right)=0.44-0.168 \mathrm{NBO} / \mathrm{T}
$$

467 which fit is accurate to within $\sim 0.06 \mathrm{~mm}^{2} \mathrm{~s}^{-1}$. Again, many factors affect $D$, and also the chemical 468 composition of the glass does not uniquely constrain its structure, so the above relationships are 469 representative, rather than exact.

470 Five of our basalts (P-MORB, Arc bas, MORB, OIB2) have a narrow range of silica 471 content (49.9-50.8 wt\% $\left.\mathrm{SiO}_{2}\right)$, which potentially permits examination of the effects of $\mathrm{Fe}, \mathrm{Ca}$ and

472 Al. The difference in $D$ between the two Hawai'ian basalts is greater than the difference

473 between our arc basalt and MORB samples, but OIB1 has crystallites, which affect its trend at 474 high T and likely perturbs its ambient value. Although the effect of particular cations could be 475 elucidated in our study of silica-rich melts (Hofmeister et al. 2014a), this was not possible for the 476 basalts studied here, among which $D$ varies little. The most important observation is that $D$ is 477 low for basalts, $\sim 0.3 \mathrm{~mm}^{2} \mathrm{~s}^{-1}$, compared to $\sim 0.5 \mathrm{~mm}^{2} \mathrm{~s}^{-1}$ for rhyolitic melts.

478 Heat capacities of glass and liquid depend linearly on density (Fig. 7) Similar 479 relationships also exist with the other parameters (not shown) which is consistent with simple 480 mixing models of oxide components representing $C_{\mathrm{P}}$ (e.g. Stebbins et al. 1984; Richet 1987). 
481 Heat capacity is largely a harmonic property (it is described by the distribution of heat energy

482 among the available states per Debye and Einstein) whereas thermal diffusivity is entirely

483 anharmonic (it arises through phonon interactions per Debye). This fundamental difference in

484 behavior permits reasonably accurate determination of $C_{\mathrm{P}}$ from composition or from vibrational 485 frequencies whereas more complicated models are required for $D$, as follows.

Temperature dependence of $D$ : three microscopic mechanisms

The initial decrease in thermal diffusivity for crystals with increasing temperature has

489 been attributed to phonon scattering (e.g., Liebfried and Schlömann 1954). At 500 K, increases

490 in thermal diffusivity have been previously observed due to spurious radiative transfer between

491 the heater and thermocouple, which results from the high transparency of many materials in the

492 near-IR (see e.g., Hofmeister et al. 2007). In our LFA measurements, this unwanted ballistic

493 radiative transfer has been removed through use of coatings and mathematical models. In our

494 previous studies of $\mathrm{SiO}_{2}$ glasses and high silica glasses, we found that $D$ of the glass increases

495 linearly with $T$ at above $\sim 1000 \mathrm{~K}$, for samples that remained glassy at these high temperatures

496 (Fig. 3; also see Hofmeister and Whittington 2012; Hofmeister et al. 2014a). For Fe-bearing

497 pyroxene glasses, we found an obvious linear increase at a much lower temperature of only 700

$498 \mathrm{~K}$ for $\mathrm{Fs}_{10} \mathrm{En}_{90}$ and the ternary $\mathrm{Fs}_{15} \mathrm{Wo}_{40} \mathrm{En}_{45}$, and more subtle increases for several other samples

499 (Hofmeister et al. 2014b). For the remelted lavas investigated here, obvious increases in $D$ occur

500 for the high silica content samples, in part due to the higher temperatures reached, and also for

501 OIB2 and the arc basalt. Decreases are seen for Fe-free synthetic glasses and for OIB1 with

502 minor crystallites (per electron microprobe). The changes are resolved due to precision within a 
503 given run being high (precision regards relative values of $D$ ), although in most cases the change

504 across the $T$-range observed is greater than the experimental uncertain in absolute values of $D$.

505 Our previous study on glasses with structures close to those of tectosilicates and with less

506 than 4 wt \% $\mathrm{FeO}$ showed a correlation of the fitting constant $\mathrm{H}$ with $\mathrm{Fe}^{2+}$ content and/or charge

507 transfer between $\mathrm{Fe}^{2+}$ and $\mathrm{Fe}^{3+}$ (Hofmeister et al. 2014a). This study also showed that the

508 existence and magnitude of positive $\partial D / \partial T$ observed for the glass was repeated for the melt. The

509 pyroxene glasses did not have a positive correlation of F, G or $\mathrm{H}$ with $\mathrm{Fe}$ content or with the

$510 \mathrm{Fe}^{3+} / \mathrm{Fe}^{2+}$ ratio (Hofmeister et al., 2014b). Neither did we find such a correlation for the lava

511 glasses.

512 In our previous study of low Fe glasses for which the structure is highly polymerized, we

513 found that the $\mathrm{HT}$ term in Equation 3 positively correlated with $\mathrm{Fe}^{2+}$ content in the presence of

$514 \mathrm{Fe}^{3+}$. This behavior is consistent with a radiative process, because the high frequency electronic

515 transitions of $\mathrm{Fe}^{2+}$ are coupled with vibronic transitions (e.g. Rossman, 1988). The data on

516 pyroxene composition glasses show more variable behavior (Hofmeister et al. 2014ab) which

517 could have been caused by small but varying amounts of crystallites in these black samples.

518 Regarding the remelted lavas, a low value of $\mathrm{H}$ is seen for dacite-andesite: unlike the other

519 remelts, this sample is green with no indication of $\mathrm{Fe}^{3+}$ whereas the brown and black samples

520 have significant $\mathrm{Fe}^{3+}$ in addition to $\mathrm{Fe}^{2+}$ and high absorbance throughout the visible indicating

521 energy exchange (Fig. 1; cf. Hofmeister et al. 2014ab). Green dacite-andesite has the lowest

522 measurable value of $\mathrm{H}$ (Table 6). Electronic-vibronic coupling does not explain the high values

523 of $\mathrm{H}$ for the high silica glasses with little Fe (Table 6): however, for basalts with similar

524 compositions, the synthetics with only a trace of $\mathrm{Fe}^{2+}$ have lower $\mathrm{H}$. 
The data on remelted lava glasses, coupled with our previous datasets, suggest that three

526 mechanisms for heat transfer exist in glasses. Existence of three mechanisms would produce the

527 variety of behaviors discussed above. One mechanism is phonon scattering, as evident in the

528 decrease in $D$ above $\sim 298 \mathrm{~K}$. Two other mechanisms are connected with the increase in $D$ with

$529 T$ at high temperature. The second mechanism is the IR polariton mechanism proposed for

530 crystals (Hofmeister et al. 2014c), as described above, which operates in the low Fe samples, and

531 apparently weakens as Si content decreases. The third mechanism involves electronic-vibronic

532 coupling of charge transfer complexes $\left(\mathrm{Fe}^{3+}-\mathrm{O}-\mathrm{Fe}^{2+}\right)$, which operates in the high Fe, oxidized

533 samples. Because the juxtaposition of Fe cations is sample specific, this mechanism is present to

534 varying degrees in Fe-bearing glasses. Quantifying the role of Fe cations in heat transfer of

535 glasses will require a suite of synthetic samples with controlled $\mathrm{Fe}^{3+} / \mathrm{Fe}^{2+}$ ratios at constant total

536 Fe content, in the absence of crystallites.

\section{Thermal Conductivity}

Thermal conductivity is the product of $D$, density, and $C_{\mathrm{P}}$ (Eq. 1), permitting inference of

540 this important property from our measurements, utilizing some previous findings. However, as a

541 consequence of this convolution, $k$ is necessarily complicated and sample specific.

542 For glasses, our computations (Eq. 1) incorporate the fits to $D$ and $C_{P}$ (Tables 6 and 7).

543 We used linearized density $\rho=\rho_{298}[1-\alpha(T-298)]$ where $\alpha$ is the typical, constant thermal

544 expansivity of $25 \times 10^{-6} \mathrm{~K}^{-1}$ (e.g. Bouhifd et al. 2015). This procedure produces a smooth curve for

$545 k$ vs $T$ for each sample (Fig. 8). Uncertainties for $k$ of glass are <4\%, after Bevington (1969),

546 considering experimental errors in $C_{P}$ and $D$, which dominate those in $\rho$. Again we note that 
547 changes in $k$ are less uncertain than the absolute values of $k$, due to uncertainties in $D$ arising

548 from sample thickness and parallelism, which are constant over each run.

$549 \quad$ For most liquids, we calculated $k$ at the liquidus temperature, using $\rho$ calculated for that

550 temperature (Table 2), the fit predicting liquid $C_{P}$ at that temperature, and the best measurement

551 of $D_{\text {melt }}$ measured above the calorimetric or viscometric glass transitions but not at liquidus

552 temperatures. We also provide $k$ for the liquid calculated for $T_{g}$, which is similar in most cases.

553 For dacite-andesite and MORB only, we used their trends of $D$ with $T$ (Table 6) and liquid

554 thermal expansivity of $75 \times 10^{-6} \mathrm{~K}^{-1}$ (Bouhifd et al. 2015) to calculate $k(T)$ in Table 9.

555 Uncertainties for $k$ of liquid are 5-8\%, possibly increasing to $10 \%$ at the liquidus, based on

556 estimating $\alpha$ and the limitations in our direct measurements of $D_{\text {melt }}$.

557 Although these uncertainties in $k$ may appear high for a modern method, our results offer

558 considerable improvement over conventional measurements of $k$, which are uncertain by $\sim 20 \%$

559 at $298 \mathrm{~K}$, and greatly increase with $T$, depending on transparency (Hofmeister 2007; Hofmeister

560 et al. 2007). Conventional measurements of thermal conductivity rarely reach temperatures

561 above $1200 \mathrm{~K}$ and systematically err due to unwanted radiative transfer.

562 The resulting smooth trends for $k$ with $T$ (Fig. 8) are less regular than the trends for $D$

563 (Fig. 3) or $C_{P}$ (Fig. 4), in part because uncertainties of a few $\%$ for each parameter are multiplied

564 in the convolution of Eq (1). More importantly, both $D$ and $C_{P}$ vary little with $T$, and in opposite

565 directions, making the variation of $k$ with $T$ weak but with the sign of the slope varying. There is

566 no indication of different mechanisms operating below and above $\sim 400 \mathrm{~K}$, which was proposed

567 based on trends for $k$ alone (Cahill and Pohl 1987).

568 The results for $k$ of glass, despite the variety of trends (Fig.8), are best fit by:

569

$$
k=\mathrm{A}+\mathrm{B} T+\mathrm{C} T^{-2}+\mathrm{D} T^{1 / 2},
$$


570 where parameters are given in Table 9. This form was deduced from Maier-Kelly fits to heat

571 capacity (reviewed by Robie et al. 1987). This discovery emphasizes that heat capacity largely

572 controls thermal conductivity in glasses, as a consequence of thermal diffusivity depending

573 weakly on temperature.

$574 \quad$ Trends of $k$ with various material properties are poorly defined (see Table 9), largely

575 because the variations in $k$ are small. Small variations in $k$ are due to the different dependence of $576 C_{P}, D$, and $\rho$ on chemical composition and scatter (cf. Figs. 6-8). The most regular trend was

577 seen for $k$ with fragility, but it was unimpressive and is not shown. We did find that glass $k$ at $578298 \mathrm{~K}$ depends oppositely of melt $k$, regardless of the parameter chosen, whereas glass $k$ at $T_{g}$ is 579 roughly independent of any parameter. From our data, $k$ appears to depend on a combination of 580 Si content, oxidation state of Fe, and hydration, but this remains to be tested by independently 581 varying the parameters.

582 We emphasize that the fundamental parameter for heat transport is thermal diffusivity 583 (Hofmeister et al. 2014c), and that basalts clearly have lower $D$ than silica-rich melts (Table 6). 584 However, thermal conductivity is important for modelling. It would be best to use our trends in $585 D$ and estimate density and heat capacity in order to model compositions other than those 586 presented here. However, rough numbers for $k_{\text {melt }}$ are called for, since a very rough number of 1 $587 \mathrm{~mm}^{2} \mathrm{~s}^{-1}$ is almost universal in geophysical models. Whereas silicic to intermediate melts have $k$ 588 between 1.8 and $1.3 \mathrm{Wm}^{-1} \mathrm{~K}^{-1}$, values for basaltic melts are more restricted, $1.3-1.5 \mathrm{Wm}^{-1} \mathrm{k}^{-1}$, with $589 \quad 1.4 \mathrm{Wm}^{-1} \mathrm{k}^{-1}$ reasonably representing any temperature.

\section{Implications for partially molten zones}

591 The difference in thermal properties between silicic and mafic liquids is smaller than the 592 variability between different minerals, although minerals also become more insulating at high 
593 temperatures. Quartz and olivine have relatively high values of $k$ and $D$, whereas pyroxenes and

594 feldspars are more insulating (Branlund and Hofmeister, 2007; Branlund and Hofmeister, 2012;

595 Hofmeister, 2012; Hofmeister and Pertermann 2008; Pertermann and Hofmeister 2006).

596 Consequently, the thermal properties of crustal rocks depend strongly on mineralogy (Merriman

597 et al. 2013). Many crustal rocks such as pelitic schists become very insulating at high

598 temperatures, with $D \sim 0.56 \mathrm{~mm}^{2} \mathrm{~s}^{-1}$ and $k \sim 1.84 \mathrm{Wm}^{-1} \mathrm{~K}^{-1}$ at typical crustal melting temperatures

599 of $\sim 1000 \mathrm{~K}$ (Whittington et al. 2009c). Leucogranite melts have $D$ and $k$ values only slightly

600 lower, $\sim 0.52 \mathrm{~mm}^{2} \mathrm{~s}^{-1}$ and $\sim 1.84 \mathrm{Wm}^{-1} \mathrm{~K}^{-1}$, so the effect of partial melting on thermal properties of

601 the crust is negligible.

602 Taking forsterite as a proxy for mantle peridotite, $D$ at $1500 \mathrm{~K}$ is $\sim 0.64 \mathrm{~mm}^{2} \mathrm{~s}^{-1}$ and $k$ is

$6032.83 \mathrm{Wm}^{-1} \mathrm{~K}^{-1}$, while values for MORB are $\sim 0.30 \mathrm{~mm}^{2} \mathrm{~s}^{-1}$ and $\sim 1.25 \mathrm{Wm}^{-1} \mathrm{~K}^{-1}$. Consequently,

604 partially molten zones in the mantle become more insulating as melting progresses (Fig. 9). This

605 feedback relationship potentially increases the melt fraction produced by decompression melting

606 under mid-ocean ridges and may contribute to the generation of large melt volumes that

607 comprise large igneous provinces (e.g. Saunders 2005). Conversely, crystallizing magmas will

608 become more effective conductors of heat as crystallization progresses, allowing an efficient

609 pathway for the removal of latent heat of crystallization.

\section{ACKNOWLEDGMENTS}

611 This work was supported by the National Science Foundation through grant EAR-1321857 to

612 AMH, EAR-1220051 to AGW, and by NASA through grant PGG-NNX12AO44G to AGW. We

613 thank Paul Carpenter (W.U.) for providing microprobe analysis; Bridget Hellwig (M.U.), Mitch

614 Schulte (NASA), Benoît Smets and Matthieu Kervyn (U. Brussels) for providing samples.

615

616 
618 Adam, G. and Gibbs, J.H. (1965) On the temperature dependence of relaxation phenomena in glass-

619 forming liquids. Journal of Chemical Physics, 43,139-146.

620 Armstrong, J.T. (1995) CITZAF, A package of correction programs for the quantitative electron 621 microbeam X-ray analysis of thick polished materials, thin films, and particles. Microbeam $622 \quad$ Analysis, 4, 177-200.

623 Avard, G. and Alan G. Whittington (2012) Rheology of arc dacite lavas: experimental determination 624 at low strain rates. Bull Volcanol (2012) 74:1039-1056

625 Bevington, P.R. (1969) Data reduction and error analysis for the physical sciences. McGraw-Hill 626 Book Co., New York.

627 Blumm, J. and Opfermann, J. (2002) Improvement of the mathematical modeling of flash 628 measurements. High Temperature High Pressure, 34, 515-521.

629 Bouhifd, M.A., Besson, P., Courtial, P., Gérardin, C., Navrotsky, A., and Richet, P. (2007)

630 Thermochemistry and melting properties of basalt. Contrib. Mineral. Petrol. 153, 689-698.

631 Bouhifd, M.A., Whittington, A.G., and Richet, P. (2015) Densities and volumes of hydrous silicate 632 melts: New measurements and predictions. Chem. Geol. 418, 40-50.

633 Branlund J.M. and Hofmeister A.M. (2007) Thermal diffusivity of quartz to 1000 degrees C: Effects 634 of impurities and the $\alpha-\beta$ phase transition. Phys Chem. Minerals. 34, 581-595.

635 Branlund J.M. and A.M. Hofmeister. (2012) Heat transfer in plagioclase feldspars. American 636 Mineralogist, 97, 1145-1154.

637 Cahill, D.G. and Pohl, R.O. (1987) Thermal conductivity of amorphous solids above the plateau. 638 Phys. Rev. B 35, 4067 (1987). 
Degiovanni, A., Andre, S., and Maillet, D. (1994) Phonic conductivity measurement of a semitransparent material. In, Tong TW (ed) Thermal conductivity 22. Technomic, Lancaster, PA, pp 623-633

642 Dingwell, D.B. 1995. Viscosity and anelasticity of melts. AGU reference shelf 2, p. 209-217.

643 Ditmars DA, Ishihara S, Chang SS, Bernstein G, West ED (1982) Enthalpy and Heat-Capacity

644 Standard Reference Material: Synthetic Sapphire $\left(\alpha-\mathrm{A}_{2}{ }_{2}{ }_{3}\right)$ from 10 to $2250 \mathrm{~K}$. J Res Natl

$645 \quad$ Bur Standards 87: 159-163

646 Fei Y. (1995) Thermal Expansion. In Mineral Physics and Crystallography. A Handbook of 647 Physical Constants (ed. T. J.Ahrens), 29-44. American Geophysical Union, Washington D.C.

648 Getson, J.M., and Whittington, A.G. (2007) Liquid and magma viscosity in the anorthite649 forsterite-diopside-quartz system and implications for the viscosity temperature paths of 650 cooling magmas, Journal of Geophysical Research, 112, B10203, DOI: 10.1029/2006JB004812

652 Giordano, D., Russell, J.K., and Dingwell, D.B. (2008) Viscosity of magmatic liquids, a model. 653 Earth and Planetary Science Letters, 271, 123-134.

654 Hellwig, B.M. (2006) The viscosity of dacitic liquids measured at conditions relevant to 655 explosive arc volcanism: determining the influence of temperature, silicate composition, and 656 dissolved volatile content. M.Sc. Thesis, University of Missouri - Columbia, 145pp.

657 Hofmeister, A.M. (2007) Pressure dependence of thermal transport properties. Proceedings of 658 the National Academy of Science 104, 9192-9197.

659 Hofmeister, A.M. (2010) Scale aspects of heat transport in the diamond anvil cell, in 660 spectroscopic modeling, and in Earth's mantle. Physics of the Earth and Planetary Interiors $661 \quad 180,138-147$. 
662 Hofmeister, A.M. (2012) Thermal diffusivity of orthopyroxenes at elevated temperature.

663 European Journal of Mineralogy, 24, 669-681.

664 Hofmeister, A.M. and Criss R.E. (2013) Earth's interdependent thermal, structural, and chemical 665 evolution, Gondwana Research. 24 490-500

666 Hofmeister A.M. and Pertermann, M. (2008)Thermal diffusivity of clinopyroxenes at elevated 667 temperature. European Journal of Mineralogy, 20, 537-549.

668 Hofmeister, A.M. and Whittington, A.G. (2012) Effects of hydration, annealing, and melting on 669 heat transport properties of fused quartz and fused silica from laser-flash analysis. Journal of $670 \quad$ Non-Crystalline Solids 358, 1072-1082.

671 Hofmeister A.M., Pertermann, M., Branlund, J. and Whittington, A.G. (2006) Geophysical 672 implications of reduction in thermal conductivity due to hydration. Geophysical Research 673 Letters 33, doi: 10.1029/2006GL026036

674 Hofmeister, A.M., Pertermann, M., and Branlund, J.M. (2007) Thermal Conductivity of the Earth.

675 In, Schubert G (ed). Treatise in Geophysics (Schubert G, Ed. In Chief) V. 2 Mineral Physics

676 (Price GD, ed.). Elsevier, The Netherlands, pp 543-578

677 Hofmeister, A.M., Whittington, A.G., and Pertermann, M. (2009) Transport properties of high albite 678 crystals and near-endmember feldspar and pyroxene glasses and melts to high temperature. 679 Contributions to Mineralogy and Petrology, 158, 381-400.

680 Hofmeister, A.M. Jonas Goldsand, Alan G. Whittington, and Reinhardt G. Criss. (2014a)

681 Effects of chemical composition and temperature on transport properties of silica-rich 682 glasses and melts. American Mineralogist 99, 564-577

683 Hofmeister, A.M., Sehlke, A. and Whittington, A.G. (2014b) Thermal diffusivity of Fe-rich 684 pyroxene glasses and their melts. Chemical Geology 384, 1-9. 
685

686

687

688

689

690

691

692

693

694

695

696

697

698

699

700

701

702

703

704

705

706

Hofmeister, A.M., Dong, J., Branlund, J.M., (2014c). Thermal diffusivity of electrical insulators at high temperatures: evidence for diffusion of phonon-polaritons at infrared frequencies augmenting phonon heat conduction, Journal of Applied Physics 115, \#163517; http://dx.doi.org/10.1063/1.4873295

Julian, C.L. (1965) Theory of heat conduction in rare-gas crystals. Physical Review A, 137, 128-137.

Lange, R.A. (1997) A revised model for the density and thermal expansivity of $\mathrm{K}_{2} \mathrm{O}-\mathrm{Na}_{2} \mathrm{O}-\mathrm{CaO}-$ $\mathrm{MgO}-\mathrm{Al}_{2} \mathrm{O}_{3}-\mathrm{SiO}_{2}$ liquids from 700 to $1900 \mathrm{~K}$, extension to crustal magmatic temperatures. Contributions to Mineralogy and Petrology, 130, 1-11.

Lev, E., Marc Spiegelman, Robert J. Wysocki, Jeffery A. Karson (2012) Investigating lava flow rheology using video analysis and numerical flow models. Journal of Volcanology and Geothermal Research 247-248, 62-73.

Liebfried, G. and Schlömann, E. (1954) Warmleitund in elektrische isolierenden Kristallen. Nachrichten von der Gesellschaft der Wissenschaften zu Göettingen Mathematik und Physik $\mathrm{K} 1,71-93$.

Maier, C. G. and Kelly, K. K. (1932) An equation for the representation of high temperature heat content data. J. Am. Chem. Soc. 54, 3243-3246.

Mehling. H., Hautzinger, G., Nilsson, O., Fricke, J., Hofmann, R., and Hahn, O. (1998) Thermal diffusivity of semitransparent materials determined by the laser-flash method applying a new mathematical model. International Journal of Thermophysics, 19, 941-949.

Merriman, J.D., Whittington, A.G., Hofmeister, A.M., Nabelek, P.I., and Benn, K. (2013) Thermal transport properties of major Archean rock types to high temperature and implications for cratonic geotherms. Precambrian Research 233, 358-372. 
Nabelek, P.I., Whittington, A.G., and Hofmeister, A.M. (2012) The influence of temperature-

708 dependent thermal diffusivity on the conductive cooling rates of plutons and temperature-

709 time paths in contact aureoles. Earth and Planetary Science Letters, 317-318, 157-164.

710 Neuville, D.R., and Richet, P. (1991) Viscosity and mixing in molten (Ca, Mg) pyroxenes and

711 garnets. Geochimica et Cosmochimica Act $a$ 55, 1011-1019.

712 Parker, J,W,, Jenkins, J.R., Butler, P.C., and Abbott G.I. (1961) Flash method of determining

713 thermal diffusivity, heat capacity, and thermal conductivity. Journal of Applied Physics. 32,

$714 \quad 1679-1684$.

715 Pertermann. M., and Hofmeister, A.M. (2006) Thermal diffusivity of olivine-group minerals at high

716 temperatures. American Mineralogist, 91, 1747-1760.

717 Pertermann. M., Whittington, A.G., Hofmeister, A.M., Spera, F.J., and Zayak, J. (2008) Thermal

718 diffusivity of orthoclase glasses and single-crystals at high temperatures. Contributions to

719 Mineralogy and Petrology, 155, 689-702. doi, 10.1007/s00410-007-0265-x

720 Plazek. D.J. and Ngai, K.L. (1991) Correlation of polymer segmental chain dynamics with

721 temperature dependent time-scale shifts. Macromolecules, 24, 1222-1224.

722 Richet, P. (1984) Viscosity and configurational entropy of silicate melts. Geochimica Cosmochimica $723 \quad$ Acta, $48,471-483$.

724 Richet, P. (1987) Heat capacity of silicate glasses. Chemical Geology 62, 111-124.

725 Richet, P., Robie, R.A., and Hemingway, B.S. (1986) Low-temperature heat capacity of diopside

726 glass $\left(\mathrm{CaMgSi}_{2} \mathrm{O}_{6}\right)$, a calorimateric test of the configurational entropy theory applied to the

727 viscosity of liquid silicates. Geochimica Cosmochimica Acta, 50, 1521-1533.

728 Robert, G. (2014) The effects of volatiles on the viscosity and heat capacity of calc-alkaline basaltic

729 and basaltic andesite liquids. Ph.D. Dissertation, University of Missouri - Columbia, 197pp. 
Robert, G., Whittington, A.G., Stechern, A., and Behrens, H. (2013) The effect of water on the

731 viscosity of a synthetic calc-alkaline basaltic andesite. Chemical Geology, 346, 135-148.

732 Robert, G., Whittington, A.G., Stechern, A, Behrens, H. (2014) Heat capacity of hydrous glasses and 733 liquids. Journal of Non-Crystalline Solids, 390, 19-30.

734 Robert, G., Knipping, J.L., Scherbarth, S., Robertson, T.E., Stechern, A., Behrens, H. and

735 Whittington, A.G. (2015) Heat capacity and viscosity of basaltic melts with $\mathrm{H}_{2} \mathrm{O} \pm \mathrm{F} \pm \mathrm{CO}_{2}$., $736 \quad$ Chemical Geology, 418, 51-65.

737 Robie, R.A., Hemingway, B.S., and Fisher, J.R. (1978) Thermodynamic properties of minerals and 738 related substances at $298.15 \mathrm{~K}$ and 1 bar $\left(10^{5}\right.$ pascals $)$ and at higher temperatures. U.S.

739 Geological Survey Bulletin, 1452, 456 pp.

740 Romine, W.L. and Whittington, A.G. (2015) A simple model for the viscosity of rhyolites as a 741 function of temperature, pressure and water content. Geochim Cosmochim Acta, 170, 281$742 \quad 300$, doi:10.1016/j.gca.2015.08.009

743 Romine, W.L., Whittington, A.G., Nabelek, P.I., and Hofmeister,.A.M. (2012) Thermal

744 diffusivity of rhyolitic glasses and melts, effects of temperature, crystals and dissolved water.

$745 \quad$ Bull Volc 74, 2273-2287, doi:10.1007/s00445-012-0661-6

746 Russell, J.K., Giordano, D., and Dingwell, D.B. (2003) High-temperature limits on viscosity of non747 Arrhenian silicate melts. American Mineralogist, 88, 1390-1394.

748 Saunders, A.D. (2005) Large Igneous Provinces: Origin and environmental consequences.

749 Elements, 1, 259-263

750 Schuessler J. A., Botcharnikov R. E., Behrens H., Misiti V., Freda C. (2008) Oxidation state of

751 iron in hydrous phonotephritic melts, American Mineralogist 93, 1493-1504.

752 Sehlke, A., Whittington, A.G., Robert, B., Harris, A., Gurioli, L., and Médard, E. (2014) 
Pahoehoe to 'a`a transition of Hawaiian lavas: an experimental study. Bulletin of

$754 \quad$ Volcanology, 76, 876-896

755 Shankland, T.J. (1972) Velocity-density systematics: derivation from Debye theory and the effect of 756 ionic size. Journal of Geophysical Research, 77, 3750-3758.

757 Whittington, A.G., Bouhifd, M.A., and Richet, P. (2009a) The viscosity of hydrous $\mathrm{NaAlSi}_{3} \mathrm{O}_{8}$ and 758 granitic melts, configurational entropy models. American Mineralogist 94, 1-16.

759 Whittington AG, Hellwig BM, Behrens H, Joachim B, Stechern A, Vetere F (2009b) The

760 viscosity of hydrous dacitic liquids: implications for the rheology of evolving silicic magmas.

$761 \quad$ Bull Volcanol 71:185-199.

762 Whittington AG, Hofmeister AM, Nabelek P (2009c) Temperature-dependent thermal diffusivity 763 of Earth's crust and implications for magmatism. Nature, 458, 319-321

764 Whittington A.G., Richet P., Polian A. (2012) Water and the compressibility of silicate glasses: a 765 Brillouin spectroscopic study. Amer Mineral 97: 455-467.

766 Wirth, K.R., Vervoort, J.D., Naiman, Z.J., 1997. The Chengwatana Volcanicsm Wisconsin and 767 Minnesota: petrogenesis of the southernmost volcanic rocks exposed in the Midcontinent $768 \quad$ Rift. Can J Earth Sci 34: 536-548.

\section{FIGURE CAPTIONS}

771

772 Fig. 1. Spectra of various electronic transitions in the UV-visible region (a) and of $\mathrm{O}-\mathrm{H}$ and $\mathrm{Fe}^{2+}$

773 d-d transitions visible-IR region (b). Curves as labeled. Vertical lines indicate peak assignments.

774 Samples have oxidation states that are not dictated by total FeO. Original thicknesses in $\mathrm{mm}$ are

7759.41 (rhyodacite), 0.47 and 1.22 (dacite), 0.36 (dacite-andesite), 8.35 (synthetic andesite-basalt, 
776 SBA), 0.21 (basalt-andesite, Fu18), 0.2 (dolerite), 3.55 (synthetic basalt, SB), and 0.040 (arc

777 basalt, $\mathrm{Fu} 06)$.

778 Fig. 2. Viscosity data for supercooled liquids near the glass transition and melts. Symbols are as

779 listed where circles are silica-rich melts, squares are intermediate lavas, and diamonds are basic.

780 Solid lines $=$ VFT curves. Dashed line $=$ the $10^{12} \mathrm{~Pa}$ s isokom.

781 Fig. 3. Thermal diffusivity vs. temperature showing fits to $\mathrm{D}=\mathrm{F} T^{-\mathrm{G}}+\mathrm{H} T$. Melt values (not

782 included in the fits) are shown with larger symbols. Except for part (a), symbols are described in

783 the legend. (a) High silica glasses. From top to bottom: plus sign and thick line = leucogranite

784 (after Hofmeister et al. 2014a). Various circles and fine line = rhyolite (Romine et al. 2012).

785 Squares and dotted line $=$ rhyodacite. Grey triangles and grey line $=$ synthetic dacite. Vertical

786 lines indicate $T_{12}$, which differs from the glass-to-liquid conversion in LFA due to rapidity of

787 measurements (see text or Pertermann et al. 2009). (b) Intermediate Si contents. For andesite-

788 basalt, data were collected from a slab before and after concentric cylinder (cc) measurements.

789 The post-cc measurements were single data points rather than averaging 3 collections, except at

$790298 \mathrm{~K}$, where 13 measurements were averaged. Thin line =linear fit to the andesite-dacite melt

791 data. (c) Basalts from island and arc environments. (d) Mid-ocean ridge and continental basalts.

792 Fig. 4. Heat capacity vs. temperature showing Maier-Kelly fits for the glass and linear fits for

793 the liquid. Insets tie symbols to compositions. An increase in $C_{P}$ with $T$ was clearly observed for

794 rhyodacite, and dacite-andesite.

795 Fig. 5. Relationships of fragility with various physical properties. Data from Tables 1, 2 and 4.

796 Least squares fits are listed in each panel. (a) Non-linear dependence of fragility on NBO/T,

797 fitted with a third-order polynomial. (b) Fragility and NBO/T vs. density. Fragility varies

798 approximately linearly with density, whereas NBO/T is better fitted with a quadratic equation. 
(c) Dependence of fragility (triangles), NBO/T (plotted as $\times 100$, circles), and density (squares)

800 on silica content, with linear fits.

801 Fig. 6. Dependence of thermal diffusivity on various physical properties. Least squares fits are 802 shown. Filled triangles and solid line $=$ glass data. Open diamonds and dotted line $=$ melt data.

803 Vertical dotted line (or grey area) separates basalts from the other remelts. Vertical arrow

804 indicates that a minimum value was observed. (a) $D$ vs $\mathrm{SiO}_{2}$ content. (b) $D$ vs. fragility. (c) $D$ vs

805 parameters expected to contribute to heat transfer, velocity of carriers and a representative

806 distance.

807 Fig. 7. Dependence of heat capacity on density for each of glass and melts. Least squares fits are 808 listed.

809 Fig.8. Thermal conductivity vs. temperature, computed using Eq. 1. In each part, different 810 patterns are used for each composition, as labeled, and liquid is shown as a heavy line with the 811 same pattern as the glass. The computed values are smooth because the inputs are smooth. Fits to 812 Eq. (7) are indistinguishable from the data for most samples. A few examples of fits to glass are 813 shown (grey curves).

814 Fig. 9. Thermal diffusivity and conductivity in partially molten zones. "Mantle" uses forsterite 815 for solid end-member and MORB for liquid end-member. "Crust" uses schist for solid end816 member and rhyolite for liquid end-member. Dashed curves are for "resistors in series" model, 817 while solid curves are for "resistors in parallel" model, representing upper and lower bounds 818 depending on melt geometry. The two are indistinguishable for crustal melting. 
824 Table 7: Isobaric heat capacities of glasses and liquids measured by differential scanning 825 calorimetry (DSC) every 30 degrees

826

\begin{tabular}{|c|c|c|c|c|c|c|c|}
\hline \multicolumn{2}{|c|}{$\begin{array}{c}\text { Leucogranite } \\
\text { Harney Peak (HP96) }\end{array}$} & \multicolumn{2}{|c|}{$\begin{array}{c}\text { Rhyolite } \\
\text { Mono Craters (ANCAR) } \\
\end{array}$} & \multicolumn{2}{|c|}{$\begin{array}{c}\text { Rhyodacite } \\
\text { synthetic (SRD) }\end{array}$} & \multicolumn{2}{|c|}{$\begin{array}{c}\text { Dacite } \\
\text { Mt. St. Helens (SH305) } \\
\end{array}$} \\
\hline $\begin{array}{l}\text { Temp. } \\
(\mathrm{K})\end{array}$ & $\begin{array}{c}\mathrm{Cp} \\
\left(\mathrm{J} \mathrm{g}^{-1} \mathrm{~K}^{-1}\right)\end{array}$ & $\begin{array}{c}\text { Temp. } \\
(\mathrm{K})\end{array}$ & $\begin{array}{c}\mathrm{Cp} \\
\left(\mathrm{J} \mathrm{g}^{-1} \mathrm{~K}^{-1}\right)\end{array}$ & $\begin{array}{l}\text { Temp. } \\
(\mathrm{K})\end{array}$ & $\begin{array}{c}\mathrm{Cp} \\
\left(\mathrm{J} \mathrm{g}^{-1} \mathrm{~K}^{-1}\right)\end{array}$ & $\begin{array}{c}\text { Temp. } \\
(\mathrm{K})\end{array}$ & $\begin{array}{c}\mathrm{Cp} \\
\left(\mathrm{J} \mathrm{g}^{-1} \mathrm{~K}^{-1}\right)\end{array}$ \\
\hline 338 & 0.961 & 338 & 1.023 & 338 & 0.834 & 337 & 0.977 \\
\hline 361 & 0.917 & 361 & 0.959 & 361 & 0.850 & 360 & 0.928 \\
\hline 389 & 0.930 & 388 & 0.956 & 388 & 0.873 & 388 & 0.919 \\
\hline 419 & 0.960 & 418 & 0.969 & 418 & 0.899 & 417 & 0.933 \\
\hline 450 & 0.988 & 450 & 0.986 & 450 & 0.925 & 449 & 0.950 \\
\hline 483 & 1.016 & 482 & 1.012 & 482 & 0.949 & 481 & 0.967 \\
\hline 516 & 1.048 & 515 & 1.043 & 515 & 0.974 & 514 & 0.991 \\
\hline 549 & 1.079 & 548 & 1.066 & 548 & 0.996 & 547 & 1.011 \\
\hline 582 & 1.105 & 581 & 1.085 & 581 & 1.015 & 580 & 1.026 \\
\hline 614 & 1.124 & 613 & 1.101 & 614 & 1.031 & 612 & 1.045 \\
\hline 647 & 1.147 & 646 & 1.114 & 646 & 1.043 & 645 & 1.063 \\
\hline 679 & 1.168 & 678 & 1.124 & 678 & 1.055 & 677 & 1.080 \\
\hline 710 & 1.181 & 709 & 1.133 & 710 & 1.071 & 709 & 1.093 \\
\hline 742 & 1.194 & 741 & 1.141 & 742 & 1.084 & 740 & 1.107 \\
\hline 773 & 1.212 & 772 & 1.155 & 773 & 1.094 & 771 & 1.124 \\
\hline 804 & 1.223 & 803 & 1.168 & 804 & 1.108 & 803 & 1.141 \\
\hline 835 & 1.234 & 834 & 1.169 & 836 & 1.117 & 834 & 1.154 \\
\hline 866 & 1.246 & 865 & 1.173 & 866 & 1.125 & 865 & 1.171 \\
\hline 897 & 1.252 & 896 & 1.178 & 897 & 1.137 & 895 & 1.187 \\
\hline 928 & 1.259 & 926 & 1.182 & 928 & 1.151 & 926 & 1.198 \\
\hline 958 & 1.277 & 957 & 1.183 & 958 & 1.160 & 957 & 1.210 \\
\hline 989 & 1.302 & 987 & 1.188 & 989 & 1.186 & 987 & 1.221 \\
\hline 1019 & 1.330 & 1018 & 1.213 & 1020 & 1.222 & 1018 & 1.259 \\
\hline 1049 & 1.352 & 1048 & 1.270 & 1050 & 1.331 & 1048 & 1.396 \\
\hline 1080 & 1.411 & 1079 & 1.343 & 1080 & 1.490 & 1079 & 1.550 \\
\hline 1110 & 1.540 & 1109 & 1.386 & 1111 & 1.398 & 1109 & 1.429 \\
\hline 1140 & 1.551 & 1139 & 1.353 & 1141 & 1.379 & 1139 & 1.421 \\
\hline 1171 & 1.481 & 1170 & 1.341 & 1171 & 1.383 & 1170 & 1.420 \\
\hline 1201 & 1.489 & 1200 & 1.338 & 1201 & 1.382 & 1200 & 1.414 \\
\hline 1231 & 1.495 & 1230 & 1.348 & 1231 & 1.381 & 1230 & 1.429 \\
\hline 1261 & 1.496 & 1261 & 1.354 & 1261 & 1.414 & 1260 & 1.430 \\
\hline 1291 & 1.472 & 1291 & 1.346 & 1291 & 1.401 & 1291 & 1.454 \\
\hline 1321 & 1.481 & 1321 & 1.342 & 1321 & 1.419 & 1321 & 1.452 \\
\hline 1351 & 1.483 & 1352 & 1.367 & 1352 & 1.424 & 1351 & 1.440 \\
\hline 1381 & 1.497 & 1382 & 1.368 & 1382 & 1.428 & 1381 & 1.438 \\
\hline 1412 & 1.479 & 1412 & 1.416 & 1412 & 1.427 & 1412 & 1.424 \\
\hline 1442 & 1.481 & 1442 & 1.519 & 1442 & 1.430 & 1442 & 1.424 \\
\hline 1472 & 1.461 & 1472 & 1.593 & 1472 & 1.415 & 1472 & 1.433 \\
\hline 1502 & 1.429 & 1503 & 1.615 & 1502 & 1.337 & 1502 & 1.437 \\
\hline 1532 & 1.417 & 1533 & 1.632 & 1532 & 1.264 & 1533 & 1.436 \\
\hline 1562 & 1.403 & 1564 & 1.612 & 1562 & 1.207 & 1563 & 1.400 \\
\hline 1592 & 1.401 & 1594 & 1.571 & 1592 & 1.191 & 1593 & 1.369 \\
\hline 1622 & 1.406 & 1624 & 1.535 & 1622 & 1.173 & 1624 & 1.300 \\
\hline 1653 & 1.393 & 1654 & 1.507 & 1653 & 1.170 & 1654 & 1.261 \\
\hline 1683 & 1.388 & 1685 & 1.446 & 1683 & 1.165 & 1684 & 1.240 \\
\hline 1713 & 1.372 & 1715 & 1.365 & 1713 & 1.158 & 1715 & 1.225 \\
\hline
\end{tabular}


827

828

829

\begin{tabular}{|l|l|l|l|l|l|l|l|}
\hline 1744 & 1.344 & 1746 & 1.351 & 1744 & 1.149 & 1745 & 1.198 \\
\hline 1761 & 1.311 & 1763 & 1.356 & 1760 & 1.145 & 1762 & 1.228 \\
\hline
\end{tabular}

\begin{tabular}{|c|c|c|c|c|c|c|c|c|c|}
\hline \multicolumn{2}{|c|}{$\begin{array}{c}\text { Dacite-andesite } \\
\text { Santiaguito (SA05-14) }\end{array}$} & \multicolumn{2}{|c|}{$\begin{array}{c}\text { Andesite-basalt* } \\
\text { SBA }\end{array}$} & \multicolumn{2}{|c|}{$\begin{array}{l}\text { Basalt-andesite* } \\
\text { Fuego (Fu18) }\end{array}$} & \multicolumn{2}{|c|}{$\begin{array}{c}\text { Dolerite } \\
\text { Chengwatana (CHW) }\end{array}$} & \multicolumn{2}{|c|}{$\begin{array}{l}\text { Basalt* } \\
\text { SB }\end{array}$} \\
\hline $\begin{array}{c}\text { Temp. } \\
(\mathrm{K})\end{array}$ & $\begin{array}{c}\mathrm{Cp} \\
\left(\mathrm{J} \mathrm{g}^{-1} \mathrm{~K}^{-1}\right)\end{array}$ & $\begin{array}{l}\text { Temp. } \\
(\mathrm{K})\end{array}$ & $\begin{array}{c}\mathrm{Cp} \\
\left(\mathrm{J} \mathrm{g}^{-1} \mathrm{~K}^{-1}\right)\end{array}$ & $\begin{array}{c}\text { Temp. } \\
(\mathrm{K})\end{array}$ & $\begin{array}{c}\mathrm{Cp} \\
\left(\mathrm{J} \mathrm{g}^{-1} \mathrm{~K}^{-1}\right)\end{array}$ & $\begin{array}{c}\text { Temp. } \\
(\mathrm{K})\end{array}$ & $\begin{array}{c}\mathrm{Cp} \\
\left(\mathrm{J} \mathrm{g}^{-1} \mathrm{~K}^{-1}\right)\end{array}$ & $\begin{array}{l}\text { Temp. } \\
\text { (K) }\end{array}$ & $\begin{array}{c}\mathrm{Cp} \\
\left(\mathrm{J} \mathrm{g}^{-1} \mathrm{~K}^{-1}\right)\end{array}$ \\
\hline 337 & 1.087 & 386 & 0.943 & 388 & 0.905 & 338 & 0.755 & 386 & 0.962 \\
\hline 360 & 1.043 & 406 & 0.941 & 413 & 0.910 & 361 & 0.833 & 406 & 0.958 \\
\hline 387 & 1.031 & 430 & 0.957 & 442 & 0.929 & 388 & 0.877 & 430 & 0.973 \\
\hline 417 & 1.047 & 455 & 0.975 & 474 & 0.953 & 418 & 0.911 & 455 & 0.991 \\
\hline 449 & 1.069 & 482 & 0.993 & 506 & 0.975 & 450 & 0.938 & 482 & 1.011 \\
\hline 481 & 1.086 & 509 & 1.010 & 539 & 0.992 & 482 & 0.966 & 509 & 1.029 \\
\hline 514 & 1.105 & 536 & 1.027 & 571 & 1.007 & 515 & 0.993 & 536 & 1.045 \\
\hline 547 & 1.123 & 564 & 1.042 & 604 & 1.026 & 547 & 1.023 & 563 & 1.056 \\
\hline 580 & 1.139 & 591 & 1.057 & 636 & 1.040 & 580 & 1.044 & 591 & 1.066 \\
\hline 612 & 1.156 & 618 & 1.073 & 668 & 1.055 & 613 & 1.059 & 618 & 1.076 \\
\hline 645 & 1.177 & 645 & 1.090 & 700 & 1.072 & 645 & 1.071 & 644 & 1.089 \\
\hline 677 & 1.196 & 671 & 1.099 & 732 & 1.084 & 677 & 1.089 & 671 & 1.095 \\
\hline 708 & 1.212 & 698 & 1.107 & 763 & 1.098 & 709 & 1.104 & 698 & 1.112 \\
\hline 740 & 1.229 & 724 & 1.118 & 794 & 1.104 & 741 & 1.110 & 724 & 1.122 \\
\hline 771 & 1.248 & 750 & 1.131 & 825 & 1.109 & 772 & 1.121 & 750 & 1.136 \\
\hline 802 & 1.261 & 776 & 1.140 & 856 & 1.114 & 803 & 1.135 & 776 & 1.151 \\
\hline 833 & 1.274 & 802 & 1.146 & 887 & 1.110 & 834 & 1.145 & 802 & 1.159 \\
\hline 864 & 1.289 & 828 & 1.155 & 917 & 1.108 & 865 & 1.149 & 828 & 1.165 \\
\hline 895 & 1.309 & 854 & 1.165 & 948 & 1.167 & 896 & 1.148 & 854 & 1.167 \\
\hline 926 & 1.334 & 880 & 1.164 & 978 & 1.397 & 927 & 1.208 & 879 & 1.175 \\
\hline 956 & 1.389 & 905 & 1.160 & 1009 & 1.497 & 957 & 1.481 & 905 & 1.176 \\
\hline 987 & 1.561 & 931 & 1.153 & 1039 & 1.463 & 988 & 1.565 & 931 & 1.165 \\
\hline 1017 & 1.690 & 956 & 1.153 & 1070 & 1.447 & 1018 & 1.524 & 956 & 1.165 \\
\hline 1048 & 1.609 & 981 & 1.180 & 1100 & 1.437 & 1049 & 1.511 & 981 & 1.211 \\
\hline 1078 & 1.609 & 1007 & 1.326 & 1130 & 1.419 & 1079 & 1.496 & 1007 & 1.415 \\
\hline 1108 & 1.615 & 1032 & 1.581 & 1160 & 1.364 & 1109 & 1.484 & 1032 & 1.652 \\
\hline 1139 & 1.618 & 1057 & 1.567 & 1190 & 1.271 & 1140 & 1.475 & 1057 & 1.610 \\
\hline 1169 & 1.649 & 1082 & 1.553 & 1221 & 0.752 & 1170 & 1.454 & 1082 & 1.598 \\
\hline 1199 & 1.649 & 1108 & 1.552 & 1251 & 0.135 & 1200 & 1.247 & 1108 & 1.604 \\
\hline 1229 & 1.640 & 1133 & 1.550 & 1281 & 0.353 & 1231 & 0.267 & 1133 & 1.604 \\
\hline 1260 & 1.636 & 1158 & 1.549 & 1311 & 0.828 & 1261 & -1.171 & 1158 & 1.606 \\
\hline 1290 & 1.663 & 1183 & 1.551 & 1341 & 1.132 & 1291 & 0.170 & 1183 & 1.600 \\
\hline 1320 & 1.684 & 1208 & 1.553 & 1371 & 1.112 & 1321 & 1.573 & 1208 & 1.568 \\
\hline 1351 & 1.670 & 1233 & 1.508 & 1401 & 1.612 & 1352 & 2.169 & 1233 & 1.505 \\
\hline 1381 & 1.672 & 1258 & 1.399 & 1431 & 1.923 & 1382 & 2.938 & 1258 & 1.352 \\
\hline 1411 & 1.668 & 1283 & 1.243 & 1461 & 1.904 & 1412 & 3.695 & 1283 & 1.117 \\
\hline 1441 & 1.689 & 1308 & 1.067 & 1491 & 2.178 & 1442 & 2.933 & 1308 & 0.826 \\
\hline 1472 & 1.745 & 1334 & 0.880 & 1521 & 2.364 & 1473 & 1.708 & 1333 & 0.450 \\
\hline 1502 & 1.799 & 1359 & 0.665 & 1551 & 2.529 & 1503 & 1.489 & 1358 & 0.036 \\
\hline 1532 & 1.808 & 1384 & 0.584 & 1582 & 1.486 & 1533 & 1.458 & 1384 & -0.097 \\
\hline 1562 & 1.793 & 1409 & 0.847 & 1612 & 1.299 & 1563 & 1.473 & 1409 & 0.142 \\
\hline 1593 & 1.743 & 1434 & 1.400 & 1642 & 1.304 & 1594 & 1.486 & 1434 & 0.642 \\
\hline 1623 & 1.694 & 1459 & 2.368 & 1672 & 1.294 & 1624 & 1.478 & 1459 & 1.248 \\
\hline 1653 & 1.673 & 1484 & 3.487 & 1702 & 1.291 & 1654 & 1.498 & 1484 & 1.999 \\
\hline
\end{tabular}




\begin{tabular}{|c|c|c|c|c|c|c|c|c|c|}
\hline 1684 & 1.672 & 1509 & 2.403 & 1732 & 1.290 & 1684 & 1.520 & 1509 & 3.333 \\
\hline 1714 & 1.674 & 1534 & 2.093 & 1752 & 1.287 & 1715 & 1.527 & 1534 & 5.050 \\
\hline 1744 & 1.685 & 1559 & 1.444 & & & 1745 & 1.524 & 1559 & 2.046 \\
\hline 337 & 1.087 & 1584 & 1.396 & & & & & 1584 & 2.157 \\
\hline & & 1609 & 1.390 & & & & & 1609 & 2.271 \\
\hline & & 1634 & 1.381 & & & & & 1634 & 1.817 \\
\hline & & 1659 & 1.378 & & & & & 1659 & 1.430 \\
\hline & & 1684 & 1.374 & & & & & 1684 & 1.404 \\
\hline & & 1710 & 1.370 & & & & & 1709 & 1.396 \\
\hline & & 1735 & 1.359 & & & & & 1735 & 1.399 \\
\hline
\end{tabular}

830

831

832

833

Table 7: continued

\begin{tabular}{|c|c|c|c|c|c|c|c|c|c|}
\hline \multicolumn{2}{|c|}{$\begin{array}{l}\text { Arc basalt* } \\
\text { Fuego (Fu06) }\end{array}$} & \multicolumn{2}{|c|}{$\begin{array}{c}\text { MORB } \\
\text { E. Pacific Rise (14Nov04) }\end{array}$} & \multicolumn{2}{|c|}{$\begin{array}{l}\text { P-MORB } \\
\text { Laki }\end{array}$} & \multicolumn{2}{|c|}{$\begin{array}{c}\text { OIB } \\
\text { Mauna Ulu (MU-SQ-4) }\end{array}$} & \multicolumn{2}{|c|}{$\begin{array}{c}\text { Continental* }^{*} \\
\text { Nyiragongo (NYI) }\end{array}$} \\
\hline $\begin{array}{l}\text { Temp. } \\
\text { (K) }\end{array}$ & $\frac{\mathrm{Cp}}{\left(\mathrm{J} \mathrm{g}^{-1} \mathrm{~K}^{-1}\right)}$ & $\begin{array}{l}\text { Temp. } \\
\text { (K) }\end{array}$ & $\begin{array}{c}\mathrm{Cp} \\
\left(\mathrm{J} \mathrm{g}^{-1} \mathrm{~K}^{-1}\right)\end{array}$ & $\begin{array}{l}\text { Temp. } \\
\text { (K) }\end{array}$ & $\begin{array}{c}\mathrm{Cp} \\
\left(\mathrm{J} \mathrm{g}^{-1} \mathrm{~K}^{-1}\right)\end{array}$ & $\begin{array}{l}\text { Temp. } \\
\text { (K) }\end{array}$ & $\underset{\left(\mathrm{J} \mathrm{g}^{-1} \mathrm{~K}^{-1}\right)}{\mathrm{Cp}}$ & $\begin{array}{l}\text { Temp. } \\
\text { (K) }\end{array}$ & $\frac{\mathrm{Cp}}{\left(\mathrm{J} \mathrm{g}^{-1} \mathrm{~K}^{-1}\right)}$ \\
\hline 388 & 388 & 338 & 0.858 & 338 & 1.029 & 336 & 1.005 & 336 & 0.966 \\
\hline 413 & 413 & 361 & 0.873 & 361 & 0.971 & 359 & 0.973 & 359 & 0.913 \\
\hline 442 & 442 & 389 & 0.897 & 388 & 0.951 & 386 & 0.985 & 387 & 0.921 \\
\hline 474 & 474 & 419 & 0.924 & 418 & 0.950 & 416 & 1.003 & 417 & 0.937 \\
\hline 506 & 506 & 450 & 0.951 & 450 & 0.958 & 447 & 1.023 & 448 & 0.957 \\
\hline 539 & 539 & 483 & 0.975 & 482 & 0.964 & 479 & 1.042 & 481 & 0.973 \\
\hline 572 & 572 & 516 & 1.000 & 515 & 0.975 & 512 & 1.060 & 514 & 0.983 \\
\hline 604 & 604 & 549 & 1.021 & 547 & 0.986 & 545 & 1.080 & 547 & 0.998 \\
\hline 636 & 636 & 581 & 1.035 & 580 & 0.999 & 578 & 1.098 & 580 & 1.008 \\
\hline 668 & 668 & 614 & 1.056 & 613 & 1.010 & 611 & 1.115 & 612 & 1.013 \\
\hline 700 & 700 & 646 & 1.082 & 645 & 1.019 & 643 & 1.125 & 645 & 1.026 \\
\hline 732 & 732 & 679 & 1.101 & 677 & 1.029 & 675 & 1.138 & 677 & 1.031 \\
\hline 763 & 763 & 710 & 1.119 & 709 & 1.042 & 707 & 1.154 & 708 & 1.037 \\
\hline 794 & 794 & 742 & 1.144 & 741 & 1.047 & 739 & 1.172 & 739 & 1.048 \\
\hline 825 & 825 & 773 & 1.172 & 772 & 1.056 & 770 & 1.190 & 771 & 1.058 \\
\hline 856 & 856 & 805 & 1.193 & 803 & 1.071 & 801 & 1.205 & 802 & 1.060 \\
\hline 887 & 887 & 836 & 1.215 & 834 & 1.075 & 832 & 1.218 & 833 & 1.054 \\
\hline 918 & 918 & 866 & 1.228 & 865 & 1.087 & 863 & 1.225 & 864 & 1.038 \\
\hline 948 & 948 & 897 & 1.241 & 896 & 1.096 & 894 & 1.224 & 894 & 1.045 \\
\hline 979 & 979 & 928 & 1.263 & 927 & 1.128 & 925 & 1.250 & 925 & 1.167 \\
\hline 1009 & 1009 & 958 & 1.420 & 957 & 1.232 & 956 & 1.500 & 955 & 1.290 \\
\hline 1039 & 1039 & 988 & 1.680 & 988 & 1.425 & 986 & 1.763 & 986 & 1.038 \\
\hline 1070 & 1070 & 1019 & 1.670 & 1018 & 1.419 & 1017 & 1.688 & 1016 & 1.032 \\
\hline 1100 & 1100 & 1049 & 1.668 & 1049 & 1.393 & 1047 & 1.644 & 1047 & 1.261 \\
\hline 1130 & 1130 & 1079 & 1.659 & 1079 & 1.311 & 1077 & 1.615 & 1077 & 1.428 \\
\hline 1161 & 1161 & 1109 & 1.676 & 1109 & 0.969 & 1107 & 1.188 & 1108 & 1.213 \\
\hline 1191 & 1191 & 1139 & 1.682 & 1140 & -0.114 & 1138 & -1.809 & 1138 & -2.178 \\
\hline 1221 & 1221 & 1170 & -0.098 & 1170 & -0.149 & 1168 & -2.902 & 1168 & 0.920 \\
\hline 1251 & 1251 & 1201 & $\begin{array}{l}-2.753 \\
\end{array}$ & 1200 & 1.013 & 1198 & 1.227 & 1199 & 1.124 \\
\hline 1281 & 1281 & 1230 & 0.995 & 1231 & 1.327 & 1229 & 1.374 & 1229 & 1.338 \\
\hline 1311 & 1311 & 1260 & 1.544 & 1261 & 1.504 & 1259 & 1.438 & 1259 & 1.501 \\
\hline 1341 & 1341 & 1290 & 1.322 & 1291 & 1.732 & 1289 & 1.563 & 1290 & 1.666 \\
\hline 1371 & 1371 & 1320 & 1.252 & 1321 & 2.120 & 1320 & 1.810 & 1320 & 1.995 \\
\hline 1401 & 1401 & 1351 & 1.343 & 1352 & 2.844 & 1350 & 2.238 & 1350 & 2.492 \\
\hline 1431 & 1431 & 1381 & 1.925 & 1382 & 3.619 & 1380 & 2.749 & 1380 & 3.867 \\
\hline
\end{tabular}




\begin{tabular}{|l|l|l|l|l|l|l|l|l|l|}
\hline 1461 & 1461 & 1411 & 3.309 & 1412 & 3.357 & 1410 & 3.600 & 1411 & 3.453 \\
\hline 1491 & 1491 & 1441 & 6.118 & 1442 & 2.102 & 1441 & 4.602 & 1441 & 1.636 \\
\hline 1521 & 1521 & 1471 & 5.222 & 1473 & 2.080 & 1471 & 3.110 & 1472 & 1.678 \\
\hline 1552 & 1552 & 1501 & 1.664 & 1503 & 1.969 & 1501 & 2.115 & 1502 & 1.790 \\
\hline 1582 & 1582 & 1531 & -0.121 & 1533 & 1.557 & 1532 & 1.569 & 1532 & 1.851 \\
\hline 1612 & 1612 & 1562 & -0.199 & 1563 & 1.544 & 1562 & 1.575 & 1563 & 1.570 \\
\hline 1642 & 1642 & 1592 & -0.352 & 1594 & 1.569 & 1592 & 1.572 & 1593 & 1.568 \\
\hline 1672 & 1672 & 1622 & -0.154 & 1624 & 1.558 & 1623 & 1.552 & 1623 & 1.564 \\
\hline 1702 & 1702 & 1652 & 0.006 & 1654 & 1.524 & 1653 & 1.556 & 1653 & 1.559 \\
\hline & & 1682 & 0.027 & 1684 & 1.489 & 1683 & 1.549 & 1684 & 1.550 \\
\hline & & 1713 & 0.005 & 1715 & 1.463 & 1714 & 1.535 & 1714 & 1.512 \\
\hline & & 1743 & 0.076 & 1745 & 1.426 & 1744 & 1.531 & 1745 & 1.417 \\
\hline & & 1760 & 0.089 & & & & & & \\
\hline
\end{tabular}

834

835 Note: Glassy starting materials always showed an increase in $C_{\mathrm{P}}$ at the glass transition

836

837

838

839

840

841 temperature, followed by a large negative apparent $C_{\mathrm{P}}$, that corresponds to latent heat released during crystallization $\left(\Delta \mathrm{H}^{\mathrm{xtl}}\right)$ of the sample. At higher temperatures we observed an abrupt increase in the heat flow signal, corresponding to melting of the crystals, followed by a return to the liquid heat capacity of $\sim 1.5 \mathrm{Jg}^{-1} \mathrm{~K}^{-1}$.

*Data below 1200 K from Robert etal. (2014) whereas data above 1200 K from Robert (2014) 
Table 1. Sample descriptions

\begin{tabular}{|c|c|c|c|c|c|c|}
\hline Lava type & Abbrev. & $\begin{array}{l}\text { Density }^{\mathrm{a}} \\
\mathrm{kg} \cdot \mathrm{m}^{-3}\end{array}$ & Color $^{b}$ & Type and Origin & $\begin{array}{l}\text { Previous } \\
\text { Sample No. }\end{array}$ & Reference \\
\hline Leucogranite & leuco & 2338 & $\begin{array}{l}\text { pale } \\
\text { brown }\end{array}$ & Remelted Harney Peak, SD & Leuco & $\begin{array}{l}D \text { (Hofmeister et al., 2014a); } \\
\eta \text { (Whittington et al., 2009a) }\end{array}$ \\
\hline Rhyolite & rhyo & 2333 & lt. brown & Remelted Mono Craters, CA & NCAR & $\begin{array}{l}D \text { (Romine et al., 2012); } \\
\eta \text { (Romine and Whittington, 2015) }\end{array}$ \\
\hline Rhyodacite & rhyo-dac & 2415 & colorless & Synthetic & SRD & - \\
\hline Dacite & dac & 2632 & brown & Remelted Mt. St. Helens & SH305 & - \\
\hline Dacite-andesite & dac-and & 2630 & green & Remelted Santiaguito, Guatemala & SA05-14 & - \\
\hline Andesite & and & 2459 & colorless & Synthetic & $\mathrm{BD}$ & - \\
\hline Andesite-basalt & and-bas & 2611 & colorless & Synthetic & SBA & $\eta($ Robert et al., 2013) \\
\hline Basalt-andesite & bas-and & 2655 & brown & Remelted Fuego, Guatemala & Fu18 & - \\
\hline Dolerite & dolerite & 2740 & brown & Remelted Chengwatana, $\mathrm{WI}^{\mathrm{c}}$ & Lab. Expt. & - \\
\hline Basalt & bas & 2679 & colorless & Synthetic & SB & $\begin{array}{l}\eta \text { at } T<1000 \mathrm{~K} \text { (Robert et al., 2015); } \\
\eta \text { at } T>1000 \mathrm{~K} \text { (Robert, 2014) }\end{array}$ \\
\hline Arc basalt & arc bas & 2770 & black & Remelted Fuego, Guatemala & $\mathrm{Fu} 06$ & $\begin{array}{l}\eta \text { at } T<1000 \mathrm{~K} \text { (Robert et al., 2015); } \\
\eta \text { at } T>1000 \mathrm{~K} \text { (Robert, 2014) }\end{array}$ \\
\hline Ocean island & OIB1 & 2822 & black & Remelted Mauna Kea quarry, HI & WU31-108 & - \\
\hline Ocean island & OIB2 & 2816 & black & Remelted Mauna Ulu, HI & MU-SQ-4 & $\eta($ Sehlke et al., 2014) \\
\hline MORB & MORB & 2783 & black & Glassy rim, East Pacific Rise ${ }^{\mathrm{d}}$ & 14Nov04 & - \\
\hline Icelandic & P-MORB & 2753 & black & Remelted lava tube roof, Iceland & LAKI & - \\
\hline $\begin{array}{l}\text { Continental } \\
\text { basalt }\end{array}$ & contl & 2873 & black & $\begin{array}{l}\text { Remelted Mt. Nyiragongo, DR. } \\
\text { Congo }^{\text {e }}\end{array}$ & NYI001 & - \\
\hline
\end{tabular}

\footnotetext{
${ }^{a}$ At $\sim 298 \mathrm{~K}$. The last digit is uncertain, except for MORB for which three different pieces with varying water contents gave a range from 2765 to $2798 \mathrm{~kg} \cdot \mathrm{m}^{-3}$. Details on MORB will be presented elsewhere.

${ }^{\mathrm{b}}$ From $\sim \mathrm{mm}$ thick sections

${ }^{\mathrm{c}}$ Sample described by Lev et al. (2012). Successive remelts of a continental basalt incorporated silica sand: the composition provided here is for the material studied here.

${ }^{\mathrm{d}}$ Collected in an Alvin dive by Mitch Schulte

${ }^{\mathrm{e}}$ Sample provided by Benoît Smets and Matthieu Kervyn
} 
Table 2. Chemical compositions determined by electron microprobe (in wt \%)

\begin{tabular}{|c|c|c|c|c|c|c|c|c|c|}
\hline & Leuco $^{a}$ & Rhyo $^{b}$ & Rhyo-dac & Dacite & Dac-and & And $^{c}$ & And-bas ${ }^{\mathrm{d}}$ & Bas-and $^{\mathrm{d}}$ & Dolerite \\
\hline $\mathrm{SiO}_{2}$ & 77.72 & 76.53 & 68.41 & 62.16 & 64.04 & 61.05 & 54.42 & 53.08 & 53.02 \\
\hline $\mathrm{TiO}_{2}$ & 0.07 & 0.07 & 0.49 & 0.58 & 0.57 & 0.71 & 1.37 & 0.88 & 1.69 \\
\hline $\mathrm{Al}_{2} \mathrm{O}_{3}$ & 13.80 & 12.92 & 18.38 & 19.83 & 18.80 & 22.19 & 20.49 & 20.42 & 15.68 \\
\hline $\mathrm{Cr}_{2} \mathrm{O}_{3}$ & bld & $\mathrm{nm}$ & bld & 0.01 & $\mathrm{~nm}$ & bld & $\mathrm{nm}$ & $\mathrm{nm}$ & 0.02 \\
\hline $\mathrm{FeO}$ & 1.00 & 0.99 & bld & 3.83 & 3.29 & bld & bld & 7.50 & 9.86 \\
\hline $\mathrm{MnO}$ & 0.06 & 0.06 & bld & 0.05 & 0.14 & bld & bld & bld & 0.17 \\
\hline $\mathrm{MgO}$ & 0.04 & 0.02 & 1.57 & 1.70 & 2.17 & 1.46 & 8.40 & 3.21 & 6.40 \\
\hline $\mathrm{CaO}$ & 0.46 & 0.97 & 4.47 & 4.46 & 5.77 & 7.82 & 10.39 & 8.94 & 9.04 \\
\hline $\mathrm{Na}_{2} \mathrm{O}$ & 3.26 & 3.81 & 4.43 & 4.46 & 4.45 & 4.33 & 3.76 & 3.93 & 2.55 \\
\hline $\mathrm{K}_{2} \mathrm{O}$ & 4.59 & 4.69 & 2.59 & 1.38 & 1.60 & 1.48 & 1.06 & 0.83 & 0.68 \\
\hline $\mathrm{P}_{2} \mathrm{O}_{5}$ & $\mathrm{~nm}$ & $\mathrm{~nm}$ & $\mathrm{~nm}$ & 0.16 & $\mathrm{~nm}$ & $\mathrm{~nm}$ & $\mathrm{~nm}$ & 0.20 & 0.12 \\
\hline Total & 101.09 & 100.06 & 100.34 & 98.69 & 100.85 & 99.04 & 99.90 & 98.99 & 99.24 \\
\hline $\mathrm{NBO} / \mathrm{T}$ & 0 & 0.02 & 0.05 & 0.09 & 0.20 & 0.06 & 0.40 & 0.33 & 0.58 \\
\hline $\mathrm{V}_{\text {molar }}, \mathrm{cm}^{3}$ & 27.81 & 27.70 & 27.08 & 26.49 & 26.33 & 26.57 & 24.76 & 25.25 & 23.93 \\
\hline $\begin{array}{l}\rho_{\text {liquid }} \\
\mathrm{kg} \mathrm{m}^{-3}\end{array}$ & 2335 & 2338 & 2402 & 2487 & 2472 & 2479 & 2538 & 2592 & 2646 \\
\hline $\mathrm{T}_{\text {liquid }}, \mathrm{K}$ & 1173 & 1173 & 1223 & 1223 & 1273 & 1273 & 1423 & 1423 & 1473 \\
\hline
\end{tabular}

Notes: bld = below limit of detection; $\mathrm{nm}=$ not measured. Compositions are the average of between 5 and 10 analyses for each sample. Analytical totals below $100 \%$ in part reflect that some iron is present as $\mathrm{Fe}_{2} \mathrm{O}_{3}$. Totals are low only for PMorb, which has a very small amount of crystallites. NBO/T calculated after Mysen et al. (1982a) approximates glass structure. NBO/T uncertainties $(2 \sigma)$ are \pm 0.01 based on chemical analysis standard deviations. Density of the liquid calculated from the composition at the indicated liquidus temperature using the formulation of Lange (1997).

${ }^{\mathrm{a}}$ Analysis by Hofmeister et al. (2014a)

${ }^{\mathrm{b}}$ Analysis by Romine et al. (2012)

${ }^{\mathrm{c}}$ Analysis of andesite from sample BD of Hellwig (2006). Similar values of $D$ were also measured for sample DF-05 of Hellwig (2006), which is the same base composition containing $0.03 \mathrm{wt} \% \mathrm{~F}$.

${ }^{\mathrm{d}}$ Analysis from Robert et al. (2013)

eAnalysis from Robert et al. (2015) 
Table 2 continued.

\begin{tabular}{lrrrrrrr}
\hline $\mathrm{wt}^{0}$ & $\mathrm{Bas}^{\mathrm{e}}$ & $\mathrm{Arc} \mathrm{bas}^{\mathrm{e}}$ & OIB1 & OIB2 & MORB & P-MORB & Contl \\
\hline $\mathrm{SiO}_{2}$ & 51.46 & 49.40 & 47.45 & 50.79 & 50.40 & 50.03 & 39.13 \\
$\mathrm{TiO}_{2}$ & 1.16 & 0.96 & 3.82 & 2.27 & 1.37 & 2.75 & 2.81 \\
$\mathrm{Al}_{2} \mathrm{O}_{3}$ & 18.62 & 17.57 & 13.94 & 12.53 & 15.62 & 13.80 & 14.90 \\
$\mathrm{Cr}_{2} \mathrm{O}_{3}$ & $\mathrm{~nm}$ & $\mathrm{~nm}$ & $\mathrm{bld}$ & 0.01 & 0.05 & 0.01 & $\mathrm{~nm}$ \\
$\mathrm{FeO}$ & $\mathrm{bld}$ & 10.56 & 13.25 & 10.35 & 9.60 & 11.74 & 12.13 \\
$\mathrm{MnO}$ & $\mathrm{bld}$ & $\mathrm{bld}$ & 0.20 & 0.17 & 0.18 & 0.22 & 0.29 \\
$\mathrm{MgO}$ & 14.87 & 7.46 & 5.46 & 10.58 & 8.08 & 5.56 & 4.08 \\
$\mathrm{CaO}$ & 9.33 & 8.97 & 10.04 & 10.50 & 11.95 & 10.27 & 12.18 \\
$\mathrm{Na} 2 \mathrm{O}$ & 3.28 & 3.10 & 3.01 & 2.16 & 2.69 & 2.64 & 5.63 \\
$\mathrm{~K}_{2} \mathrm{O}$ & 0.71 & 0.60 & 1.00 & 0.43 & 0.10 & 0.43 & 5.42 \\
$\mathrm{P}_{2} \mathrm{O}_{5}$ & $\mathrm{~nm}$ & 0.16 & $\mathrm{~nm}$ & 0.21 & $\mathrm{~nm}$ & $\mathrm{~nm}$ & 1.48 \\
$\mathrm{Total}$ & 99.44 & 98.79 & 98.17 & 100.00 & 100.03 & 97.44 & 98.90 \\
\hline $\mathrm{NBO} \mathrm{T}$ & 0.67 & 0.64 & 0.76 & 0.92 & 0.75 & 0.76 & 1.01 \\
\hline $\mathrm{V}_{\text {molar }}, \mathrm{cm}^{3}$ & 23.26 & 23.62 & 23.77 & 22.56 & 23.20 & 23.26 & 24.23 \\
\hline$\rho_{\text {liquid }}$ & 2591 & 2687 & 2678 & 2711 & 2689 & 2722 & 2720 \\
$\mathrm{~kg} \mathrm{~m}^{-3}$ & & & & & & & \\
$\mathrm{~T}_{\text {liquid }}, \mathrm{K}$ & 1473 & 1473 & 1473 & 1473 & 1473 & 1473 & 1473 \\
\hline
\end{tabular}


Table 3. Viscosity measurements

\begin{tabular}{|c|c|c|c|c|c|c|c|c|c|c|c|c|}
\hline \multicolumn{3}{|l|}{ Rhyo-dac } & \multicolumn{3}{|l|}{ Dacite } & \multicolumn{2}{|l|}{ Dac-and } & \multicolumn{3}{|l|}{ Bas-and $^{c}$} & \multicolumn{2}{|c|}{ Dolerite } \\
\hline$T(\mathrm{~K})$ & $\log \eta(\mathrm{Pa}$ & & $T(\mathrm{~K})$ & $\log \eta(\mathrm{Pa} \mathrm{s})$ & & $T(\mathrm{~K})$ & $\log \eta(\mathrm{Pa} \mathrm{s})$ & $T(\mathrm{~K})$ & $\log \eta(\mathrm{Pas}$ & & $T(\mathrm{~K})$ & $\log \eta(\mathrm{Pa} \mathrm{s})$ \\
\hline 1021 & 12.38 & $\mathrm{a}$ & 1009 & 12.22 & $\mathrm{a}$ & 967.8 & 11.97 & 932.8 & 12.75 & & 935.9 & 12.00 \\
\hline 1030 & 12.19 & $\mathrm{a}$ & 1030 & 11.66 & $\mathrm{~b}$ & 974.4 & 11.74 & 942.8 & 12.22 & & 950.1 & 11.37 \\
\hline 1041 & 11.86 & $\mathrm{a}$ & 1040 & 11.39 & b & 985.2 & 11.37 & 953.0 & 11.71 & & 959.8 & 10.97 \\
\hline 1051 & 11.60 & $\mathrm{~b}$ & 1046 & 11.20 & $\mathrm{~b}$ & 990.8 & 11.19 & 962.7 & 11.35 & & 963.6 & 10.76 \\
\hline 1061 & 11.27 & $\mathrm{a}$ & 1050 & 11.08 & $\mathrm{~b}$ & 994.6 & 11.06 & 972.7 & 10.99 & & 969.8 & 10.50 \\
\hline 1071 & 11.06 & $\mathrm{~b}$ & 1050 & 11.01 & $\mathrm{a}$ & 1006 & 10.72 & 982.9 & 10.65 & & 975.1 & 10.32 \\
\hline 1082 & 10.70 & $\mathrm{a}$ & 1055 & 10.87 & $\mathrm{a}$ & 1010 & 10.61 & 993.0 & 10.32 & & 982.4 & 10.07 \\
\hline 1091 & 10.55 & $\mathrm{~b}$ & 1061 & 10.78 & $\mathrm{~b}$ & 1021 & 10.28 & 1003 & 10.00 & & 983.9 & 9.98 \\
\hline 1096 & 10.33 & $\mathrm{a}$ & 1065 & 10.67 & $\mathrm{~b}$ & 1025 & 10.16 & 1013 & 9.71 & & 989.5 & 9.83 \\
\hline 1111 & 10.06 & b & 1070 & 10.49 & $\mathrm{a}$ & 1031 & 10.00 & 1025 & 9.38 & & 994.5 & 9.63 \\
\hline 1114 & 9.92 & $\mathrm{a}$ & 1071 & 10.47 & $\mathrm{a}$ & 1035 & 9.88 & 1518 & 2.41 & $\mathrm{c}$ & 994.7 & 9.65 \\
\hline 1115 & 9.89 & $\mathrm{a}$ & 1076 & 10.39 & $b$ & 1045 & 9.62 & 1544 & 2.24 & $\mathrm{c}$ & 998.8 & 9.49 \\
\hline 1121 & 9.82 & $\mathrm{~b}$ & 1081 & 10.26 & b & 1065 & 9.12 & 1570 & 2.09 & $\mathrm{c}$ & 1005 & 9.29 \\
\hline 1124 & 9.69 & $\mathrm{a}$ & 1086 & 10.12 & b & 1066 & 9.13 & 1595 & 1.94 & $\mathrm{c}$ & 1013 & 9.03 \\
\hline 1126 & 9.73 & $\mathrm{~b}$ & 1090 & 10.01 & $b$ & 1431 & 3.93 & 1620 & 1.81 & $\mathrm{c}$ & 1013 & 8.87 \\
\hline 1129 & 9.59 & $\mathrm{a}$ & 1095 & 9.88 & $\mathrm{a}$ & 1451 & 3.74 & 1669 & 1.55 & $\mathrm{c}$ & 1023 & 8.70 \\
\hline 1135 & 9.50 & $\mathrm{a}$ & 1100 & 9.76 & b & 1470 & 3.57 & 1720 & 1.32 & $\mathrm{c}$ & 1033 & 8.16 \\
\hline 1136 & 9.51 & b & 1106 & 9.64 & $\mathrm{a}$ & 1490 & 3.40 & 1745 & 1.21 & $\mathrm{c}$ & 1478 & 2.00 \\
\hline 1136 & 9.51 & $\mathrm{~b}$ & 1108 & 9.57 & $\mathrm{a}$ & 1514 & 3.21 & 1770 & 1.10 & $\mathrm{c}$ & 1502 & 1.84 \\
\hline 1139 & 9.39 & $\mathrm{a}$ & 1116 & 9.42 & $\mathrm{a}$ & 1539 & 3.03 & 1796 & 0.99 & $\mathrm{c}$ & 1548 & 1.55 \\
\hline 1144 & 9.28 & $\mathrm{a}$ & 1120 & 9.32 & $\mathrm{a}$ & 1563 & 2.86 & 1803 & 0.97 & $\mathrm{c}$ & 1595 & 1.29 \\
\hline 1146 & 9.30 & $\mathrm{~b}$ & 1120 & 9.30 & b & 1587 & 2.70 & 1827 & 0.88 & $\mathrm{c}$ & 1643 & 1.06 \\
\hline 1155 & 9.08 & $\mathrm{a}$ & 1403 & 4.93 & & 1612 & 2.55 & & & & 1692 & 0.85 \\
\hline 1162 & 8.94 & $\mathrm{a}$ & 1413 & 4.80 & & 1636 & 2.41 & & & & 1741 & 0.65 \\
\hline 1489 & 4.53 & & 1432 & 4.59 & & 1660 & 2.27 & & & & 1789 & 0.47 \\
\hline 1508 & 4.37 & & 1452 & 4.40 & & 1684 & 2.15 & & & & 1838 & 0.31 \\
\hline 1528 & 4.17 & & 1471 & 4.17 & & 1685 & 2.14 & & & & 1857 & 0.25 \\
\hline 1530 & 4.25 & & 1491 & 4.01 & & 1709 & 2.01 & & & & & \\
\hline 1548 & 4.06 & & 1510 & 3.87 & & 1733 & 1.88 & & & & & \\
\hline 1567 & 3.91 & & 1530 & 3.70 & & 1757 & 1.76 & & & & & \\
\hline
\end{tabular}




\begin{tabular}{llllll}
1575 & 3.89 & 1549 & 3.54 & 1782 & 1.66 \\
1587 & 3.77 & 1569 & 3.39 & & \\
1606 & 3.63 & 1588 & 3.25 & & \\
1625 & 3.53 & 1627 & 2.99 & & \\
1626 & 3.49 & 1647 & 2.87 & & \\
1645 & 3.36 & 1685 & 2.63 & & \\
1665 & 3.23 & 1705 & 2.53 & & \\
1684 & 3.11 & 1724 & 2.42 & & \\
1684 & 3.12 & 1743 & 2.33 & & \\
1704 & 2.99 & 1773 & 2.19 & & \\
1723 & 2.88 & 1774 & 2.16 & \\
1734 & 2.81 & & & \\
1743 & 2.77 & & & \\
1762 & 2.67 & & & \\
1773 & 2.63 & & & \\
1774 & 2.56 & & & & \\
\hline
\end{tabular}

Notes: Uncertainties discussed in the text.

$\mathrm{a}, \mathrm{b}$ indicate two different cores in the parallel plate viscometer.

$\mathrm{x}$ indicates unexpectedly high values that suggest crystallization.

c Samples FU18 (bas-and) and FU06 (arc basalt) from Robert (2014) 
Table 3, continued.

\begin{tabular}{|c|c|c|c|c|c|c|c|c|c|c|c|c|c|}
\hline \multicolumn{3}{|c|}{ Arc basalt $^{c}$} & \multicolumn{2}{|l|}{ OIB1 } & \multicolumn{3}{|l|}{ MORB } & \multicolumn{3}{|l|}{ P-MORB } & \multicolumn{3}{|c|}{ Continental } \\
\hline$T(\mathrm{~K})$ & $\log \eta(\mathrm{Pa} \mathrm{s}$ & & $T(\mathrm{~K})$ & $\log \eta(\mathrm{Pa} \mathrm{s})$ & $T(\mathrm{~K})$ & $\log \eta(\mathrm{Pa} \mathrm{s})$ & & $T(\mathrm{~K})$ & $\log \eta(\mathrm{Pa} \mathrm{s}$ & & $T(\mathrm{~K})$ & $\log \eta(\mathrm{Pa}$ & \\
\hline 912.4 & 13.13 & & 978.8 & 12.48 & 959.1 & 11.22 & $\mathrm{x}$ & 903.1 & 12.79 & $\mathrm{a}$ & 934.4 & 12.13 & $\mathrm{a}$ \\
\hline 922.9 & 12.49 & & 993.6 & 11.49 & 964.9 & 10.87 & $\mathrm{x}$ & 912.2 & 12.16 & $\mathrm{a}$ & 943.2 & 11.76 & $\mathrm{~b}$ \\
\hline 932.5 & 11.93 & & 1003 & 10.90 & 973.5 & 10.59 & & 922.4 & 11.76 & $\mathrm{a}$ & 947.5 & 11.55 & $\mathrm{a}$ \\
\hline 947.6 & 11.22 & & 1013 & 10.36 & 975.3 & 10.56 & & 925.4 & 11.85 & $b$ & 953.5 & 11.19 & $\mathrm{a}$ \\
\hline 958.0 & 10.80 & & 1018 & 9.97 & 984.9 & 10.14 & & 927.0 & 11.54 & $\mathrm{a}$ & 954.6 & 11.22 & $\mathrm{a}$ \\
\hline 984.0 & 9.80 & & & & 998.4 & 9.59 & & 945.8 & 10.93 & $\mathrm{~b}$ & 980.3 & 10.29 & $\mathrm{~b}$ \\
\hline 994.3 & 9.48 & & & & 1001 & 9.49 & & 946.5 & 10.68 & $\mathrm{a}$ & 980.7 & 10.21 & $\mathrm{a}$ \\
\hline 1467 & 2.03 & $\mathrm{c}$ & & & 1006 & 9.38 & & 951.1 & 10.37 & $\mathrm{a}$ & 985.3 & 10.09 & $\mathrm{~b}$ \\
\hline 1493 & 1.80 & $\mathrm{c}$ & & & 1016 & 8.91 & & 961.4 & 10.09 & $\mathrm{a}$ & 990.3 & 9.89 & $\mathrm{~b}$ \\
\hline 1519 & 1.63 & $\mathrm{c}$ & & & 1024 & 8.76 & & 966.0 & 10.01 & $\mathrm{a}$ & 995.1 & 9.69 & $b$ \\
\hline 1621 & 1.09 & $\mathrm{c}$ & & & 1621 & 1.95 & & 985.0 & 9.21 & $\mathrm{a}$ & 1008 & 9.13 & b \\
\hline 1647 & 0.97 & $\mathrm{c}$ & & & 1622 & 1.95 & & 985.1 & 9.42 & b & 1012 & 9.06 & $\mathrm{a}$ \\
\hline 1671 & 0.86 & $\mathrm{c}$ & & & 1669 & 1.70 & & 988.6 & 9.22 & b & 1026 & 8.49 & $\mathrm{a}$ \\
\hline 1696 & 0.76 & $\mathrm{c}$ & & & 1670 & 1.70 & & 990.4 & 9.19 & $b$ & 1038 & 7.93 & $\mathrm{a}$ \\
\hline 1722 & 0.66 & $\mathrm{c}$ & & & 1675 & 1.70 & & 992.1 & 8.79 & $\mathrm{a}$ & 1477 & 1.78 & \\
\hline 1747 & 0.56 & $\mathrm{c}$ & & & 1698 & 1.57 & & 1002 & 8.79 & b & 1502 & 1.44 & \\
\hline 1773 & 0.47 & $\mathrm{c}$ & & & 1698 & 1.57 & & 1003 & 8.74 & b & 1502 & 1.45 & \\
\hline 1798 & 0.39 & $\mathrm{c}$ & & & 1699 & 1.57 & & 1009 & 8.23 & $\mathrm{a}$ & 1502 & 1.42 & \\
\hline 1807 & 0.36 & $\mathrm{c}$ & & & 1718 & 1.47 & & 1394 & 3.89 & $\mathrm{x}$ & 1548 & 1.11 & \\
\hline 1828 & 0.30 & $\mathrm{c}$ & & & 1718 & 1.48 & & 1443 & 2.98 & $\mathrm{x}$ & 1549 & 1.11 & \\
\hline & & & & & 1719 & 1.49 & & 1465 & 2.85 & $\mathrm{x}$ & 1550 & 1.12 & \\
\hline
\end{tabular}




$\begin{array}{rrrrrr}1785 & 1.20 & 1614 & 1.57 & 1646 & 0.64 \\ 1785 & 1.20 & 1638 & 1.49 & 1646 & 0.64 \\ 1816 & 1.10 & 1687 & 1.29 & 1694 & 0.40 \\ 1816 & 1.08 & 1715 & 1.16 & 1694 & 0.42 \\ 1816 & 1.09 & 1736 & 1.11 & 1694 & 0.40 \\ 1858 & 0.97 & 1774 & 1.02 & 1742 & 0.20 \\ 1858 & 0.96 & 1775 & 1.03 & 1743 & 0.23 \\ 1861 & 0.93 & & & 1743 & 0.21 \\ 1861 & 0.94 & & & 1790 & 0.02 \\ & & & & 1791 & 0.00 \\ & & & & & -0.09\end{array}$


Table 4. Fits to viscosity data of the form $\log (\eta)=A+B /(T-C)$

\begin{tabular}{|c|c|c|c|c|c|c|c|c|c|c|c|c|c|}
\hline sample & Leuco $^{a}$ & Rhyo $^{b}$ & Rhyo-dac & Dacite & Dac-and & And-bas ${ }^{c}$ & Bas-and & Dolerite & Basalt $^{d}$ & Arc-bas $^{d}$ & $\mathrm{OIB}^{\mathrm{e}}$ & P-MORB & Contl \\
\hline A & -7.06 & -6.00 & -4.43 & -4.68 & -4.50 & -4.81 & -3.96 & -4.09 & -5.20 & -3.89 & -5.10 & -2.54 & -4.81 \\
\hline B & 18159 & 11452 & 9029.8 & 8655.5 & 7967.9 & 6826.7 & 6077.6 & 5293.6 & 6597.5 & 5018.7 & 6230.3 & 4054.9 & 5685.1 \\
\hline $\mathrm{C}$ & 141.1 & 222.0 & 486.2 & 500.1 & 482.4 & 582.2 & 567.2 & 607.5 & 599.3 & 616.7 & 554.7 & 638.3 & 601.2 \\
\hline No. Pts. & 43 & 22 & 46 & 41 & 31 & 24 & 22 & 27 & 33 & 25 & 27 & 25 & 41 \\
\hline rmsd & 0.02 & 0.06 & 0.03 & 0.04 & 0.02 & 0.04 & 0.03 & 0.06 & 0.07 & 0.04 & 0.11 & 0.09 & 0.08 \\
\hline $\mathrm{T}_{12}(\mathrm{~K})^{\mathrm{f}}$ & 1093.7 & 1080.6 & 1035.8 & 1019.2 & 965.3 & 988.3 & 948.0 & 936.5 & 982.9 & 932.5 & 919.0 & 917.2 & 939.4 \\
\hline $\mathrm{m}^{\mathrm{g}}$ & 21.9 & 22.7 & 31.0 & 32.7 & 33.0 & 40.9 & 39.7 & 45.8 & 44.1 & 46.9 & 43.1 & 47.8 & 46.7 \\
\hline
\end{tabular}

${ }^{\mathrm{a}}$ Whittington et al. (2009a)

${ }^{\mathrm{b}}$ Romine and Whittington (2015)

${ }^{c}$ Sample SBA from Robert et al. (2013)

${ }^{\mathrm{d}}$ Fits to data on dry samples of basalt SB and arc basalt Fu06 from Robert (2014)

${ }^{\mathrm{e}}$ Sehlke et al. (2014)

${ }^{\mathrm{f}}$ The digits reported for $T_{12}$ are needed to accurately ascertain fragility.

${ }^{\mathrm{g}}$ Fragility, $\mathrm{m}=\mathrm{B} /\left[T_{12}\left(1-\mathrm{C} / T_{12}\right)^{2}\right]$, with parameters $\mathrm{B}, \mathrm{C}$ and $T_{12}$ obtained from the VTF fit. 
Table 5. Thermal diffusivity values ( $T$ in $\mathrm{K} ; D$ in $\mathrm{mm}^{2} \mathrm{~s}^{-1}$ )

\begin{tabular}{|c|c|c|c|c|c|c|c|c|c|c|c|c|c|c|c|}
\hline \multicolumn{2}{|c|}{ rhyodacite } & \multicolumn{2}{|l|}{ dacite } & \multicolumn{2}{|c|}{ dacite-andesite } & \multicolumn{2}{|c|}{ andesite $^{a}$} & \multicolumn{2}{|c|}{ and-basalt ${ }^{\mathrm{b}}$} & \multicolumn{2}{|c|}{ basalt-andesite } & \multicolumn{2}{|c|}{ dolerite $\# 3^{\mathrm{c}}$} & \multicolumn{2}{|c|}{ dolerite $\# 4^{\mathrm{b}}$} \\
\hline$T$ & $D$ & $T$ & $D$ & $T$ & $D$ & $T$ & $D$ & $T$ & $D$ & $T$ & $D$ & $T$ & $D$ & $T$ & $D$ \\
\hline 294.1 & 0.592 & 295.4 & 0.535 & 293.5 & 0.569 & 294.9 & 0.567 & 294.4 & 0.549 & 294.2 & 0.536 & 294.6 & 0.544 & 294.5 & 0.512 \\
\hline 349.6 & 0.540 & 344.2 & 0.514 & 337.7 & 0.557 & 347.4 & 0.555 & 345.8 & 0.528 & 338.1 & 0.513 & 348.9 & 0.529 & 346.7 & 0.484 \\
\hline 404.4 & 0.517 & 405.9 & 0.500 & 388.8 & 0.546 & 411.1 & 0.536 & 410.9 & 0.513 & 390.2 & 0.496 & 403.2 & 0.512 & 410.7 & 0.476 \\
\hline 475.5 & 0.504 & 477.7 & 0.485 & 448.0 & 0.535 & 475.3 & 0.524 & 485.2 & 0.499 & 444.5 & 0.486 & 479.9 & 0.495 & 475.0 & 0.463 \\
\hline 553.7 & 0.491 & 557.8 & 0.480 & 515.6 & 0.522 & 555.0 & 0.516 & 554.2 & 0.484 & 518.2 & 0.474 & 554.5 & 0.487 & 555.7 & 0.456 \\
\hline 644.7 & 0.472 & 653.0 & 0.479 & 598.8 & 0.516 & 646.7 & 0.506 & 643.5 & 0.478 & 598.4 & 0.469 & 645.9 & 0.484 & 645.9 & 0.451 \\
\hline 749.7 & 0.479 & 753.3 & 0.470 & 689.5 & 0.509 & 748.9 & 0.500 & 750.5 & 0.466 & 693.4 & 0.461 & 745.1 & 0.482 & 748.4 & 0.448 \\
\hline 855.3 & 0.470 & 860.9 & 0.470 & 794.0 & 0.502 & 859.6 & 0.495 & 859.6 & 0.460 & 783.1 & 0.460 & 872.1 & 0.476 & 862.5 & 0.445 \\
\hline 974.6 & 0.466 & 998.0 & 0.466 & 902.1 & 0.497 & 960.3 & 0.490 & 970.8 & 0.438 & 882.9 & 0.456 & 1031 & 0.446 & 959.5 & 0.44 \\
\hline 1126 & 0.443 & 1118 & 0.464 & 1027 & 0.490 & 1008 & 0.490 & 1069 & 0.395 & 981.3 & 0.447 & 1164 & 0.377 & 1062 & 0.345 \\
\hline 1154 & 0.446 & 1177 & 0.472 & 1072 & 0.487 & 1041 & 0.487 & 1090 & 0.358 & 1010 & 0.446 & 1202 & xtls. & 1095 & 0.341 \\
\hline 1184 & 0.406 & 1235 & 0.433 & 1146 & 0.440 & 1077 & 0.489 & 1115 & 0.356 & 1039 & 0.444 & & & 1125 & 0.345 \\
\hline 1214 & 0.391 & 1293 & 0.427 & 1182 & 0.419 & 1082 & 0.484 & 1134 & 0.352 & 1068 & 0.426 & & & 1156 & 0.358 \\
\hline 1244 & 0.387 & 1351 & 0.417 & 1219 & 0.426 & 1106 & 0.485 & 1176 & 0.362 & 1096 & 0.388 & & & 1181 & xtls \\
\hline 1274 & 0.395 & 1405 & 0.429 & 1329 & 0.431 & 1131 & 0.480 & 1203 & & 1152 & 0.383 & & & & \\
\hline \multirow[t]{4}{*}{1324} & 0.380 & 1459 & 0.413 & 1439 & 0.436 & 1156 & 0.454 & & & 1209 & 0.455 & & & & \\
\hline & & & & & & 1180 & 0.428 & & & & & & & & \\
\hline & & & & & & 1232 & 0.418 & & & & & & & & \\
\hline & & & & & & 1282 & 0.415 & & & & & & & & \\
\hline
\end{tabular}

Notes: Uncertainties are $\sim \pm 2 \%$, except at room temperature where uncertainties are $\pm 3-5 \%$ per standardization.

${ }^{\text {a }}$ Results for sample DF-05 (andesite with $0.03 \mathrm{wt} \% \mathrm{~F}$ from Hellwig 2006) were identical within uncertainties and provided $D_{\text {melt }}=0.416$ mm ${ }^{2} \mathrm{~s}^{-1}$ from 1175 to $1428 \mathrm{~K}$.

${ }^{\mathrm{b}}$ Data from andesite-basalt (SBA) before concentric cylinder measurements.

${ }^{\mathrm{c}}$ Dolerite \#3 was the sample as received. Dolerite \#4 was measured after remelting. 
Table 5, continued.

\begin{tabular}{|c|c|c|c|c|c|c|c|c|c|c|c|c|c|}
\hline \multicolumn{2}{|c|}{ Basalt (synthetic) } & \multicolumn{2}{|c|}{ Arc basalt } & \multicolumn{2}{|l|}{ OIB1 } & \multicolumn{2}{|l|}{ OIB2 } & \multicolumn{2}{|c|}{ MORB } & \multicolumn{2}{|c|}{ P-MORB } & \multicolumn{2}{|c|}{ Continental } \\
\hline$T$ & $D$ & $T$ & $D$ & $T$ & $D$ & $T$ & $D$ & $T$ & $D$ & $T$ & $D$ & $T$ & $D$ \\
\hline 294.3 & 0.542 & 293.9 & 0.520 & 293.5 & 0.461 & 296.6 & 0.529 & 293.2 & 0.556 & 295.2 & 0.555 & 293.2 & 0.472 \\
\hline 347.0 & 0.516 & 336.6 & 0.487 & 377.0 & 0.445 & 350.0 & 0.501 & 337.1 & 0.536 & 337.2 & 0.543 & 337.2 & 0.446 \\
\hline 411.6 & 0.496 & 384.7 & 0.471 & 474.2 & 0.434 & 413.1 & 0.477 & 378.3 & 0.519 & 390.5 & 0.530 & 388.9 & 0.430 \\
\hline 474.2 & 0.485 & 447.1 & 0.454 & 574.4 & 0.429 & 478.7 & 0.465 & 429.9 & 0.502 & 445.4 & 0.513 & 451.1 & 0.418 \\
\hline 555.2 & 0.475 & 515.9 & 0.443 & 699.4 & 0.429 & 562.9 & 0.455 & 478.0 & 0.493 & 515.7 & 0.506 & 517.7 & 0.408 \\
\hline 646.0 & 0.467 & 596.1 & 0.439 & 824.7 & 0.425 & 654.2 & 0.453 & 553.8 & 0.483 & 597.0 & 0.489 & 602.6 & 0.403 \\
\hline 747.5 & 0.461 & 688.6 & 0.440 & 949.6 & 0.416 & 759.5 & 0.444 & 625.2 & 0.479 & 687.9 & 0.479 & 693.4 & 0.394 \\
\hline 859.1 & 0.451 & 779.9 & 0.440 & 1074 & 0.404 & 869.4 & 0.449 & 725.2 & 0.474 & 789.0 & 0.474 & 793.6 & 0.389 \\
\hline 957.7 & 0.442 & 879.5 & 0.439 & 1223 & 0.458 & 992.8 & 0.456 & 825.0 & 0.468 & 900.0 & 0.460 & 902.1 & 0.388 \\
\hline 1062 & 0.426 & 991.2 & 0.442 & 1348 & 0.402 & 1096 & 0.364 & 901.3 & 0.464 & 1020 & 0.450 & 1030 & 0.346 \\
\hline 1096 & 0.342 & 1051 & 0.386 & 1374 & 0.388 & 1095 & 0.402 & 949.7 & 0.455 & 1140 & 0.477 & 1073 & 0.390 \\
\hline 1126 & 0.335 & 1077 & 0.370 & 1398 & 0.407 & 1095 & 0.399 & 974.5 & 0.449 & 1261 & 0.453 & 1113 & 0.407 \\
\hline 1155 & 0.331 & 1104 & 0.398 & 1424 & 0.170 & 1147 & 0.494 & 997.8 & 0.405 & 1382 & 0.399 & 1145 & 0.480 \\
\hline 1179 & 0.330 & 1161 & 0.428 & & & 1202 & 0.485 & 1023 & 0.309 & 1482 & 0.205 & 1186 & 0.480 \\
\hline \multirow[t]{5}{*}{1231} & xtls. & & & & & 1343 & 0.472 & 1048 & 0.289 & & & & \\
\hline & & & & & & & & 1073 & 0.369 & & & & \\
\hline & & & & & & & & 1097 & 0.376 & & & & \\
\hline & & & & & & & & 1124 & 0.370 & & & & \\
\hline & & & & & & & & 1470 & 0.310 & & & & \\
\hline
\end{tabular}


Table 6. Thermal diffusivity initial values and fitting parameters.

\begin{tabular}{|c|c|c|c|c|c|c|c|c|}
\hline Sample & $\begin{array}{l}\text { Thickness } \\
\mathrm{mm}\end{array}$ & $\begin{array}{l}T \\
{ }^{\circ} \mathrm{C}\end{array}$ & $\begin{array}{l}D_{298} \\
\mathrm{~mm}^{2} \mathrm{~s}^{-1}\end{array}$ & \multicolumn{3}{|c|}{$D=\mathrm{F} T^{-\mathrm{G}}+\mathrm{H} T$} & $\begin{array}{l}T_{\text {melt }} \\
\mathrm{K}\end{array}$ & $\begin{array}{l}D_{\text {melt }} \\
\mathrm{mm}^{2} \mathrm{~s}^{-1}\end{array}$ \\
\hline Rhyolite $^{\mathrm{b}}$ & $0.4-0.9$ & 21.0 & 0.63 & $2.9587 \pm 0.6$ & $0.28256 \pm 0.034$ & $12.647 \pm 1.9$ & 1330 & 0.52 \\
\hline Dacite & 0.389 & 22.1 & 0.535 & $2.2637 \pm 0.3$ & $0.2655 \pm 0.024$ & $10.482 \pm 1.3$ & 1300 & 0.42 \\
\hline Dacite-andesite & 0.38 & 20.2 & 0.57 & $1.7065 \pm 0.12$ & $0.19834 \pm 0.013$ & $5.8235 \pm 0.9$ & $>1180$ & $0.42^{\mathrm{g}}$ \\
\hline Andesite (syn.) & 0.886 & 21.6 & 0.567 & $2.682 \pm 0.37$ & $0.28213 \pm 0.025$ & $11.05 \pm 1.5$ & $>1175$ & $0.42 \mathrm{~h}$ \\
\hline Bas-and & 0.527 & 20.9 & 0.57 & $2.9178 \pm 0.62$ & $0.31099 \pm 0.039$ & $11.241 \pm 2.1$ & 1120 & 0.39 \\
\hline Dolerite $\# 3 \mathrm{~d}^{\mathrm{a}}$ & 0.885 & 21.2 & 0.543 & $2.7491 \pm 0.56$ & $0.29749 \pm 0.038$ & $12.639 \pm 2.3$ & 1100 & $<0.37$ \\
\hline Dolerite\#4 & 0.895 & 21.1 & 0.512 & $2.5599 \pm 0.61$ & $0.29707 \pm 0.043$ & $11.546 \pm 2.3$ & 1100 & 0.34 \\
\hline Basalt (syn.) & 0.976 & 21.0 & 0.542 & $2.5776 \pm 0.58$ & $0.28395 \pm 0.041$ & $8.3044 \pm 2.5$ & 1100 & 0.33 \\
\hline Arc basalt & 0.71 & 20.6 & 0.54 & $8.5283 \pm 2.3$ & $0.51659 \pm 0.048$ & $20.721 \pm 1.8$ & 1080 & 0.36 \\
\hline OIB1 & 0.935 & 20.4 & 0.46 & $0.67838 \pm 1.0$ & $0.0704 \pm 0.022$ & & 1150 & $\sim 0.25$ \\
\hline P-MORB & 0.846 & 21.9 & 0.56 & $1.4342 \pm 0.4$ & $0.16726 \pm 0.004$ & & 1500 & $>0.2$ \\
\hline Continental & 0.748 & 19.9 & 0.47 & $4.4707 \pm 1.0$ & $0.41267 \pm 0.041$ & $13.284 \pm 1.8$ & 1030 & $<0.34^{\mathrm{i}}$ \\
\hline
\end{tabular}

Notes: Syn. indicates synthetic, which lacked $\mathrm{Fe}^{3+}$ associated with many natural samples. Designations \#1 and \#2 indicate runs were performed on different sections of the same sample. Except as footnoted, values of $D$ immediately upon melting are presented, because several samples crystallized shortly thereafter. The fits provide $D$ in $\mathrm{mm}^{2} \mathrm{~s}^{-1}$ using $T$ in $\mathrm{K}$. Coefficient $\mathrm{G}$ has no units. Units of coefficient $\mathrm{F}$ depend on the value of G. Coefficient $\mathrm{H}$ has units of $\mathrm{mm}^{2} \mathrm{~s}^{-1} \mathrm{~K}^{-1} \cdot \chi^{2}$ ranged from 0.0001 to 0.0005 . High uncertainties in coefficient $\mathrm{F}$ are due to tradeoffs in fitting exponent $\mathrm{G}$. To reproduce the data, all digits that are shown for $\mathrm{F}, \mathrm{G}$, and $\mathrm{H}$ are needed. These fits can be projected up to the melting temperature less $\sim 100 \mathrm{~K}$. ${ }^{\text {a }}$ Data on $D$ from Hofmeister et al. (2014)

${ }^{\mathrm{b}}$ Data on $D$ from Romine et al. (2012)

${ }^{c}$ Fit to and-bas data on chips both before and after concentric cylinder measurements. $D_{\text {melt }}$ constrained by multiple runs.

${ }^{\mathrm{d}}$ Dolerite \#1 had color zonation and is not reported. Dolerite\#3 is the sample as received, whereas dolerite\#4 was remelted.

${ }^{\mathrm{e}}$ From glassy rim which is wet compared to the core, as indicated by its low melting temperature.

${ }_{\mathrm{f}}^{\mathrm{f}}$ From the interior, which is dry as indicated by having the nominal melting temperature of basalts.

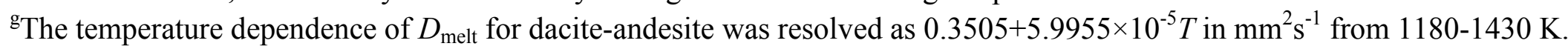


${ }^{\mathrm{h}}$ Constant $D_{\text {melt }}=0.416$ was observed from $1180-1430 \mathrm{~K}$ for the andesite with $0.03 \mathrm{wt} \% \mathrm{~F}$, which equals $D$ of F-free andesite upon melting. ${ }^{\mathrm{i}}$ Melting may have been incomplete due to outgassing and crystallization.

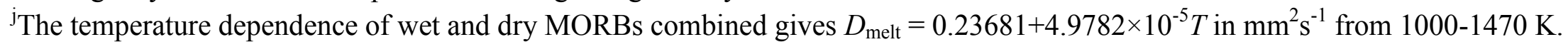

\section{TABLE 7 is vertical and is after the references in the}

\section{ms file}


Table 8. Fits to heat capacity in $\left(\mathrm{J} \mathrm{g}^{-1} \mathrm{~K}^{-1}\right)$ against temperature in $\mathrm{K}$.

\begin{tabular}{|c|c|c|c|c|c|c|c|c|c|c|c|c|c|c|}
\hline & Leuco & Rhyolite & Rhyodac & Dacite & Dac-and & And-bas ${ }^{\mathrm{a}}$ & Bas-and $^{\mathrm{a}}$ & Dolerite & $\mathrm{Bas}^{\mathrm{a}}$ & $\operatorname{Arc~bas}^{\mathrm{a}}$ & MORB & P-MORB & OIB2 & Contl. \\
\hline \multicolumn{15}{|l|}{ Glass } \\
\hline $\mathrm{a}$ & 1.07 & 1.19 & 0.95 & 0.79 & 0.85 & 1.00 & 1.06 & 1.036 & 0.92 & 0.91 & 0.66 & 0.83 & 0.919 & 0.95 \\
\hline $\mathrm{b}$ & 0.00027 & 0.00005 & 0.00025 & 0.00045 & 0.00051 & 0.00023 & 0.00012 & 0.00019 & 0.00032 & 0.0003 & 0.00066 & 0.00030 & 0.00037 & 0.00016 \\
\hline$c \times 10^{-4}$ & -4.13 & -4.63 & -2.76 & -0.915 & -0.315 & -2.80 & -3.85 & -3.66 & -1.56 & -2.45 & -0.170 & -0.168 & -1.20 & -1.35 \\
\hline$C_{P, g}$ at $298 \mathrm{~K}$ & 0.68539 & 0.68353 & 0.71370 & 0.82106 & 0.96651 & 0.75324 & 0.66222 & 0.68048 & 0.8397 & 0.732 & 0.83754 & 0.90048 & 0.89413 & 0.84566 \\
\hline$T_{\mathrm{g}}(\mathrm{K})$ & 1080 & 1047 & 1044 & 1042 & 978 & 1013 & 968 & 947 & 1008 & 948 & 964 & 965 & 953 & 947 \\
\hline$C_{P, g}$ at $T_{\mathrm{g}}$ & 1.33 & 1.203 & 1.183 & 1.253 & 1.353 & 1.23 & 1.14 & 1.18 & 1.22 & 1.17 & 1.29 & 1.12 & 1.26 & 1.09 \\
\hline \multicolumn{15}{|l|}{ Liquid } \\
\hline d & 1.49 & 1.31 & 1.17 & 1.38 & 1.54 & 1.90 & 1.71 & 1.49 & 1.98 & 1.67 & 1.81 & 1.39 & 1.77 & 1.63 \\
\hline e & 0 & -0.00003 & 0.00018 & 0.00004 & 0.00008 & -0.00031 & -0.00025 & $6.49 \times 10^{-6}$ & -0.00034 & -0.00012 & -0.00014 & 0.00007 & -0.00013 & -0.00004 \\
\hline $2 \sigma$ & 0.02 & 0.01 & 0.02 & 0.03 & 0.09 & 0.01 & 0.02 & 0.04 & 0.02 & 0.02 & 0.01 & 0.11 & 0.02 & 0.02 \\
\hline$C_{P, l}$ at $T_{\mathrm{g}}$ & 1.49 & 1.34 & 1.36 & 1.42 & 1.62 & 1.58 & 1.30 & 1.50 & 1.63 & 1.55 & 1.68 & 1.46 & 1.65 & 1.59 \\
\hline$C_{P, \text { conf }}$ & 0.162 & 0.138 & 0.178 & 0.167 & 0.271 & 0.375 & 0.17 & 0.321 & 0.41 & 0.38 & 0.384 & 0.340 & 0.391 & 0.499 \\
\hline$C_{P, l}$ at $T_{\text {liquid }}$ & 1.49 & 1.28 & 1.39 & 1.43 & 1.64 & 1.46 & 1.35 & 1.50 & 1.48 & 1.49 & 1.60 & 1.49 & 1.58 & 1.57 \\
\hline$T_{\max }$ & 1400 & 1550 & 1550 & 1750 & 1750 & 1750 & 1750 & 1750 & 1750 & 1650 & 1100 & 1750 & 1750 & $\sim 1600$ \\
\hline
\end{tabular}

Notes: All fits are to data collected with the Netzsch calorimeter. For Maier-Kelly (1932) glass fits, $C_{P}=\mathrm{a}+\mathrm{b} T+\mathrm{c} T^{-2}$ with $2 \sigma<0.01$ and $T<T_{\mathrm{g}}$. For linear fits to liquid data, $C_{P}=\mathrm{d}+\mathrm{e} T$ with $2 \sigma$ and $T_{\max }$ as reported. For $T_{\text {liquid }}$ see Table 2. Experimental accuracies are $1 \%$ for glass and $2 \%$ for melt based on repeated measurements on $\alpha-\mathrm{Al}_{2} \mathrm{O}_{3}$.

${ }^{\mathrm{a}}$ Robert et al. (2014) provide data on and-bas (labeled SBA therein); bas-and (Fu18); bas (SB); and arc basalt (Fu06). 
Table 9. Fits to glass thermal conductivity $=\mathrm{A}+\mathrm{B} T+\mathrm{C} T^{-2}+\mathrm{D} T^{1 / 2}$ and selected liquid $k$ (in $\mathrm{W} \mathrm{m} \mathrm{m}^{-1}$ ) against temperature (in $\mathrm{K}$ ).

\begin{tabular}{|c|c|c|c|c|c|c|c|c|c|c|c|c|c|c|}
\hline & Leuco & Rhyolite & Rhyodac & Dacite & Dac-and & And-bas & Bas-and & Dolerite & Basalt & Arc bas & MORB & P-MORB & OIB2 & Contl \\
\hline \multicolumn{15}{|l|}{ Glass } \\
\hline A & 2.8683 & 2.7578 & 2.3706 & 1.7444 & 1.7973 & 1.9808 & 2.2837 & 2.2931 & 2.2099 & 2.5728 & 1.8148 & 1.5682 & 2.3872 & 1.9863 \\
\hline $\mathrm{B} \times 10^{4}$ & 11.609 & 12.292 & 14.002 & 13.104 & 10.577 & 6.6136 & 10.735 & 12.6983 & 11.064 & 22.7959 & 17.759 & 4.046 & 21.658 & 12.735 \\
\hline $\mathrm{C}$ & -64532 & -71174 & -40254 & -12497 & -2953.7 & -40598 & -54011 & -52463 & -21139 & -34545 & 1768.9 & 3189.7 & 8296.5 & 7263.5 \\
\hline $\mathrm{D} \times 10^{2}$ & -8.7197 & -7.6603 & -7.7977 & -4.926 & -3.4101 & -3.8249 & -6.1831 & -6.607 & -5.3125 & -10.661 & -6.0827 & -1.8849 & -9.273 & -6.4536 \\
\hline$k$ at $298 K$ & 0.98 & 1.00 & 0.99 & 1.14 & 1.41 & 1.06 & 0.93 & 0.94 & 1.21 & 1.02 & 1.28 & 1.37 & 1.33 & 1.13 \\
\hline \multicolumn{15}{|l|}{ Liquid } \\
\hline$k_{\text {liquid }}$ at $\mathrm{T}_{\mathrm{g}}$ & 1.81 & 1.55 & 1.27 & 1.48 & 1.64 & 1.40 & 1.31 & 1.36 & 1.41 & 1.52 & 1.29 & 1.46 & 1.52 & $1.3-1.5$ \\
\hline$k_{\text {liquid }}$ at $T_{\text {liquid }}$ & 1.80 & 1.55 & 1.30 & 1.49 & 1.73 & 1.29 & 1.36 & 1.36 & 1.28 & 1.44 & 1.34 & 1.22 & 1.46 & $\sim 1.4$ \\
\hline
\end{tabular}

Notes: Data on glass thermal conductivity are accurate to better than $4 \%$, whereas those for the liquid range are $\sim 5 \%$ and increasing to $\sim 8 \%$ at the liquidus, see text. For $T_{\text {liquid, }}$ see Table 2. Parameters in fits are not rounded to ensure reproduction of the calculations. For the dacite-andesite and MORB liquids, $D(T)$ is known, providing higher accuracy; for the other samples $D$ is assumed to be constant. Assuming $\alpha=7.5 \times 10^{-6} \mathrm{~K}^{-1}$ (Bouhifd et al. 2015) provides $k_{\text {liquid }}=1.3298+0.00031647 T$ for dacite-andesite and $k_{\text {liquid }}=1.2005+9.2508 \times 10^{-5} T$ for MORB. 


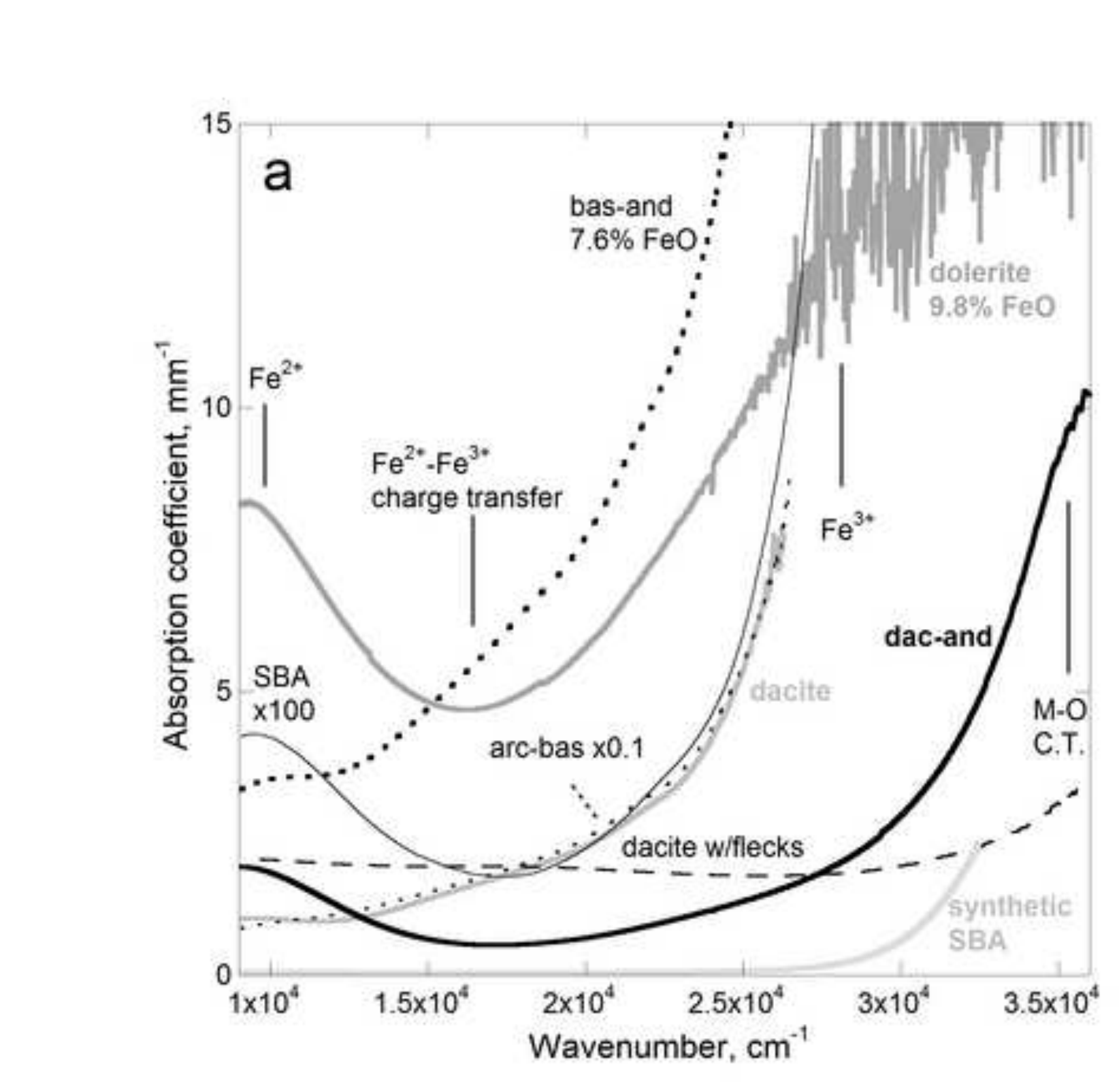

rence

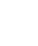

\section{.}

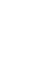
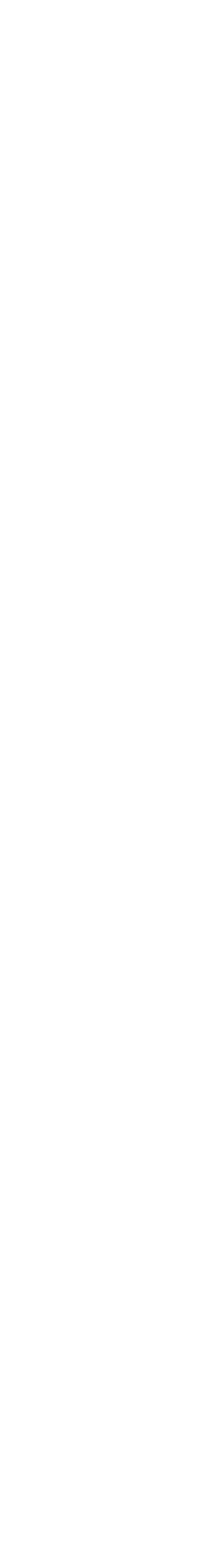


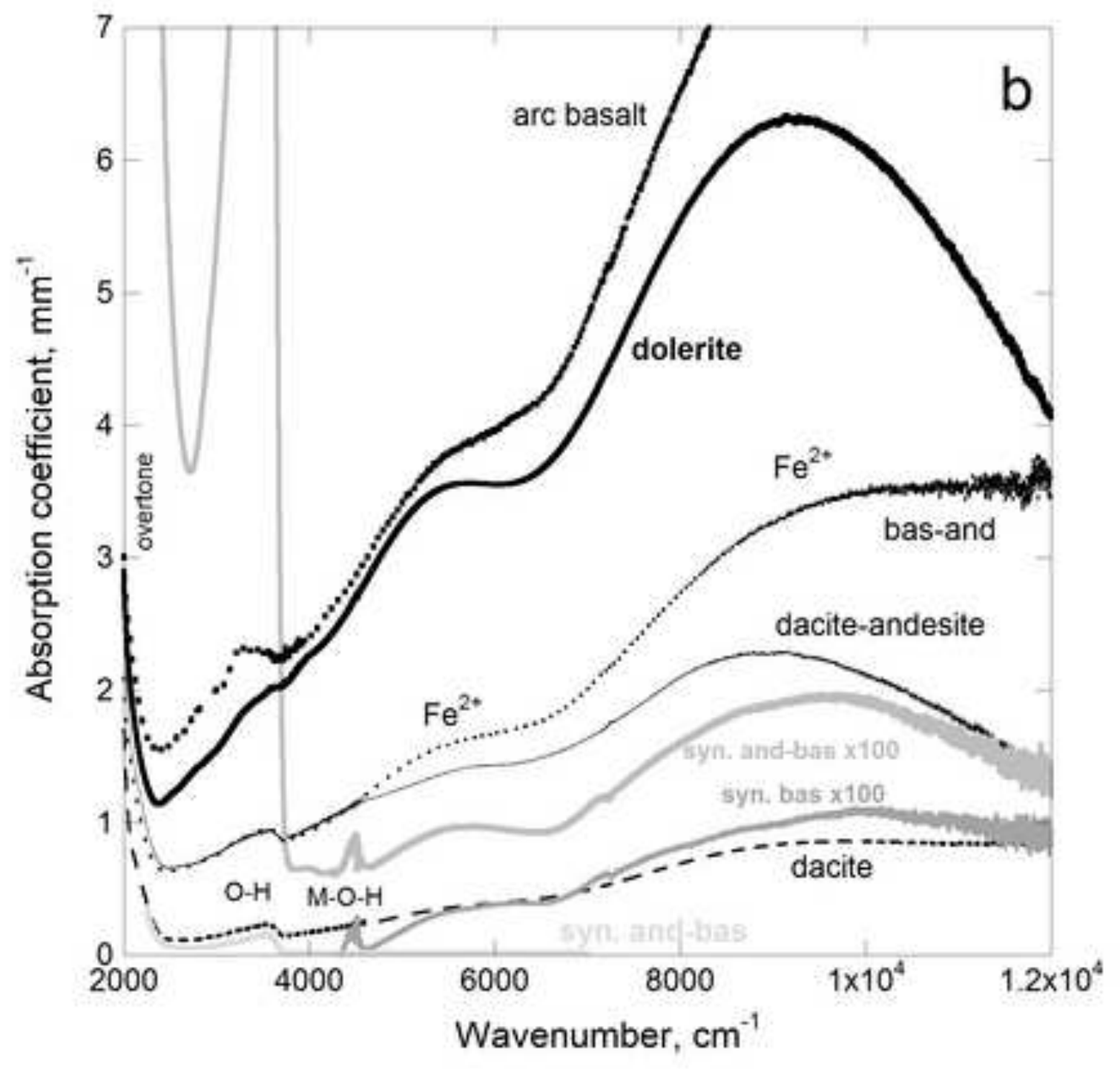

Figure 1b

\title{
Figure 1b
}

Wavenumber, $\mathrm{cm}^{-1}$

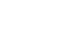




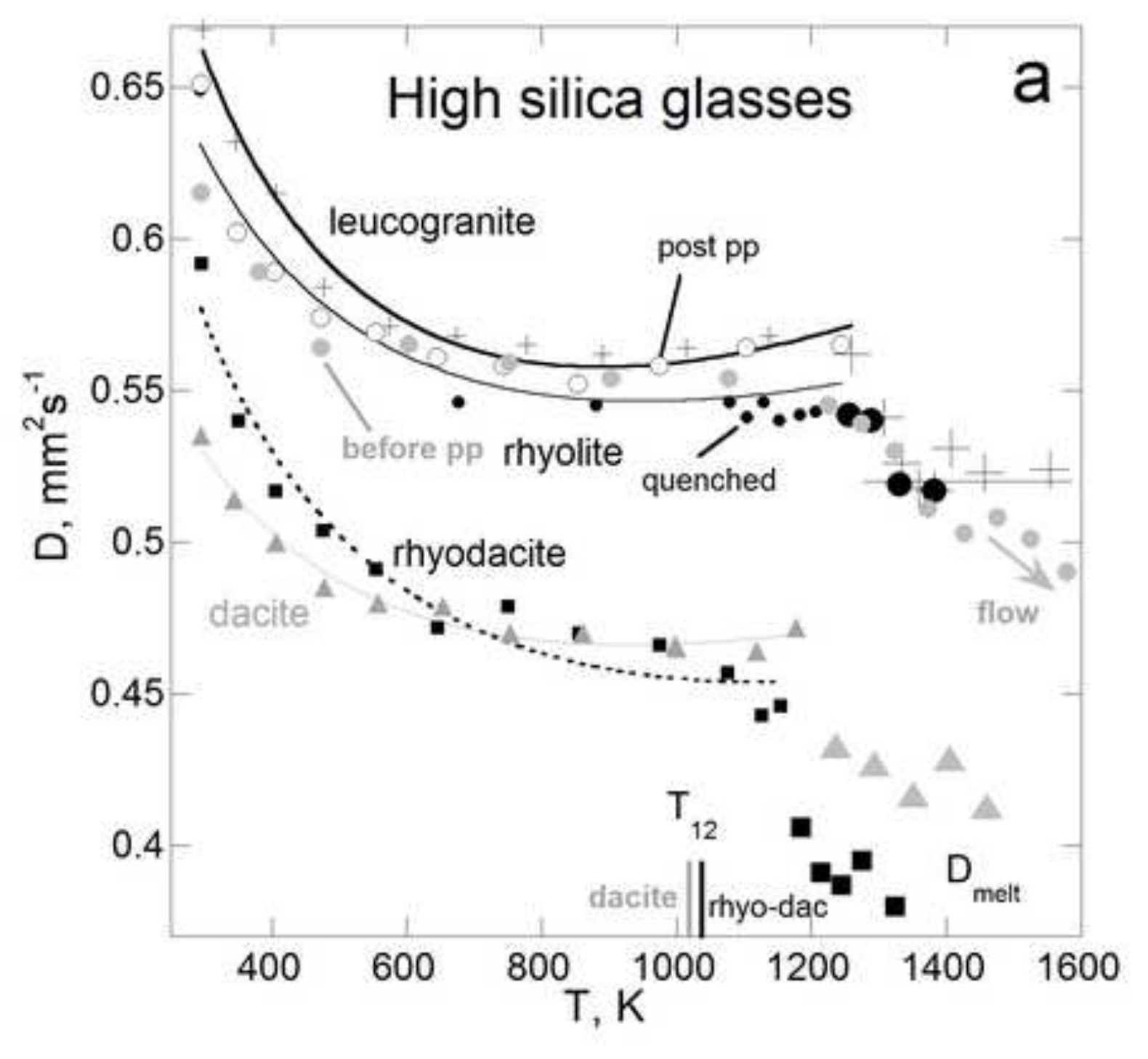

Figure $3 a$

列




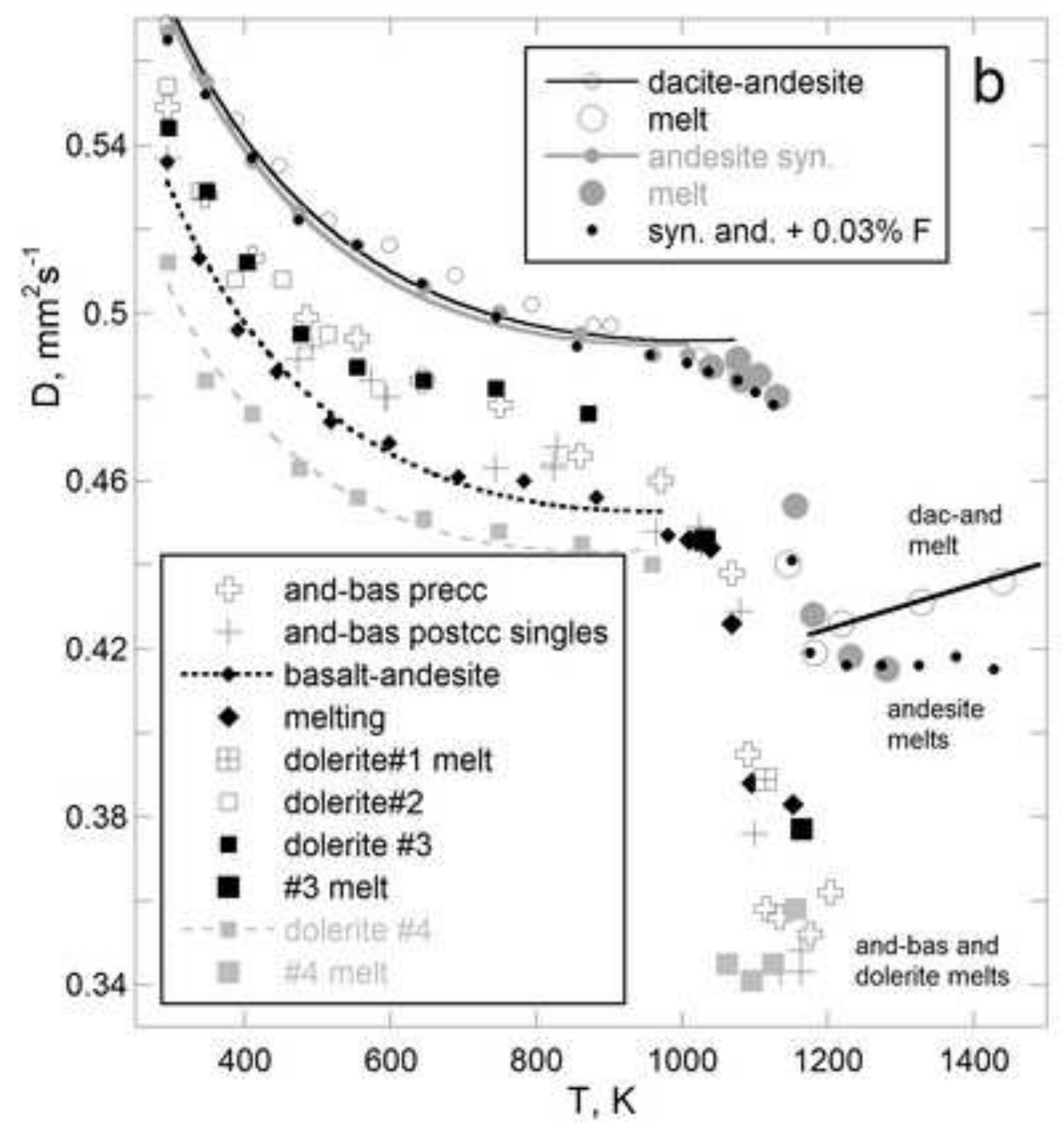

Figure $3 b$

Figure 3 b

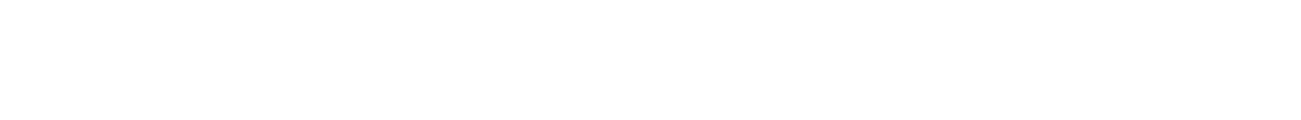
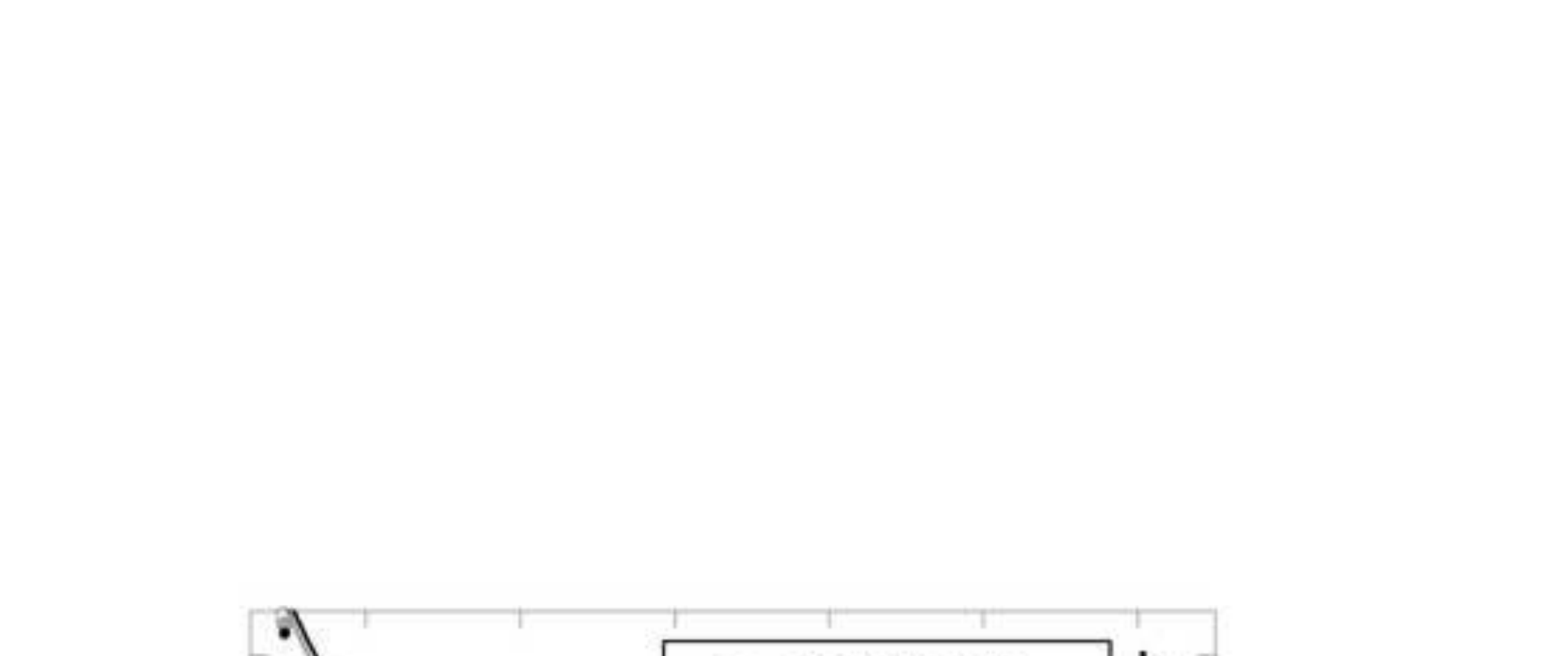


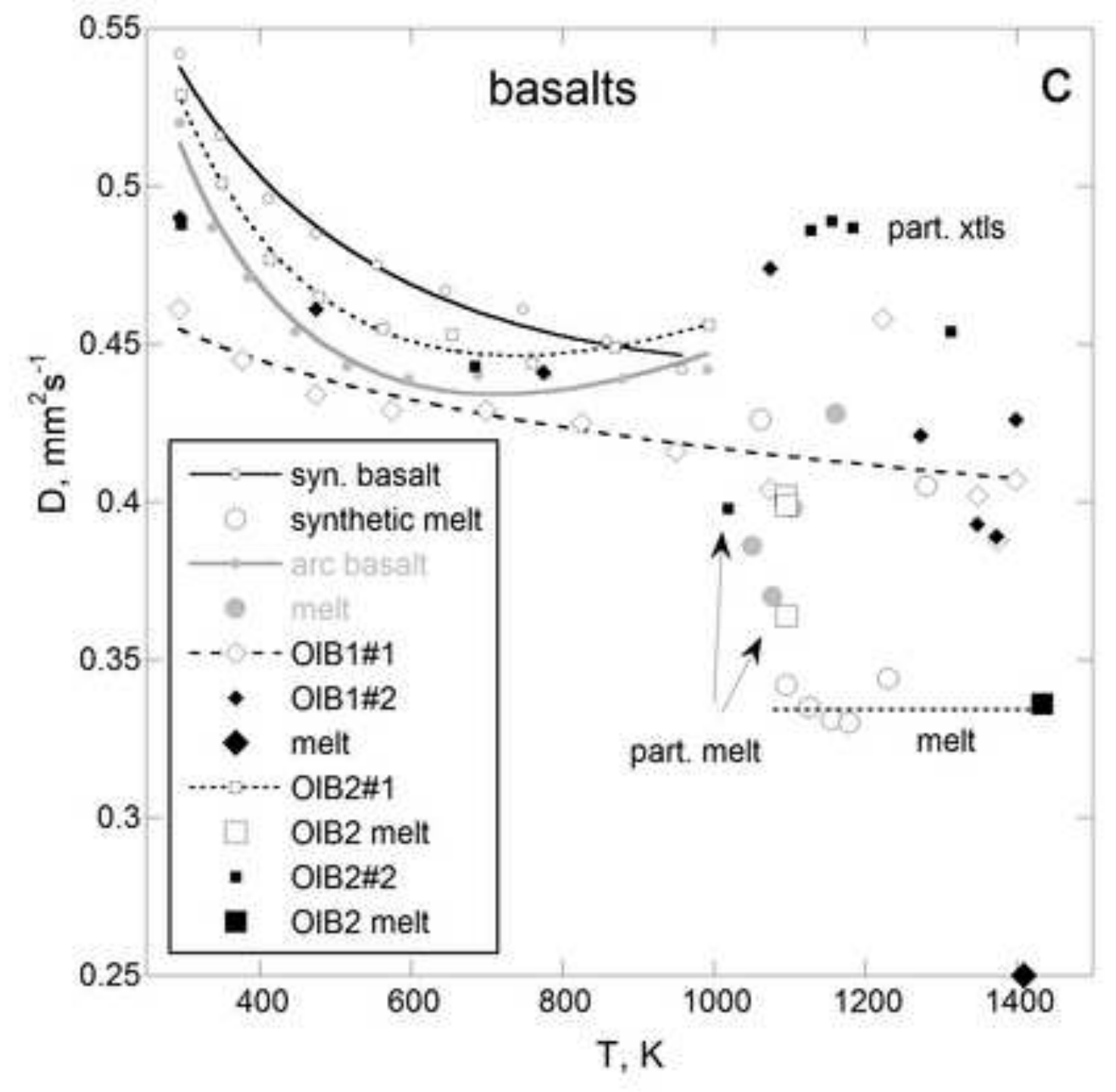

Figure 3c 


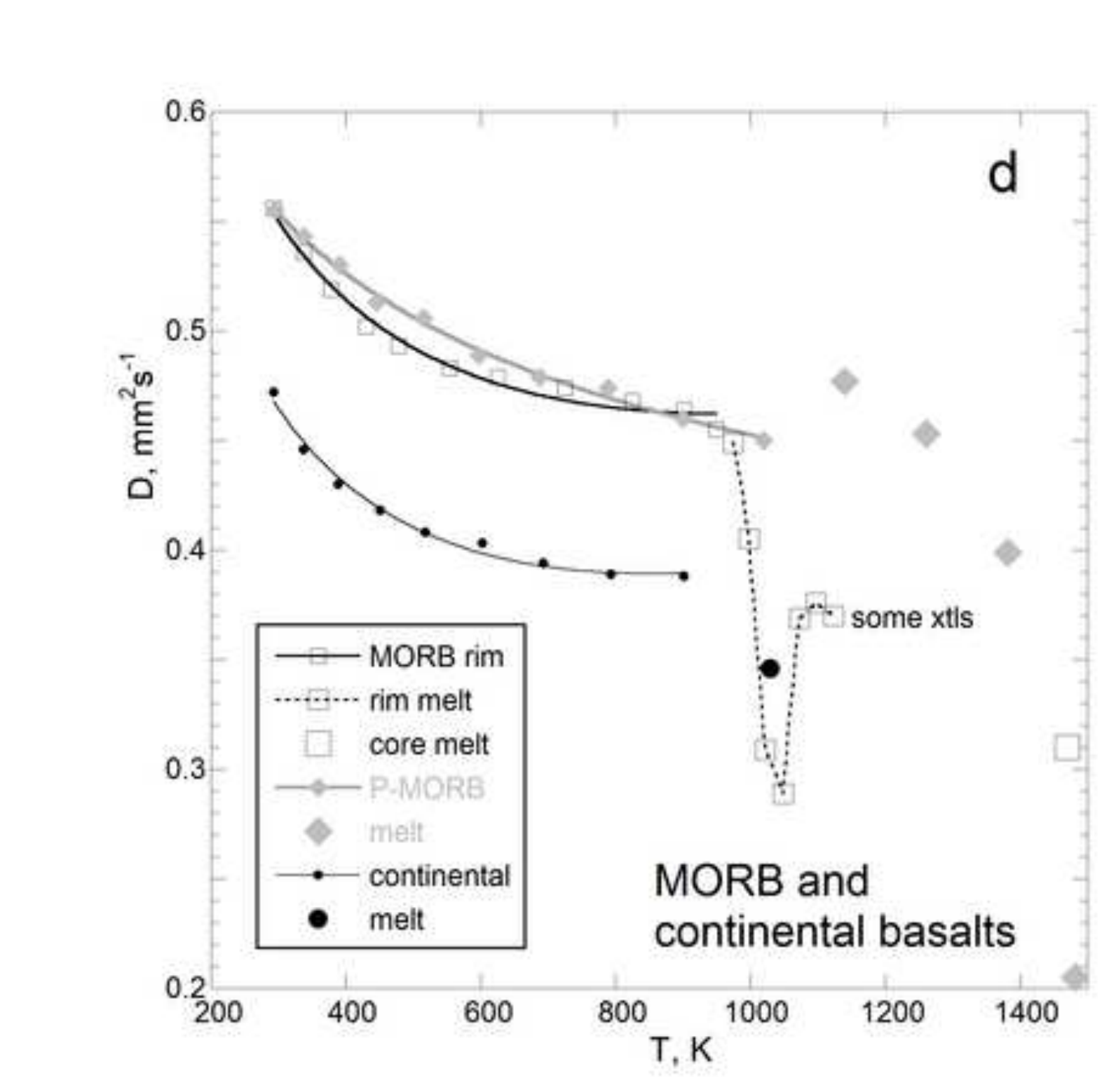

Figure 3d

(⿸丆口

Fure $3 d$

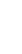
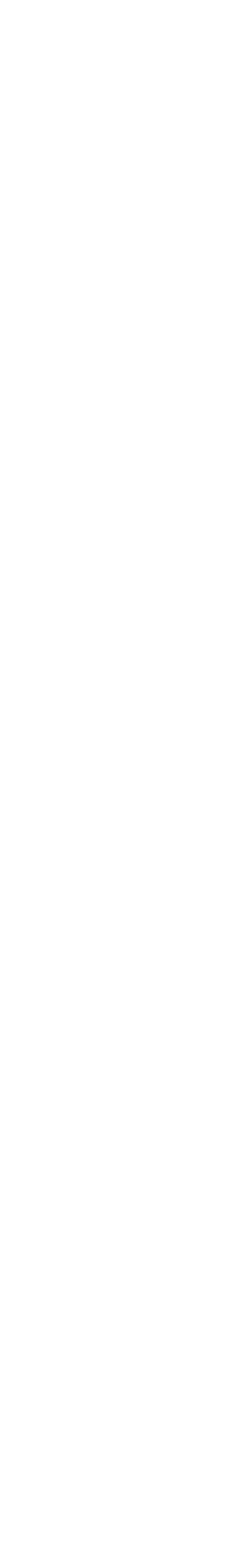


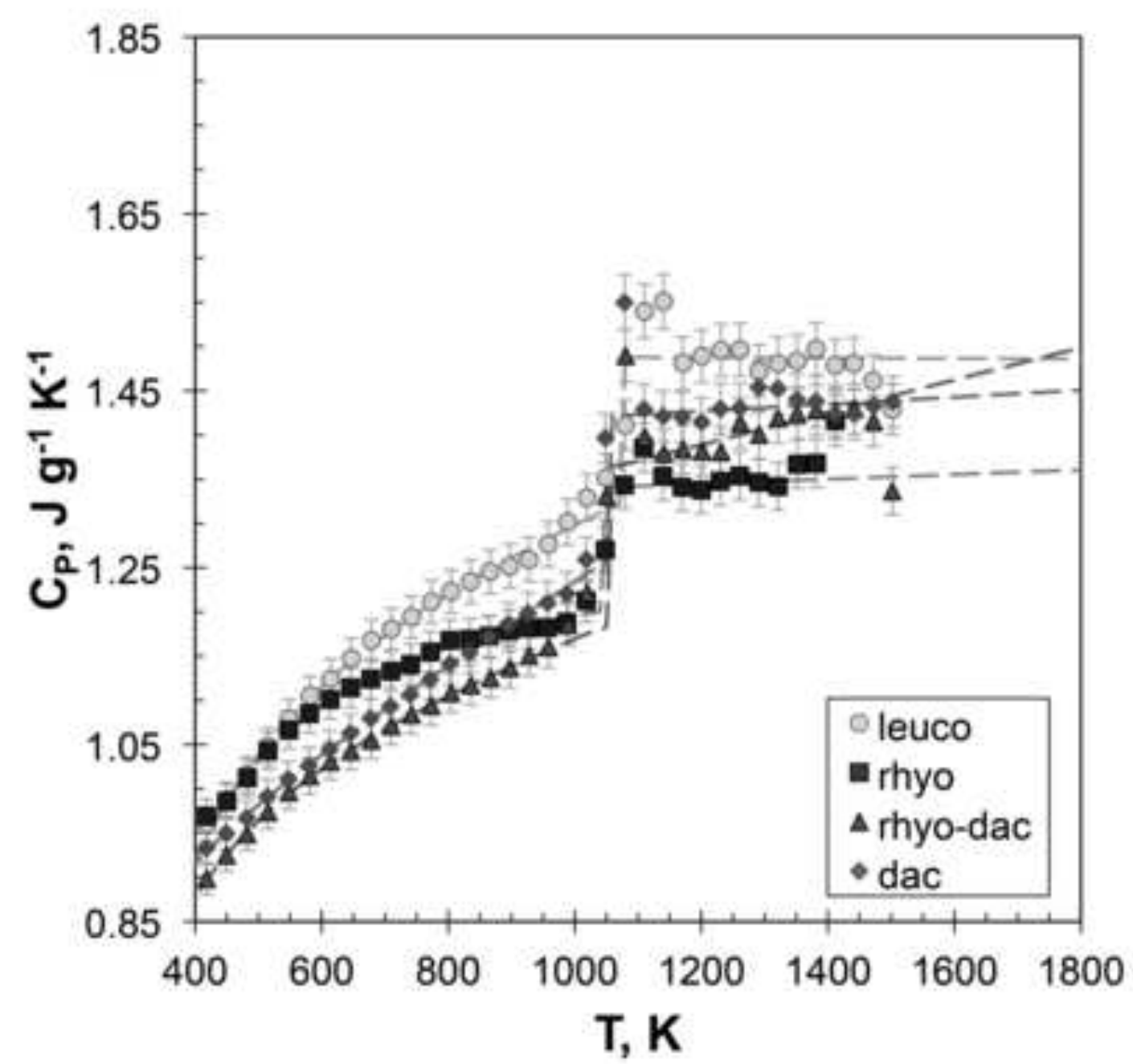

$\mathrm{T}, \mathrm{K}$ 


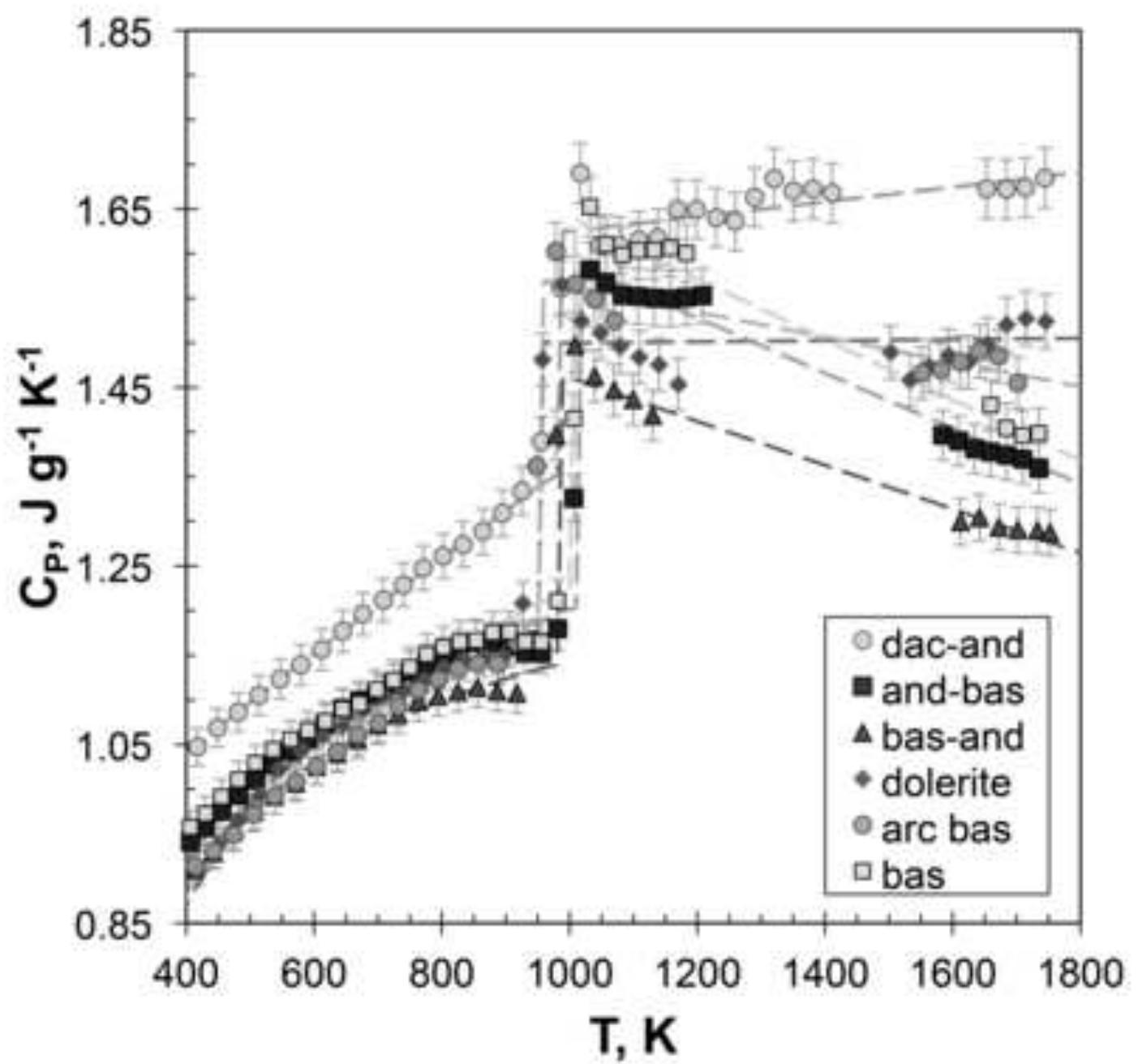




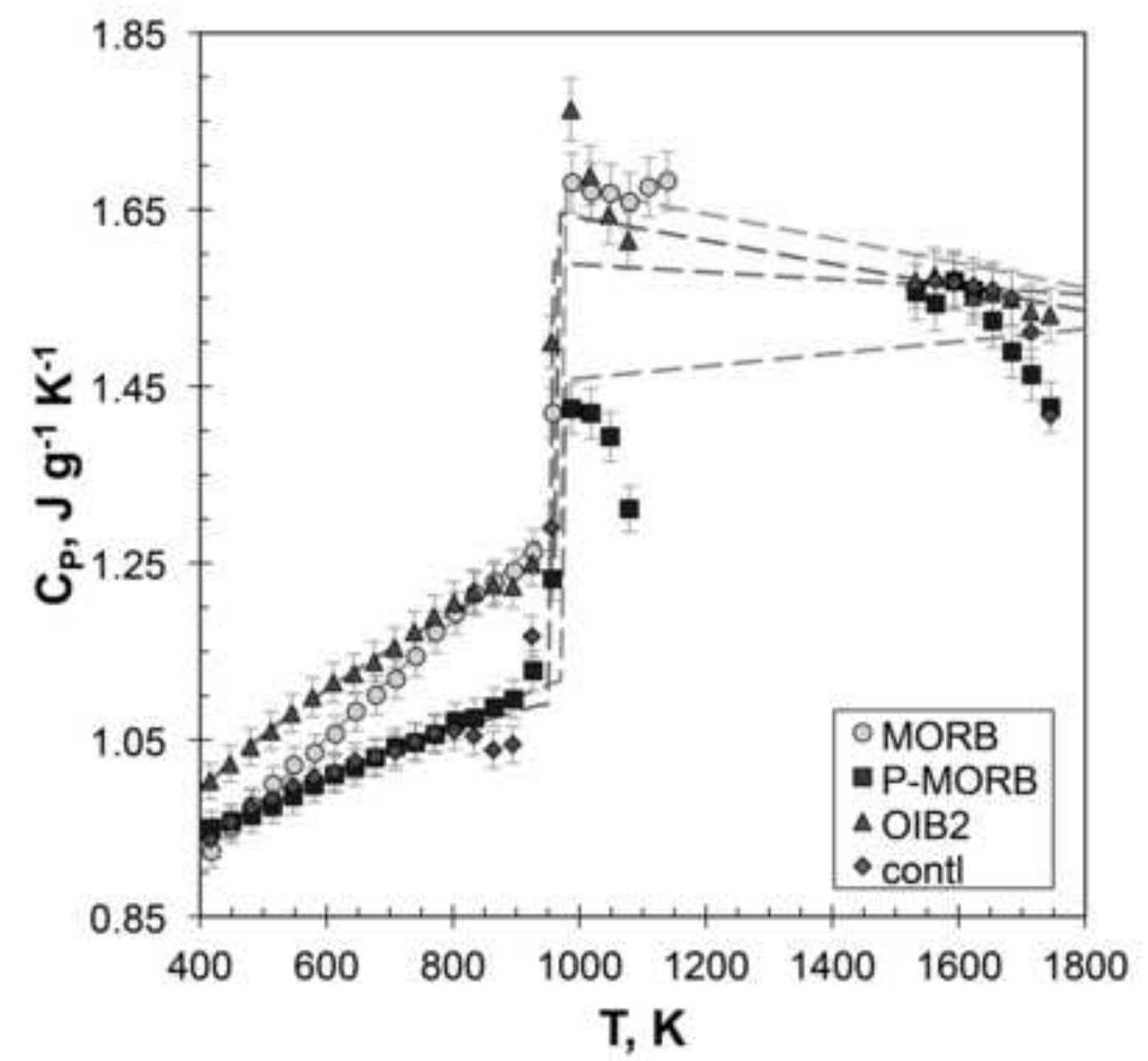

,

$$
\text { . }
$$




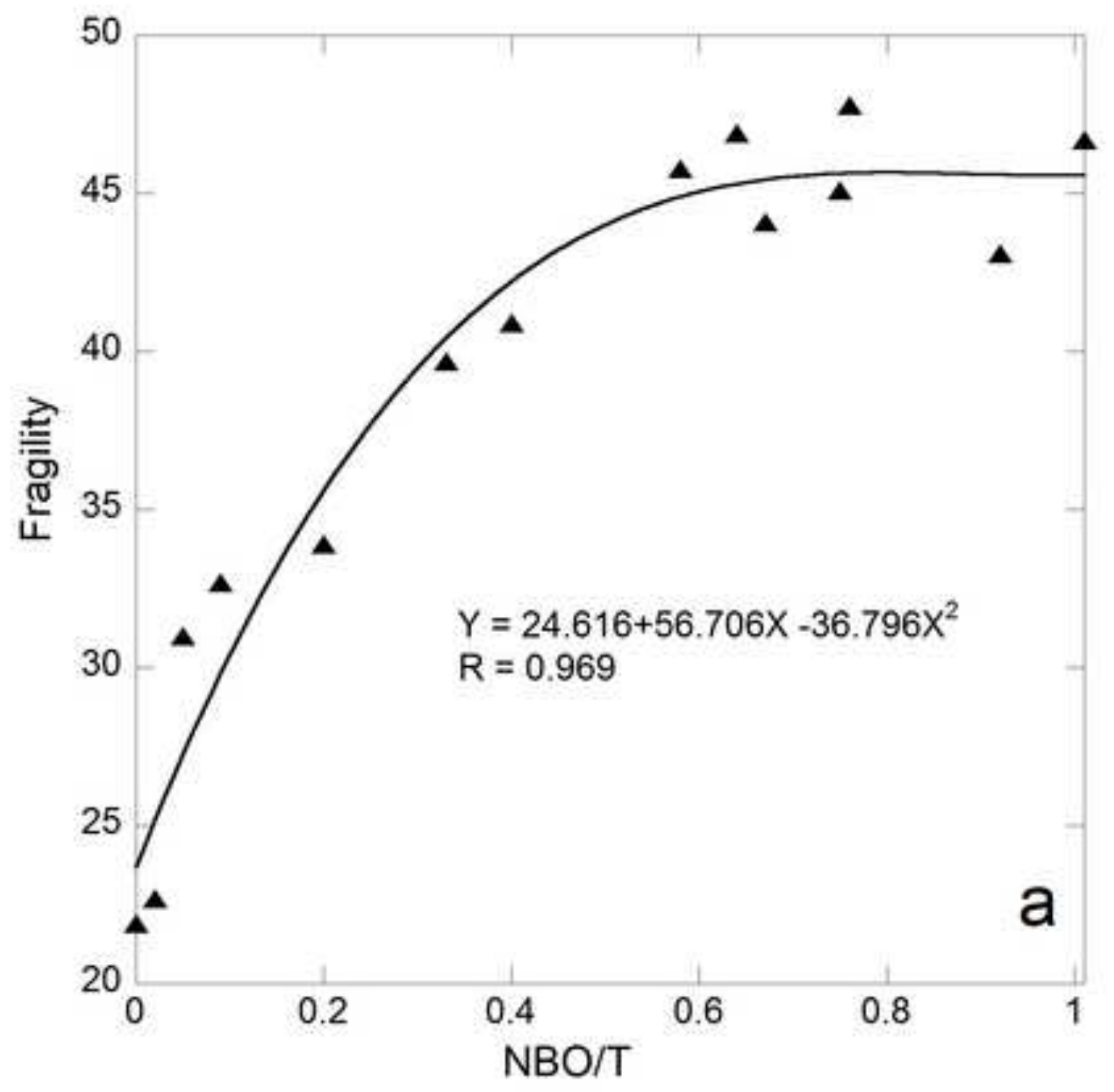




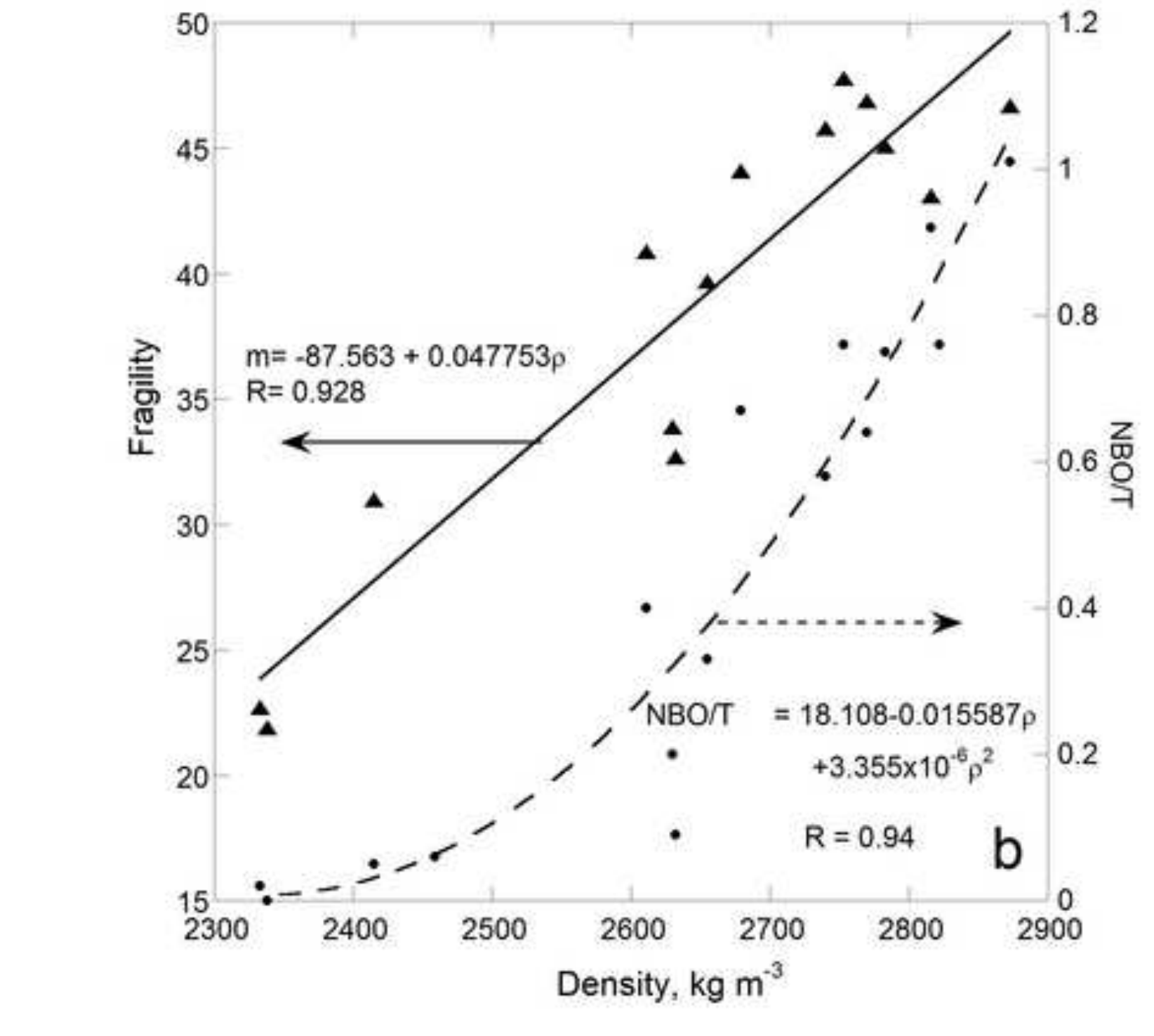

Figure $5 b$

(1)

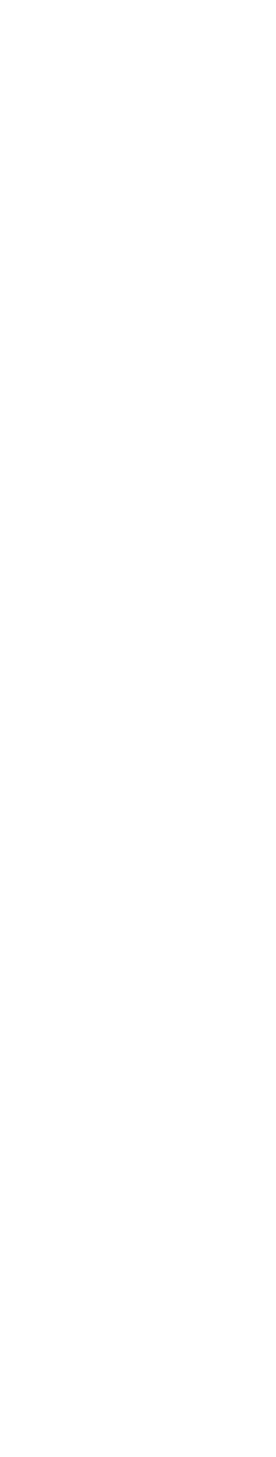

.

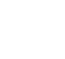




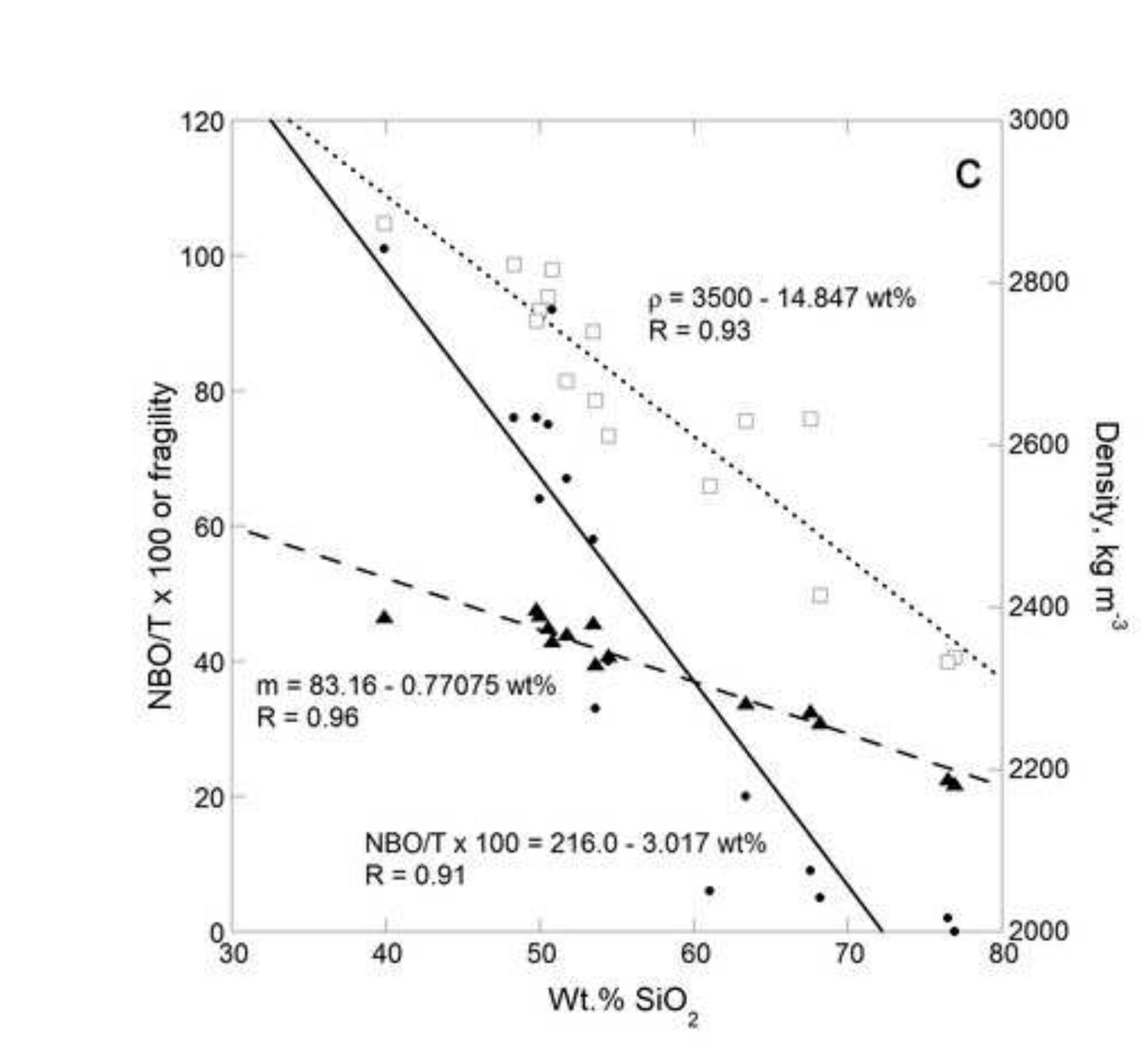

Figure 5c

P

Fure

. 


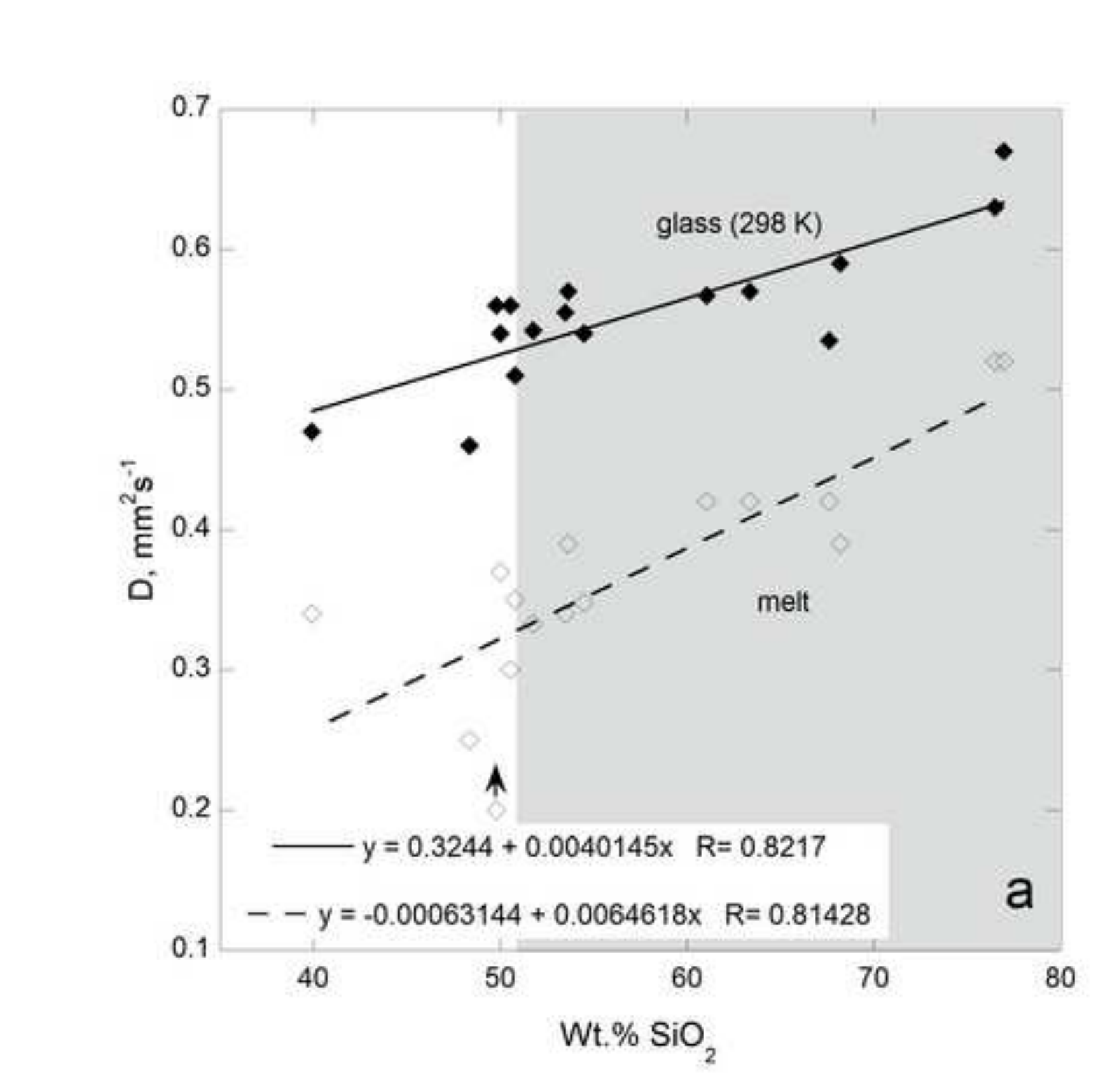

Figure $6 a$

.

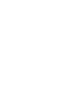




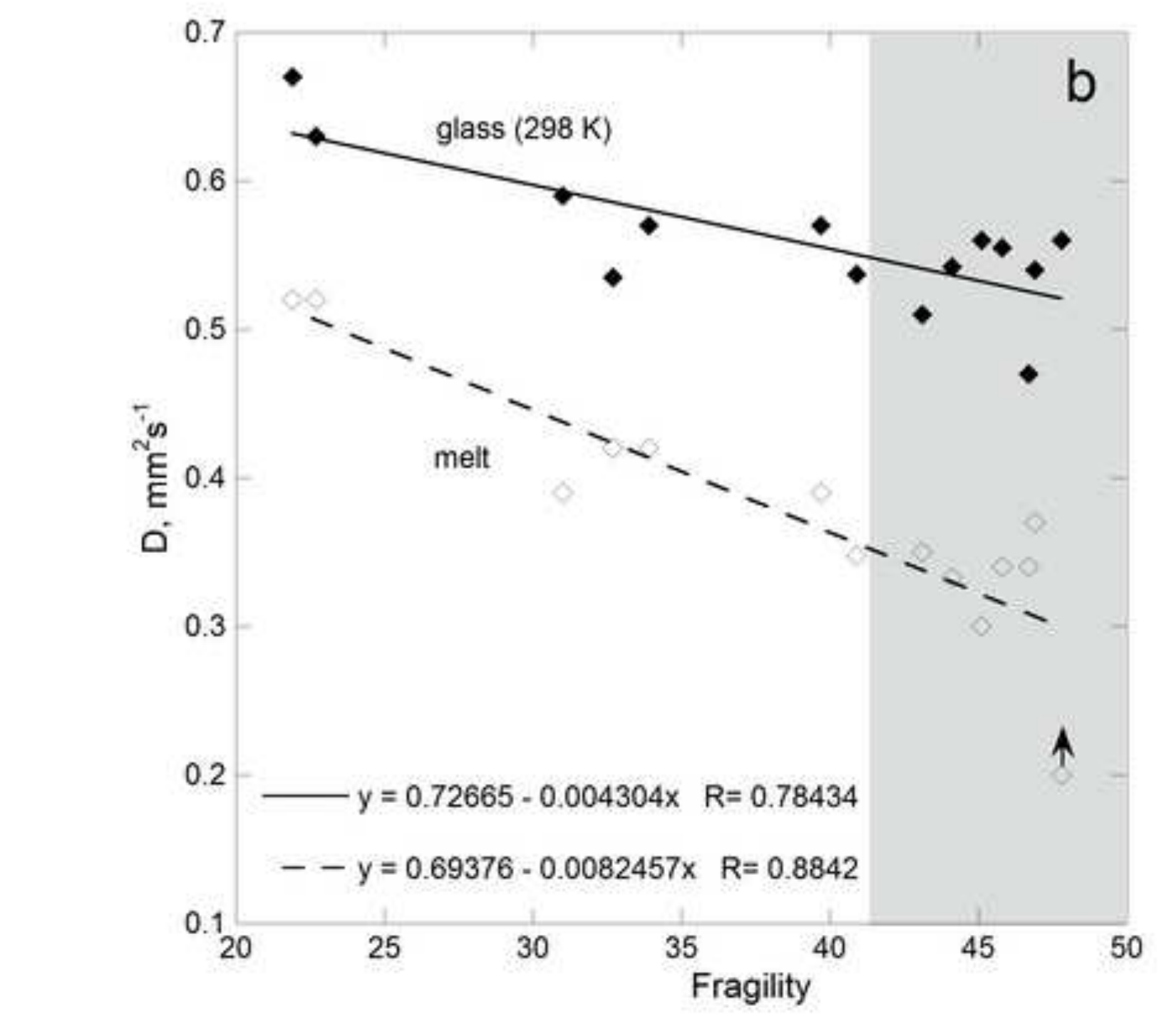

Figure $6 b$

Figure $6 \mathrm{~b}$

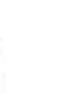

.

\author{
Fragity
}
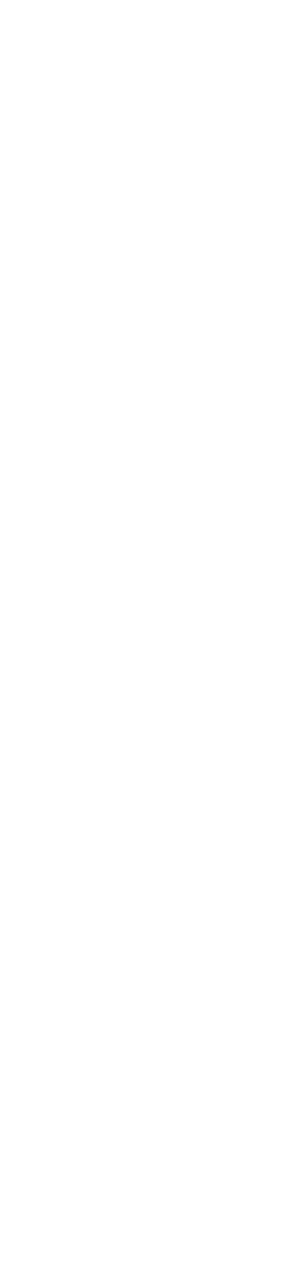


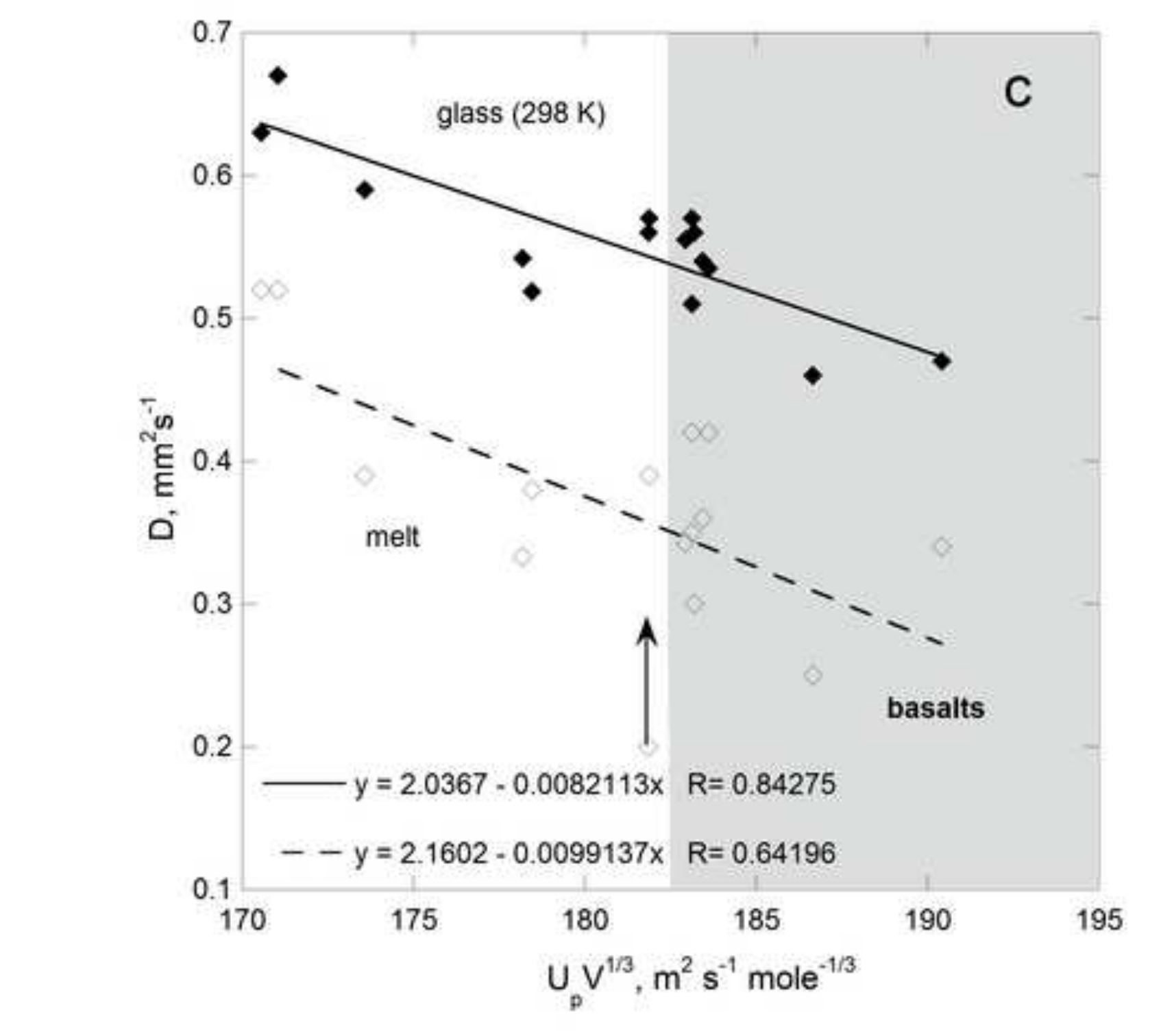

Figure $6 c$

Po

Fure 6c

c

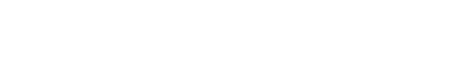
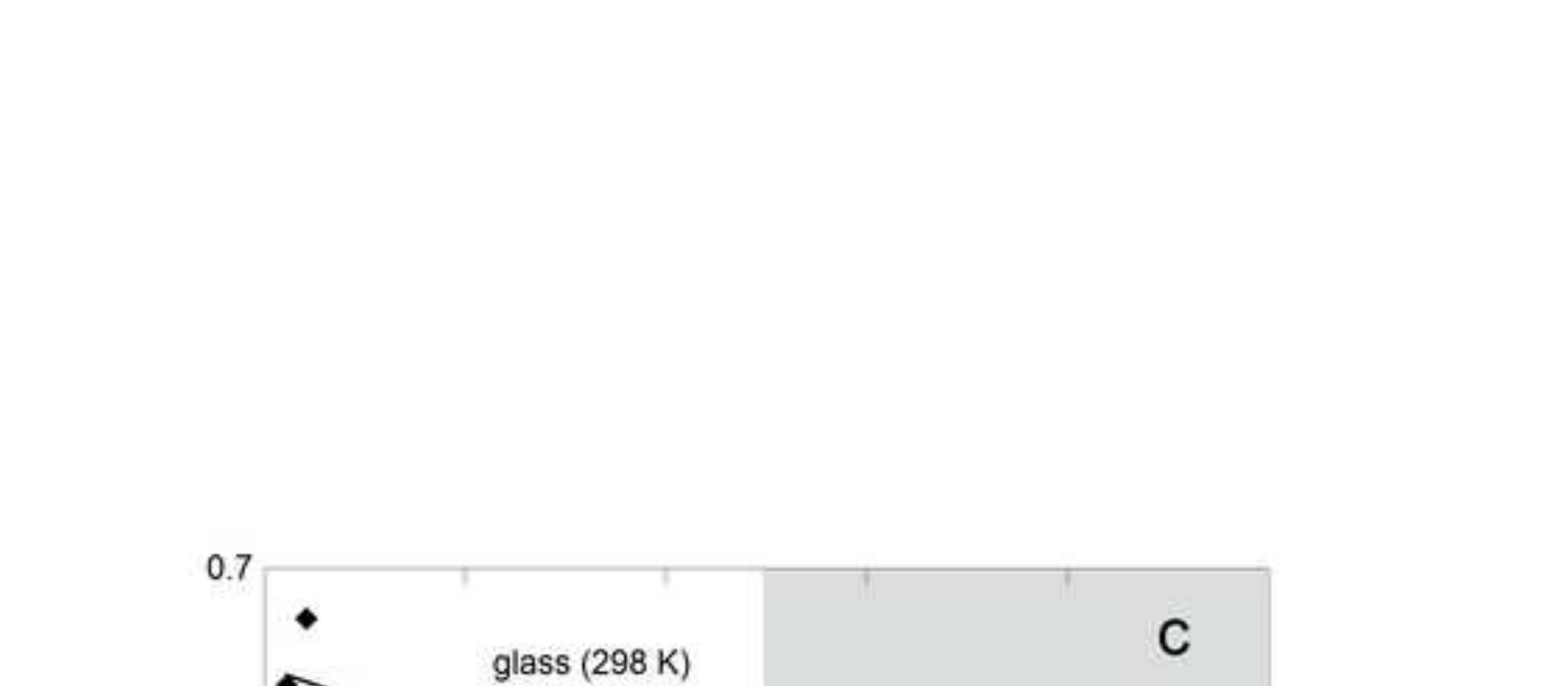

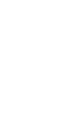

$\sqrt{2}+x^{2}$

列

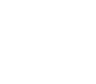
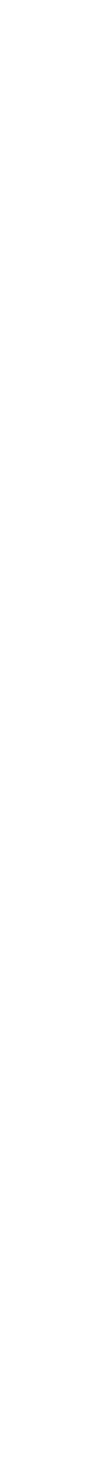

$$
u_{p}, m^{2} s^{-1} \text { mole }
$$




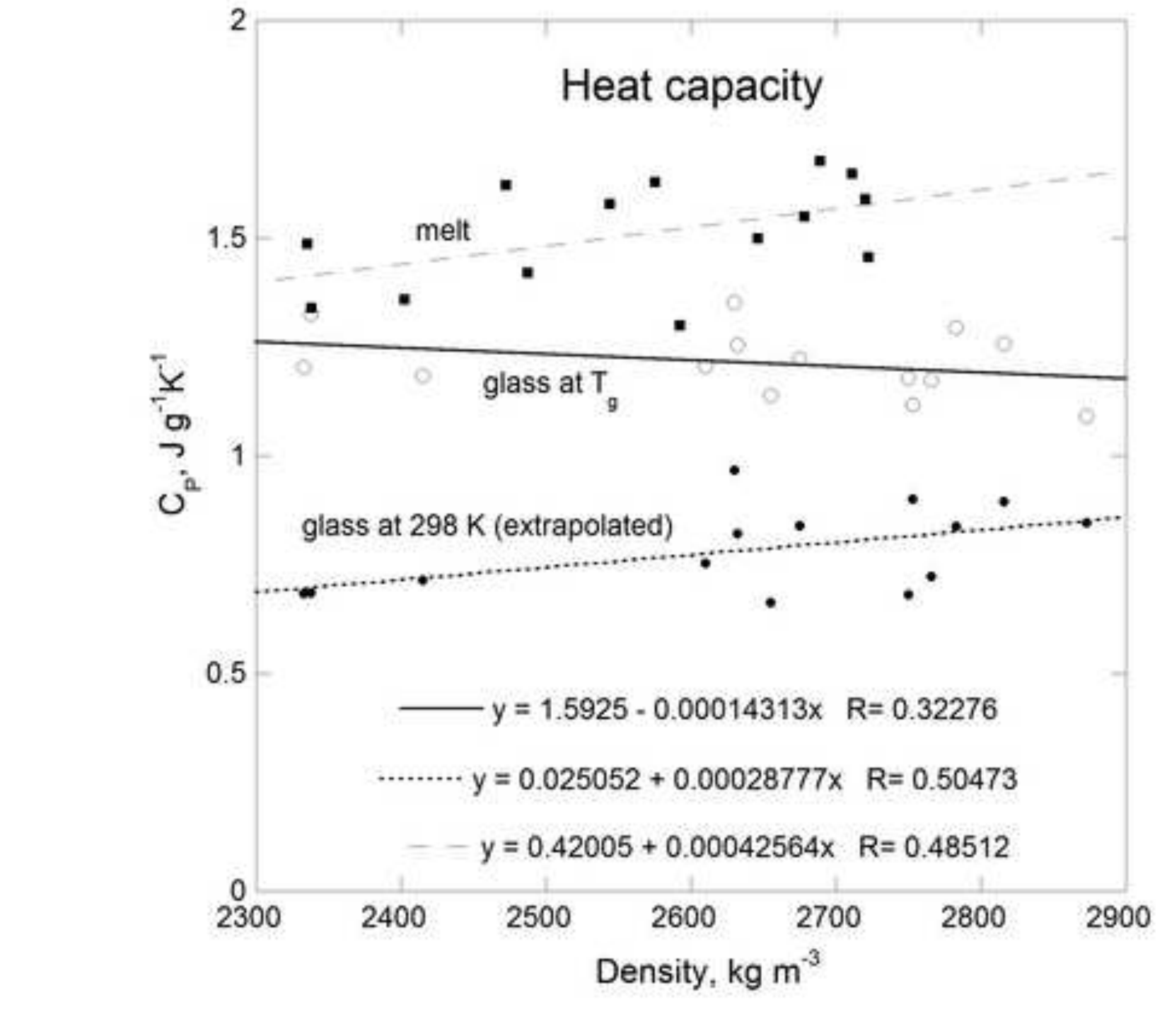

Figure 7

\section{gure 7}

chas
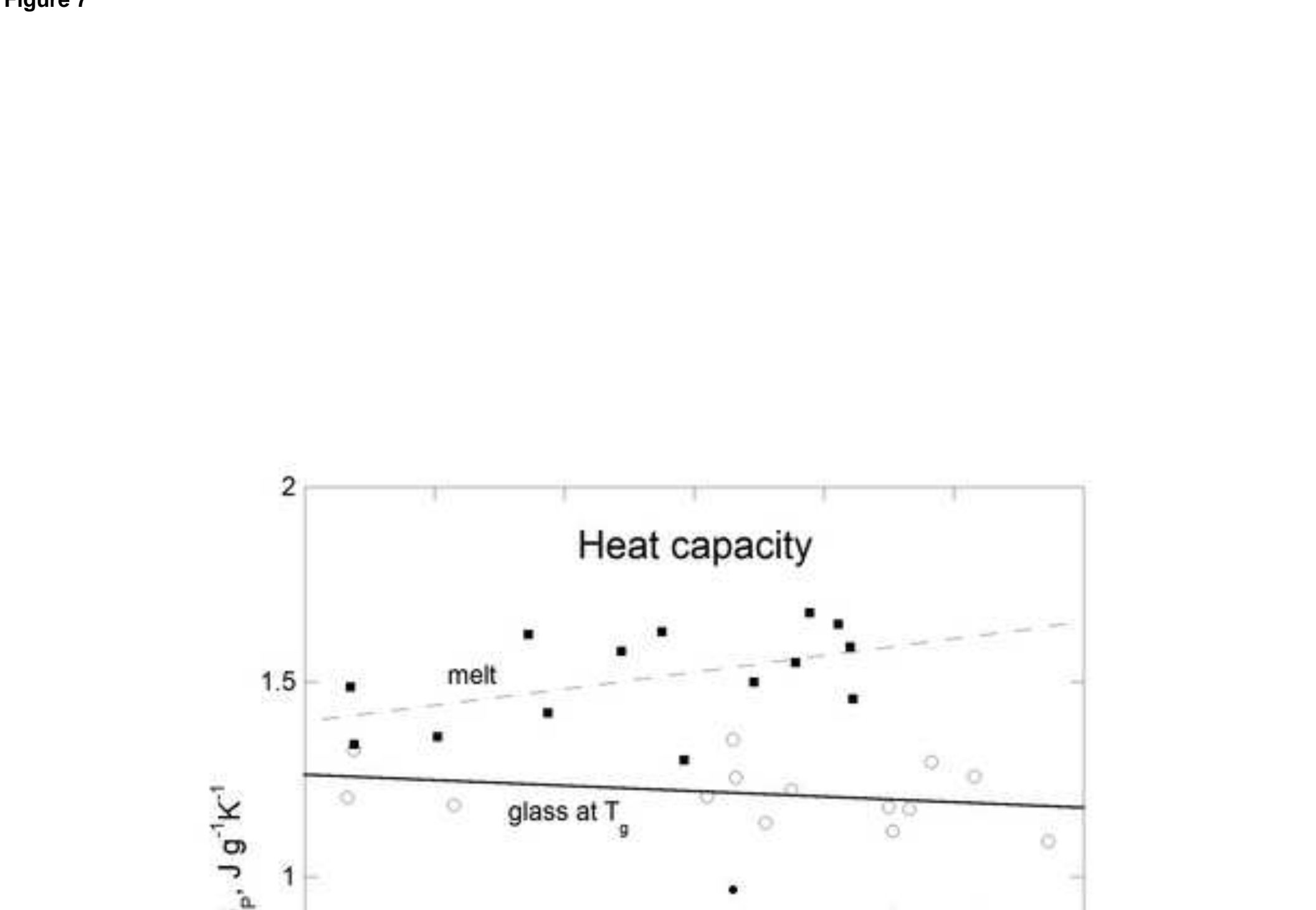

t.

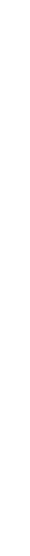

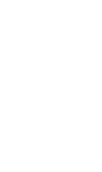

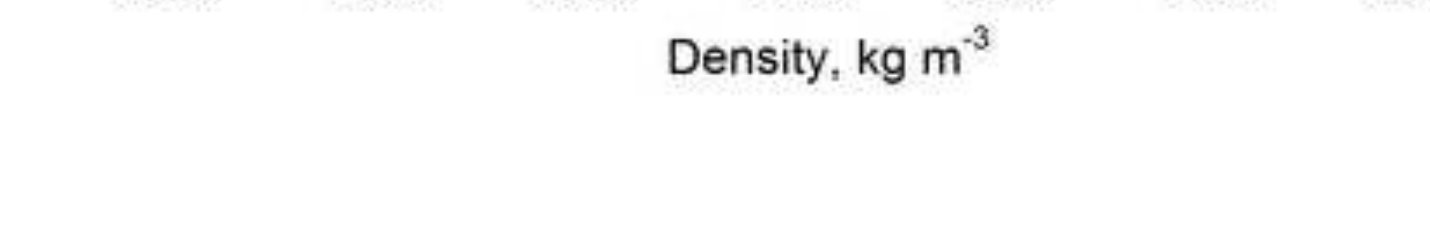




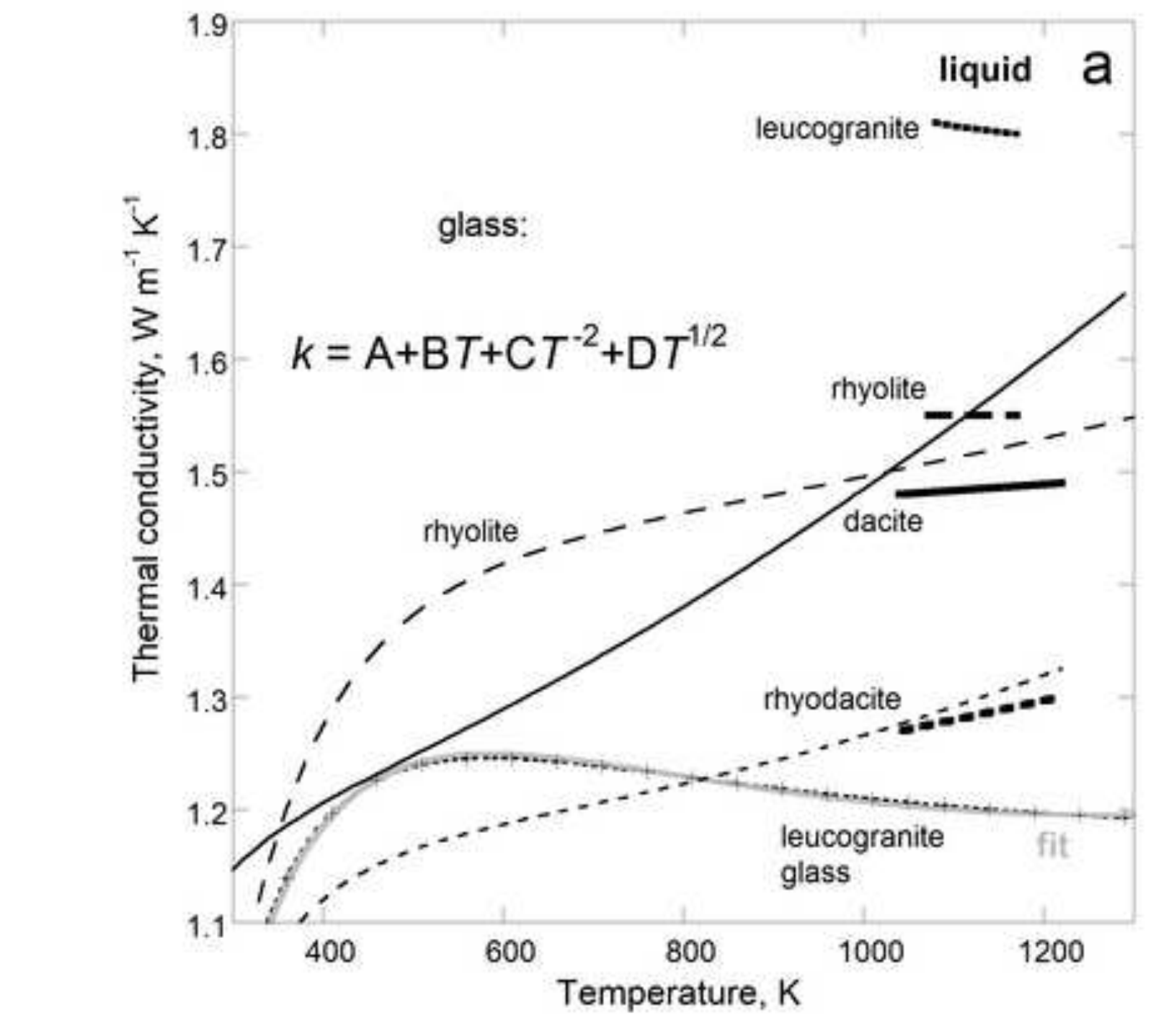

Figure $8 a$

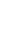

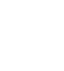




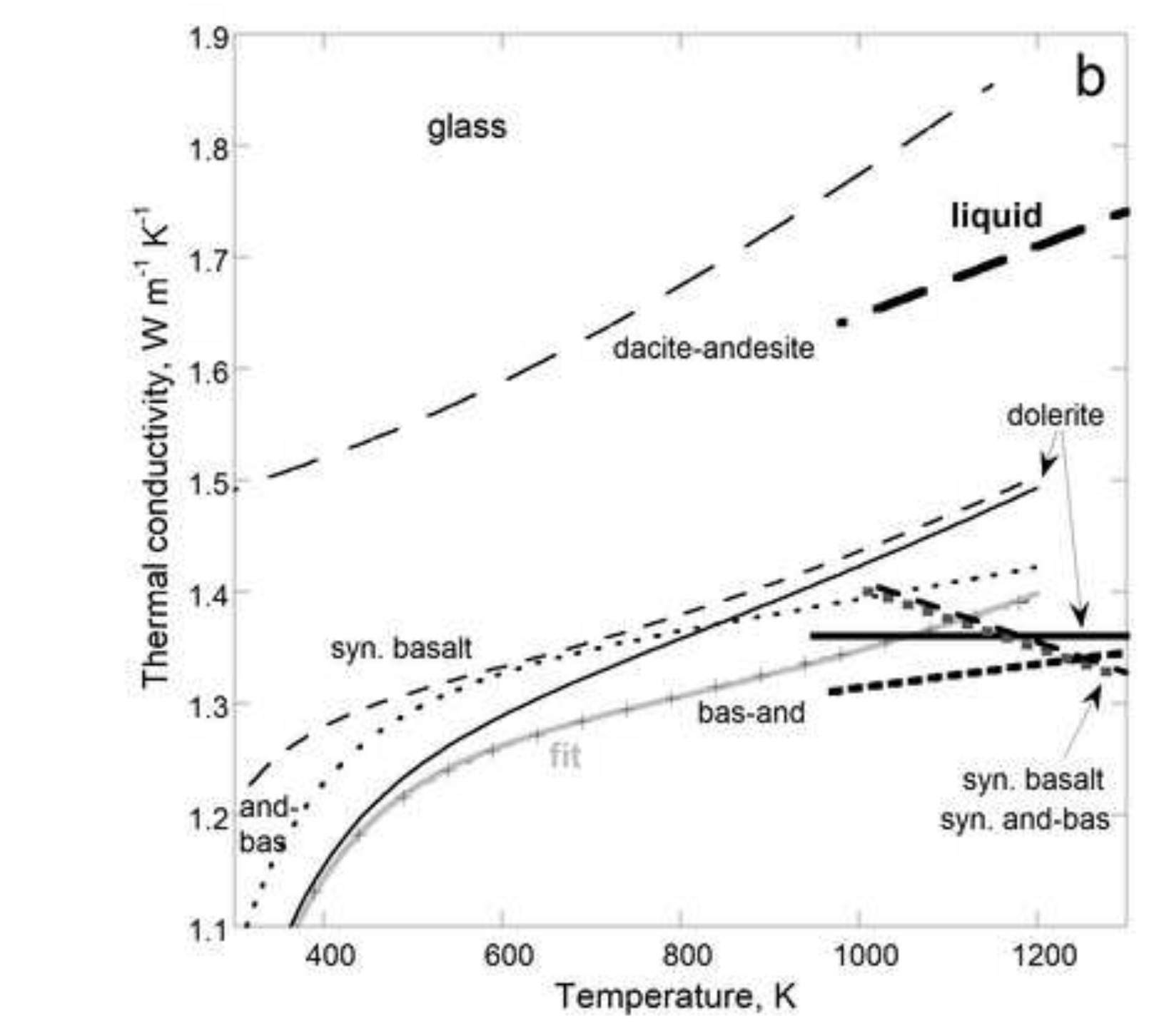

Figure $8 b$

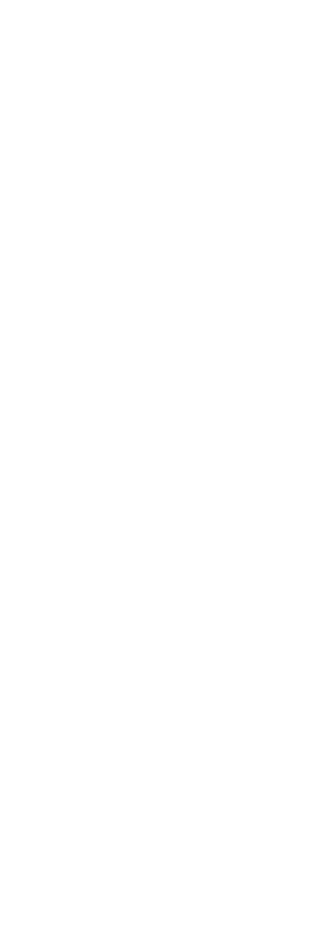




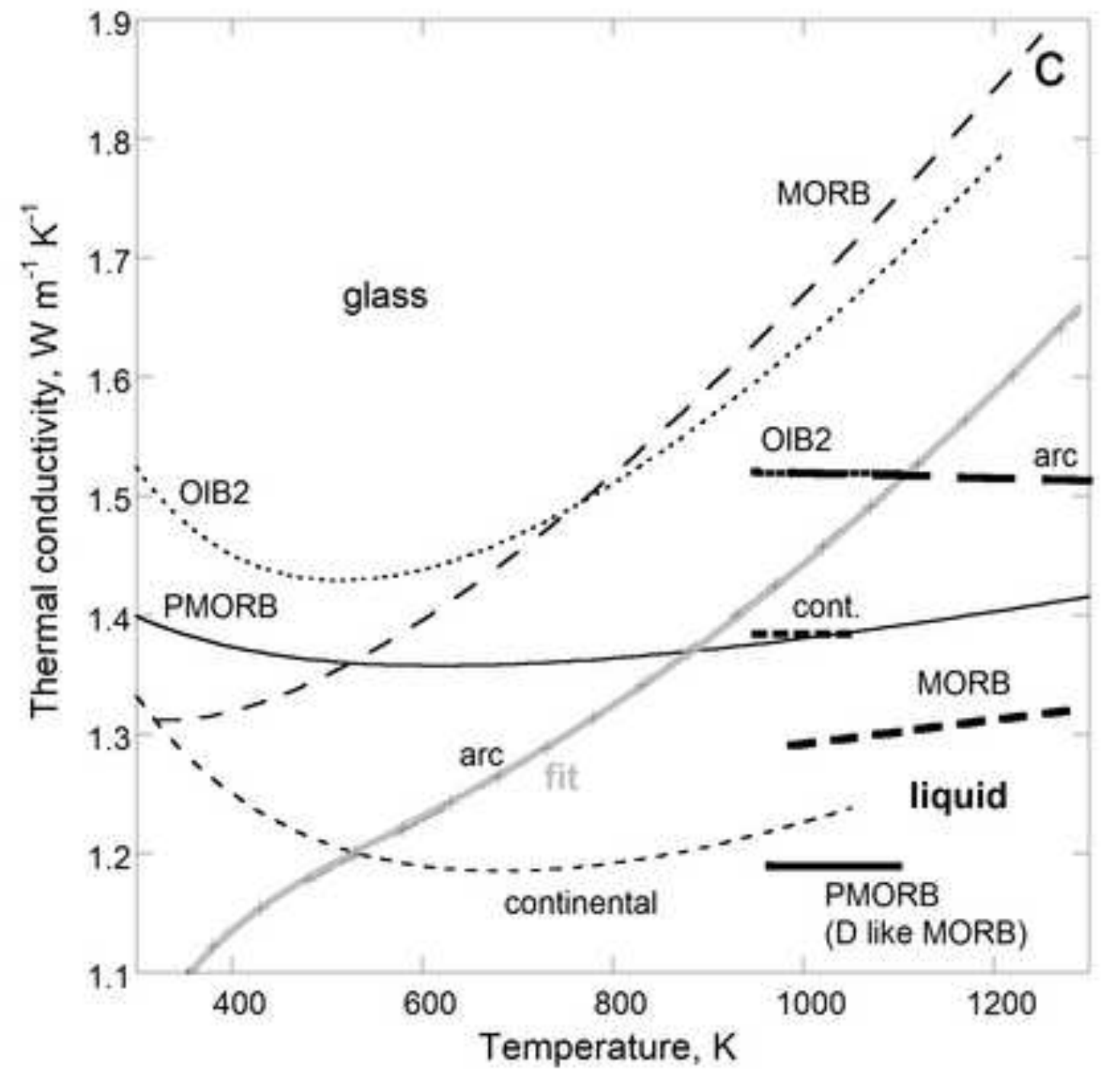

Figure 8c

\author{
Temperature, $\mathrm{K}$
}

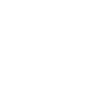

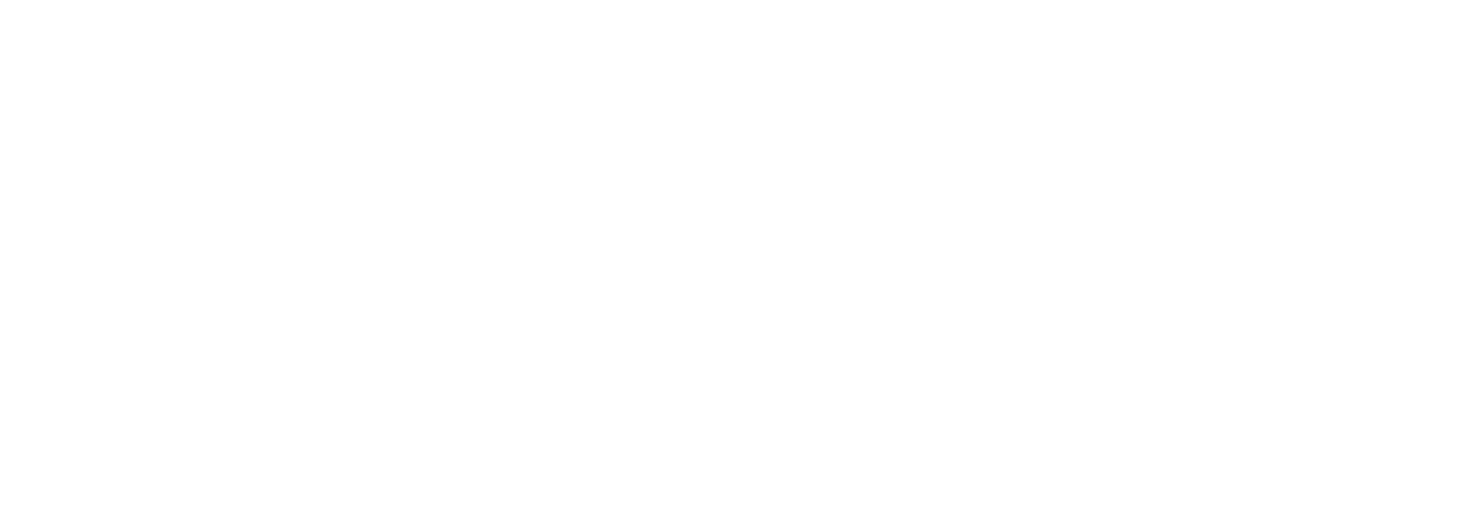




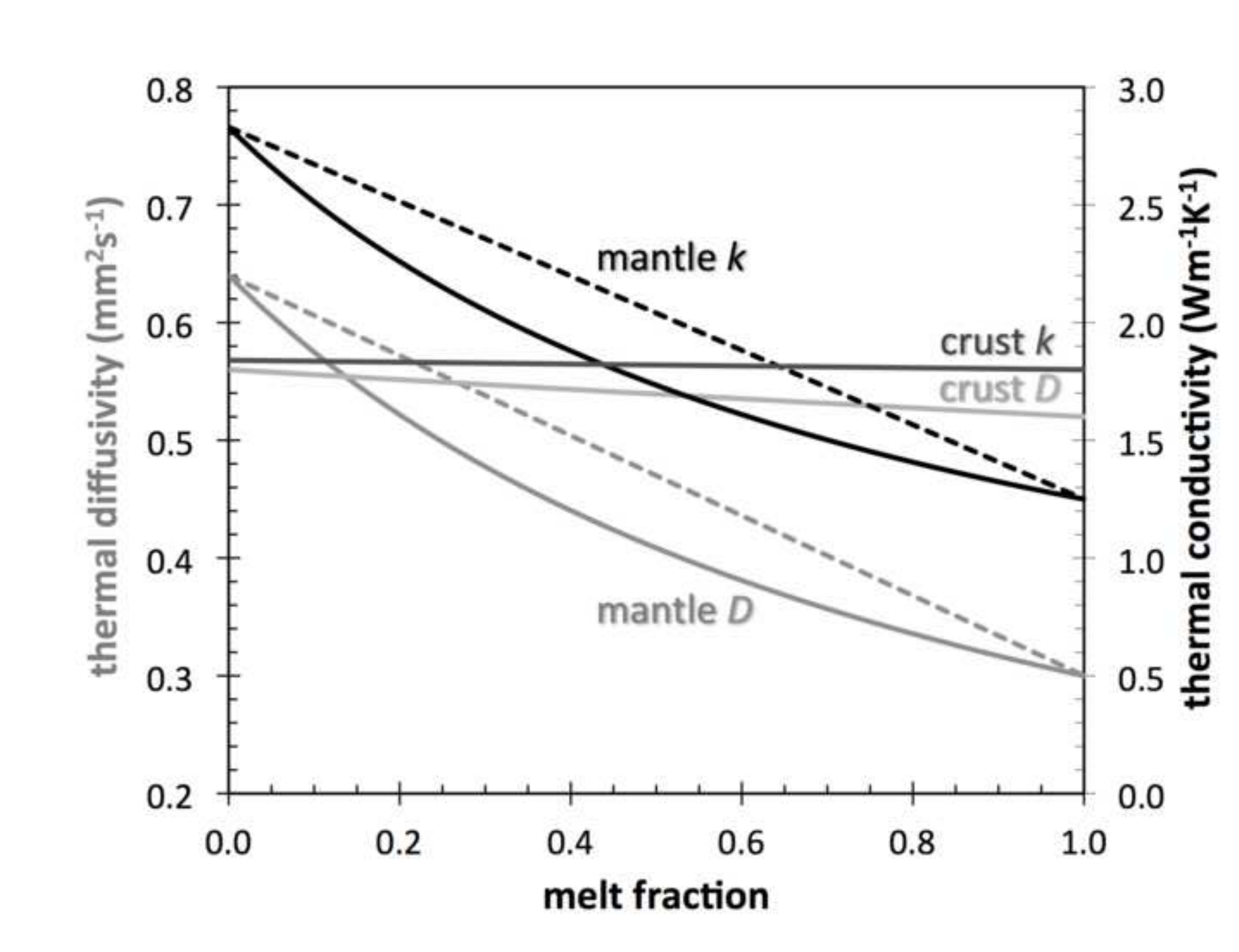

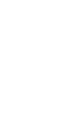
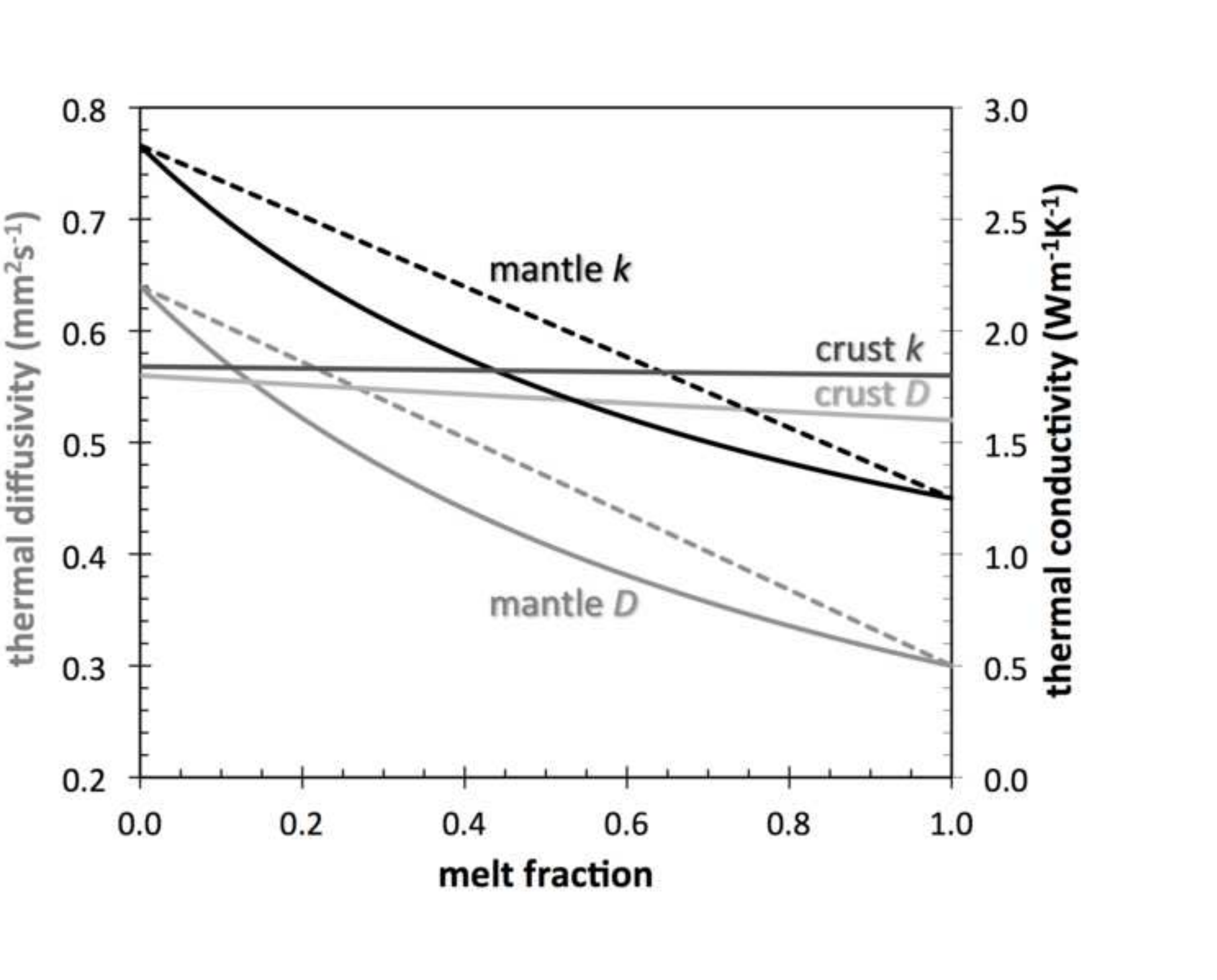

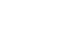

(

